\title{
The Krapina Dental Remains ${ }^{1}$
}

\author{
MILFORD H. WOLPOFF
}

Department of Anthropology, University of Michigan, Ann Arbor, Michigan 48109

\begin{abstract}
KEY WORDS Krapina - Teeth · Dental aging - Occlusal eruption . Neandertals . Evolution · Survivorship
\end{abstract}

\begin{abstract}
An analysis of age, specimen associations, demographic characteristics, and metric features is presented for the Krapina dental sample. A critical analysis of emergence criteria applicable to skeletal samples leads to an occlusal eruption schedule which can be used to determine wear rates. These are used to provide dental ages for the Krapina jaws and isolated teeth. A number of individual associations of isolated teeth with existing jaws and with each other result in an estimated individual count between 75 and 82. Demographic analysis indicates that the specimens do not accurately sample a living population; numerous adults as well as children under the age of three are not represented. Metric analysis indicates a moderate range of variation. The interproximal wear rates are low, and no evidence of tooth size associated differential survivorship can be demonstrated. The sample fits in a European evolutionary sequence of reducing posterior and expanding anterior permanent teeth, while the deciduous teeth seem to undergo expansion through the Würm glaciation.
\end{abstract}

The Hušnjakovo rock shelter, located in the Croatian town of Krapina, yielded the first large sample of demonstrably archaic human remains. Excavated under the directorship of Doctor D. Gorjanovic-Kramberger between 1899 and 1905, the size of the hominid sample is yet to be surpassed at any pre-modern Homo fossil locality. Moreover, the use of fluorine analysis marked the first independently proven association of fossil hominids and extinct fauna. Current estimates date the bulk of the sample to the Riss/Würm Interglacial and early Würm glacial, although some individuals are later (Malez, '70). ${ }^{2}$

The dental sample from Krapina consists of 281 teeth and tooth fragments. Of these, 191 were catalogued as isolated specimens while the remaining 90 were preserved in jaws. Some of the dental material was described in the four major papers that resulted from the excavations (Gorjanovic-Kramberger, '01, '02, '04, '05) and again in Gorjanovic's monograph ('06) although at no time were all of the specimens described or included in the site averages published in the above as well as in additional papers dealing specifically with the teeth ('07, '08a,b, '09, '10).
Data for specific Krapina teeth and averages for the site that appeared in the earlier literature were taken from Gorjanovic's publications (de Terra, '03; Adloff, '07, '08, '09, 10,

\footnotetext{
' Research supported by a grant from the National Academy of Sciences and NSF Grant BNS 75-21756.

2 In a more recent visit to Zagreb ('78) I was informed that Gor janovic originally penciled the level number on every piece of bone from the site, faunal as well as hominid. Because Gorjanovic changed his numbering sygtem during the excavations, there remains some confusion in this level information. Eight original levels were initially labeled 1-7 (a $6 \mathrm{a}$ and $6 \mathrm{~b}$ were distinguished). This was changed to a 9 -level description beginning with I (below the former level 1 ) and continuing 2-9. Since the penciled level information was recorded in the field, parts of the same specimen could have different numbers, or conversely a number recorded earlier in the ex cavations could refer to a different level in the later system. Thus cranium $\mathrm{E}$ consists of fragments with a penciled " 3 " (earlier discovered) as well as others with a penciled "4". Similarily, a frag ment with a penciled " 5 " may actually come from level 5 , or if dis covered earlier may really come from level 6 . Levels I, 8 , and 9 are unique to the second more complete system. Although over the years many of these numbers were inadvertently rubbed off of the speei mens, this information could still be ascertained for much of the human asteological material. Unfortunately, level numbers could not be clearly determined for individual isolated teeth. For mandibles the following levels were able to be determined: $C$ (7), D (4), E (5), G (6), H (3), J (4), and K (5). Maxillary levels that could be ascertained were B (7), C (5), D (4), E (4), F (4). On the other ostealogical material, counting each composite specimen only once, two come from level 8 , and one each from levels $7,5,2$, and $I$. The remaining 116 numbered specimens are from levels 3 or 4 . Since these almost certainly are actually from 4 (the "Home Zone"), earlier designated as 3 in total 122 (or 91\%) of the specimens retaining numbers come from the "Homo Zone." This suggests that the bulk of the dental sample was likely also from this level
} 
'27; Hrdlička, '23, '24, '30). Some additional specimens were described by Kallay ('49, ' 55 , '69, '70), but it was Brace who first presented systematic summary data for the entire dental sample ('67). A more complete treatment of the dentition was published by Smith ('76) in a monograph which provided the first full set of dental measurements and summary statistics.

This paper focuses on a metric and distributional analysis of the Krapina dental sample. A critical analysis of the dental wear-based aging technique and the determination of an applicable eruption schedule for fossil samples is followed by the application of this schedule to age determinations for the Krapina teeth. A number of specimen associations are made, providing the basis for a discussion of individual count and the demographic characteristics of the sample. The dentitions are subjected to a comparative metric analysis and an analysis of age-related metric features. Finally, the position of the Krapina dentitions in a general evolutionary framework and in the specific Upper Pleistocene European sequence is discussed.

\section{AGE DETERMINATION}

Age determination was attempted using the tooth wear based procedure first published by Miles ('63) and modified for the analysis of the South African australopithecine dentitions by Mann (75). The procedure utilizes incompletely erupted dentitions to establish criteria for the number of years in functional occlusion for particular teeth; functional occlusion is defined by the presence of occlusal wear. For instance, if it is assumed that the $M_{1}$ first comes into occlusion at six years, and $\mathbf{M}_{2}$ at 11 years, the $M_{1}$ in a mandible with a newly erupted $\mathbf{M}_{2}$ (i.e., showing a minimum of acclusal wear) exhibits five years of occlusal wear. Use of this procedure in analyzing skeletal samples involves so many problems and uncertainties that a review of the underlying basis for Krapina age determinations is necessary.

\section{Some assumptions}

Four assumptions underlie the successful application of the procedure; each of these can be validly questioned.

(1) A known sequence of eruption times must be assumed for the sample.

(2) Uniform eruption times must be applied to each immature individual.

(3) The pattern of wear must be fairly consistent for all the individuals aged.
(4) The assumption must be made that the wear rate for each tooth is independent of age and consistent in each tooth class.

\section{Populational eruption time differences}

The first assumption creates a number of difficulties; any survey of the literature demonstrates that numerous different eruption schedules are "known" for human populations (Dahlberg and Menegaz-Bock, '58; Steggerda and Hill, '42; Genovés, '63; Legoux, '66; Friedlaender and Bailit, '69). Sources of variation include different definitions of what constitutes eruption, cross-sectional versus longitudinal studies, nutritional and other environmental influences on the timing of development and eruption, and the likely presence of genetically based populational differences.

\section{Constraints in comparing published eruption schedules}

A number of problems combine in limiting the comparability of published eruption schedules. The most important of these are the definition of what criteria are used to determine eruption, the recording interval and age range of the study, the question of whether the study is cross-sectional or longitudinal, and the mathematical treatment of the data.

Dental eruption is a continuous lifelong process (Carlson, '44; Begg, '54). Even during the period of crown formation, there is a progressive increase of the distance between the top of the crown and the base of the mandible in the lower jaw, and a similar increase for the upper jaw when measured from the base of the orbit. Due to gnathic growth there may not be actual movement of the crown towards the alveolar margin; however, once root formation begins such relative movement can be recognized. Crown completion and root formation begin a period of rapid eruption (unaffected by gingival emergence), continuing until the tooth reaches occlusion. Eruption continues throughout life; once the root is complete this process of occlusal adjustment involves the entire tooth, maintaining the crown (or what remains of it) in the occlusal plane. The continuity of this process provides the basis for numerous different definitions of "eruption."

Hurme ('48) presented a brief review of differing eruption definitions; the actual range of definitions exceed even these. At one extreme lies those studies for which no criteria are given (Panek, '65; Shourie, '46; MacKay and Martin, '52; Hellman, '23, '43; Bean, '14; 
Banerjee and Mukherjee, '67). While at the other lies studies such as the James and Pitts ('12) analysis in which five stages of eruption are noted, beginning with "breaking the gum" and terminating with "attainment of occlusal level." The most common of the eruption criteria is the appearance of a cusp or cusps through the gum (gingival eruption). Because this criterion allows the widest range of comparisons, the ensuing discussion will be limited to these studies.

A second problem involves the interval of the age classes used in scoring and the time range of the study. The longer intervals are sometimes necessitated by problems in ascertaining the "true age" of the individuals studied. Nonetheless, studies with resolution limited to a yearly interval suffer from potential inaccuracy and artificially lowered variances unless the sample size is extraordinarily high. Moreover, systematic "upward rounding" under these conditions results in incompatabilities between cross-sectional and longitudinal studies (see below). A potentially more serious problem lies in the age range of the study. Many of the published eruption schedules were determined from samples beginning at five or six years, and in some cases terminating at 12 . Teeth with eruption time ranges that extend beyond the limits of the sample must be eliminated from comparisons, since the average times of eruption will be incorrectly determined (elevated at the low end of the range and lowered at the upper end of the range).

A final aspect of the problems arising from range is the definition of intervals in crosssectional studies. Children aged to six years, for instance, may be samples from the 5- to 6year span, the 5.5 to 6.5 - year span, or the 6- to 7-year span. This can have an obvious effect on the eruption times calculated and unfortunately, many studies do not indicate the definition of the range utilized.

The problems involved in comparing crosssectional and longitudinal data have been discussed in some detail by Dahlberg and Menegaz-Bock ('58). These authors point out that a cross-sectional study can generally attain much larger sample size than a longitudinal one, and that since longitudinal studies can only record teeth after eruption the resulting estimations of when a tooth erupts are systematically too high. This bias increases in magnitude for studies with longer intervals between examinations. It might be better to eliminate longitudinal studies from compari- sons than to attempt compensation for the systematic bias, since in any event the sample sizes tend to be small. Unfortunately, this disallows the use of Steggerda and Hill's samples ('42).

Problems in mathematical treatment can range from simple procedures that render samples uncomparable such as Boas' ('27) systematic addition of 20 days to the recorded age of "erupting" deciduous teeth, to the more complex problems of data smoothing and normality (Gates, '66). If the underlying distribution of eruption times is normal, a normal probability curve fitting procedure is valid (Kelin et al., '38). However, systematic departure from normality, especially in the presence of marked skewing for the upper range, can make such data smoothing techniques less than accurate. An additional problem in nonnormal distributions is that the mean and median come to represent rather different aspects of central tendency and cannot be directly compared; studies giving the median such as Bean ('14) and Kamlanathan et al. ('60) cannot be compared with most others. One more recently applied procedure is to use a probit analysis to smooth data; a logarithmic transform provides an unskewed cumulative frequency curve for eruption times, and a probit transform into normal deviates allows a regression analysis fitting the transformed observations to the maximum likelihood estimate of the probit line (Finney, '52). Many recent studies have used this procedure, and some of the older data have been reworked (Friedlaender and Bailit, '69; Eveleth and de Souza Freitas, '69) providing a series of comparable smoothed eruption schedules.

The final problems which limit comparisons involve sample size and the possible extraction of deciduous teeth. Sample size is critical because of the normal variability in eruption times within populations (Garn and Lewis, '57; Garn et al., '59) and the tendency to use yearly timespans for recording emergence. The effect of deciduous tooth extraction is to speed up permanent eruption times for the relevant replacing teeth (Hunt, '61; Adler, '58).

\section{Environmental sources of systematic variation}

Both nutrition during the growth period and the degree of tooth use can systematically alter eruption times. Lewis and Garn ('60) demonstrate a relationship between tooth formation and other measures of maturation 
while other studies indicate a significant correlation between tooth development and eruption time (Garn and Lewis, '57). The tooth development and maturation correlations are lowest during infancy and increase through adolescence. Besides demonstrating an underlying relationship between tooth development and maturation of other body elements, these data indicate the likelihood of nutritional correlates with the eruption schedule (Garn et al., '65; Garn and Russell, '71). The largest single study attempting to ascertain the nutritional effects on tooth emergence by dividing a sizable American White and Black sample in to lower and higher economic groupings, clearly indicated later eruptions in the males of both lower economic groups while no significant differences could be found for the females (Garn et al., '73).

Thus, these studies suggest that nutritional status can affect the eruption schedule, especially at the extremes. However, the magnitude of the effect is not great. Even in the male sample discussed above, the eruption time difference was small and was greatly outweighed by the apparent populational genetic differences. Similarly, studies of the deciduous eruption schedule have failed to establish a firm relationship between nutrition and emergence times (Bambach et al., '73; Meridith, '46). In sum, these data indicate that nutritional status is probably not an important consideration in constructing models for fossil samples.

Other possible effects of the environment and tooth eruption include climate, chemicals in the diet, and tooth use. Eveleth ('66) suggested that the tropical climate may act to accelerate maturation; Friedlaender and Bailit consider the hypothesis but find the evi. dence equivocal ('69), and Houpt et al. ('67) argue rather strongly against it. The addition or deletion of certain chemicals from the normal diet can also alter eruption times. For instance, one study by Short ('44) demonstrated some eruption delay in areas where there is fluorine in the drinking water. Further work by Møller ('65) indicated that the causal agency is decay retardation in the deciduous teeth; with the addition of fluorine the lower frequency of caries results in later loss of the primary dentition and consequently later eruption of the permanent teeth (Adler, '58). Finally, it has been suggested that substantial attrition of the primary teeth speeds up permanent tooth eruption (Campbell, '25; Hunt,
'61). The presumed mechanism would be the early loss of heavily worn primary teeth. A further suggestion is that marked wear of the early erupting permanent teeth speeds up eruption of the later erupting ones, possibly as the result of mesial drift (Begg, '54). While there is an obvious adaptive advantage to rapid tooth eruption under conditions of marked occlusal wear, the fact is that this relation has never been verified.

\section{Genetic variation}

The case for a genetic basis to eruption timing is well established (Hatton, '55; Garn et al., '60; Bailit et al., '70; Garn et al., '65), and the magnitude of the genetic basis appears to be substantial. Combined with the relatively low degree of influence that can be demonstrated for the factors discussed above, it is likely that populational differences in the eruption schedule are mostly a reflection of genetic difference (Friedlaender and Bailit, '69; Garn et al., '73).

Yet, if it is assumed that the major contribution to populational differences is genetic, observable variation follows no clear pattern. Early studies such as Suk's ('19) seem to show that Africans have more rapid eruption times than Europeans in the permanent teeth. More recent analysis suggests this may not be the case (Richardson et al., '76). In fact, teeth in Michigan blacks (Garn et al., '72). erupt more slowly than in British school children (Clements et al., '53). Similarly, while Ferguson et al. ('57) report earlier deciduous tooth emergence in American Blacks than in American Whites, a difference is not supported by Rhoads et al. ('45) and others. In sum, it would appear that genetic differences are not con. sistent over broad geographic areas; they are populational rather than "racial."

\section{An applicable gingival eruption schedule}

No unambiguous procedure exists for picking the most applicable eruption schedule for age determination in fossil hominids. One reason for this is the strength of the genetic component to eruption time determination. While the most applicable schedule might be based on the living population most closely related to the fossil sample in question, this information generally remains unknown. Furthermore, even if known, the temporal differences involved and the likelihood of changes in selection over these timespans 
TABLE 1

Estimation of average occlusal eruption ages for fossil hominid samples. The data presented include maximum, minimum and average gingival eruption for comparable living human population means, the estimated difference between gingival eruption (emergence) and occlusal eruption, and the corresponding occlusal eruption schedule. See text for further details

\begin{tabular}{|c|c|c|c|c|c|c|}
\hline & \multicolumn{3}{|c|}{$\begin{array}{l}\text { Population means: } \\
\text { gingival eruption }\end{array}$} & \multirow{2}{*}{$\begin{array}{c}\text { Occlusal } \\
\text { eruption } \\
\text { lag }\end{array}$} & \multirow{2}{*}{$\begin{array}{c}\text { Estimated } \\
\text { occlusal } \\
\text { mean }\end{array}$} & \multirow{2}{*}{$\begin{array}{c}\text { Mean } \\
\text { occlusal } \\
\text { eruption }\end{array}$} \\
\hline & Maximum & Minimum & Average & & & \\
\hline $\mathrm{I}^{1}$ & 7.7 & 6.2 & 6.8 & 0.4 & 7.2 & 7 \\
\hline $\mathbf{I}^{2}$ & 8.5 & 7.1 & 7.8 & 0.6 & 8.4 & 8 \\
\hline $\mathrm{C}$ & 11.3 & 9.3 & 10.5 & 0.6 & 11.1 & 11 \\
\hline $\mathrm{P}^{3}$ & 10.7 & 8.9 & 9.7 & 0.5 & 10.2 & 10 \\
\hline$P^{4}$ & 11.3 & 10.0 & 10.7 & 0.4 & 11.1 & 11 \\
\hline $\mathbf{M}^{1}$ & 6.4 & 5.0 & 5.9 & 0.5 & 6.4 & 6 \\
\hline $\mathrm{M}^{2}$ & 12.3 & 10.1 & 11.6 & 0.7 & 12.3 & 12 \\
\hline $\mathbf{M}^{3}$ & 25.1 & 16.3 & 18.7 & & $19.4^{1}$ & 19 \\
\hline$I_{1}$ & 6.4 & 5.2 & 6.0 & 0.4 & 6.4 & 6 \\
\hline $\mathrm{I}_{2}$ & 7.5 & 6.1 & 6.9 & 0.5 & 7.4 & 7 \\
\hline $\mathrm{C}$ & 10.4 & 8.8 & 9.7 & 0.5 & 10.2 & 10 \\
\hline $\mathbf{P}_{3}$ & 11.0 & 9.3 & 10.1 & 0.7 & 10.8 & 11 \\
\hline $\mathrm{P}_{4}$ & 12.0 & 10.1 & 10.9 & 0.4 & 11.3 & 11 \\
\hline$M_{1}$ & 6.2 & 4.7 & 5.7 & 0.6 & 6.3 & 6 \\
\hline $\mathbf{M}_{2}$ & 11.6 & 9.8 & 11.0 & 0.7 & 11.7 & 12 \\
\hline $\mathrm{M}_{3}$ & 24.8 & 16.3 & 18.4 & & $19.1^{1}$ & 19 \\
\hline $\mathrm{dI}^{1}$ & 0.8 & 0.7 & 0.8 & $0.3^{2}$ & 1.1 & 1 \\
\hline $\mathrm{dI}^{2}$ & 1.1 & 0.9 & 1.0 & 0.3 & 1.3 & 1 \\
\hline $\mathrm{dC}$ & 1.5 & 1.4 & 1.5 & 0.4 & 1.9 & 2 \\
\hline $\mathrm{d}^{\mathbf{1}}$ & 1.4 & 1.2 & 1.3 & 0.5 & 1.8 & 2 \\
\hline $\mathrm{dM}^{2}$ & 2.3 & 1.8 & 2.0 & 0.5 & 2.5 & 3 \\
\hline $\mathrm{dI}_{1}$ & 0.7 & 0.6 & 0.6 & 0.3 & 0.9 & 1 \\
\hline $\mathrm{dI}_{2}$ & 1.2 & 1.0 & 1.1 & 0.3 & 1.4 & 1 \\
\hline $\mathrm{dC}$ & 1.6 & 1.4 & 1.5 & 0.4 & 1.9 & 2 \\
\hline $\mathrm{dM}_{\mathrm{t}}$ & 1.4 & 1.2 & 1.3 & 0.5 & 1.8 & 2 \\
\hline $\mathrm{dM}_{2}$ & 2.3 & 1.8 & 2.0 & 0.5 & 2.5 & 3 \\
\hline
\end{tabular}

${ }^{1}$ Uses second molar eruption lag.

${ }^{2}$ Deciduous eruption lags estimated.

${ }^{3}$ Rounded to nearest year.

would result in the same uncertainty. Since using any schedule will precipitate an unknown amount of error, the goal is to minimize the error since it cannot be eliminated. With this in mind, one approach is to use an average eruption schedule for comparable living human groups samples over as broad a geographic range as possible. The advantages to this procedure are that it makes no assumptions as to whether or not the fossil population had unusually rapid eruption times, and by averaging across population differences which are largely genetic-based, data are provided roughly reflecting an average genome for Homo sapiens. If there is systematic error introduced by this procedure, it is probably on the side of over-aging.

The data used here for determining average eruption times for the permanent dentition (except M3) are derived from cross-sectional studies of the following populations: Euro- peans represented by a Michigan White sample (Garn et al., '72) and British school children (Clements et al., '53); Africans represented by a West African sample from the Brong Ahafo region of Ghana (Houpt et al., '67), and East African sample from Uganda (Krumholt et al., '71) and a mixed American sample of Michigan Blacks likely including some admixture (Garn et al., '72); Melanesians represented by a Bougainville sample (Friedlaender and Bailit, '69; Asiatics represented by a Japanese (Eveleth and de Souza Freitas, '69) and South Chinese (Lee et al., '65) sample, and a sample of Pima Amerinds (Dahlberg and Menegaz-Bock, '58). M3 figures were based on data from actually erupted teeth (Chagula, '60; Houpt et al., '67) and from Steggerda and Hill's ('42) longitudinal study. The longitudinal figures were modified to be comparable with cross-sectional data using average differences calculated from data pro- 
vided by Dahlberg and Menegaz-Bock ('58). Thus, M3 data are for East Africans and Ghanans, Maya and Navajo Amerinds, and American Whites. These particular choices were made amongst the larger number of published populations which represented living Africans, Asiatics and Europeans because they minimized problems in interpretation, interval and range while maximizing sample size. Eruption in all cases was determined by cusps visibly piercing the gum. Males and females were averaged for each population and the grand average and range of population means was then calculated (table 1).

Ages for the eruption for the deciduous teeth were based on an average of Bougainville Melanesians (Friedlaender and Bailit, '69), Americans of European descent published by Sandler ('44) and smoothed using a probit analysis by Friedlaender and Bailit ('69), Bantu (MacKay and Martin, '52), Tunisians (Bourtourline and Tesi, '72), and Koreans published by Yun ('57) and smoothed by Friedlaender and Bailit ('69).

\section{OCCLUSAL ERUPTION}

\section{Eruption in skeletal samples}

Unfortunately, the gingival eruption schedule cannot be directly applied to a skeletal sample. Application of gingival eruption schedules determined from living populations to fossil samples involves non-comparable data since the criteria for determining eruption can not be the same. For instance, Wallace ('77) uses surface scratching to score for gingival eruption in australopithecines; however, it is unclear whether such scratching begins when the gum is pierced by a cusp (the criterion used for living people), when the tooth reaches the occlusal level, or at some point between these stages. Consequently, does one compare his eruption sequences with gingival eruption sequence data, occlusal eruption sequence data (these are not the same), or neither of these? Garn et al. ('57) suggest several different eruption categories: gingival (appearance through the gums), alveolar (appearance of the crowns out of the alveoli), and occlusal (attainment of occlusal level). Each of these provides different eruption times and sequences. Of these only occlusal eruption can be determined unambigu. ously for skeletal material. Yet few eruption schedules have ever been published for attainment of occlusal level.

\section{Gingival and occlusal relations}

The most commonly used criterion for gingival eruption is the appearance of one or more cusps through the gum. Only a few published studies provide data allowing the comparison of the eruption schedule determined by this criterion with the eruption schedule for attainment of occlusal level. One of these is the comparison of South African Zulu and Czech school children presented by Suk ('19). The study provides the percentage of individuals within each age bracket (1 year) that have teeth in occlusal eruption (at the occlusal level), and the additional percentage of individuals within each age bracket with erupting teeth (broken through the gum but not at the occlusal level). Adding these two percentages together results in a percentage which is equivalent to gingival eruption as defined above. It is the gingival eruption schedule that Hellman (43) calculated from these data. The Zulu sample was studied by Suk himself, while the Czech sample was studied by J. Matiegka, who provided the data for Suk's analysis. The data sets do not appear fully comparable; in Suk's Zulu data the percentages of erupting teeth in each age category are very small compared with the percentages of teeth in occlusion while in Matiegka's Czech data, the percentages of erupting teeth are generally much larger, often exceeding the percentages of teeth in occlusion. It seems likely that Matiegka used more sensitive criteria to determine whether teeth were erupting or in occlusion. Published data indicate that considerable time can elapse between alveolar eruption and occlusal eruption. For instance, considering the mandibular teeth from $\mathrm{P}_{3}$ to $\mathrm{M}_{2}$, this average difference can range from ten months in male $\mathrm{P}_{3}$ 's to 18 months in male $\mathrm{M}_{2}$ 's (Garn et al., '65). Consequently, Matiegka's data are the more useful of those presented by Suk, even though the sample size for the Czech school children is smaller.

Two eruption schedules were determined for the Czech sample, gingival eruption times and occlusal eruption times. Mean eruption times for each were calculated according to Kaber's method (Hayes and Mantel, '58) for right and left side in all the teeth with eruption ranges not extending beyond the age range of the study (6-19) years. This resulted in excluding I1, M1, and M3 in both jaws. Right and left sides were then averaged for the comparison of occlusal and gingival eruption times in the 
remaining teeth of both jaws. While only data for male subjects were presented, a similar analysis of Suk's Zulu data for both sexes indicates that there was no significant difference in gingival-occlusal eruption time lags for males and females. The average differences between gingival and occlusal eruption were determined by substracting the average time of gingival eruption from the average time of occlusal eruption for each tooth.

A similar analysis was attempted for English children, using data for almost 5,000 children, recorded over 3-month intervals, published by James and Pitts ('12). The data are not fully comparable because of a difference in the definition of "erupted teeth." Although the authors discriminated five stages of eruption beginning with "breaking the gum" and terminating with "attainment of occlusal level," the data they present for "erupted teeth" includes teeth in the last two categories (more than half the crown erupted and fully erupted). Consequently, comparing gingival eruption schedules to schedules for erupted teeth will underestimate the difference between gingival and occlusal eruption.

In this case, the teeth that could be analyzed were constrained by the upper age limit of the sample, 12 years. Only the incisors and the first molars could be used, thus largely complementing the analysis of Matiegka's data. In the single tooth common to both analyses (I2), the difference between gingival and occlusal eruption times was 0.1 year greater for both the Czech maxillary and mandibular sample. This suggests that the results are roughly comparable and can be combined, and that the combination presents an underestimate of the time difference between gingival and occlusal eruption in European children. The combined values are presented in table 1.

\section{Direct determinations}

Few studies present occlusal eruption data directly and thus provide a basis for determin ing whether these results are reasonable. One of these, based on data from the Fels Institute in Ohio (Garn et al., '65) gives times for attainment of occlusal level in a large sample of European origin. Using an average for the sexes, the eruption times are about a half-year later than those in table 1 for $P_{3}-M_{1}$, while the $\mathbf{M}_{2}$ times are the same. Could this difference be the result of the fact that average eruption times for American Whites are later than the combined populational average given in table 1. Unfortunately, gingival eruption times were not published for the Fels study so that a direct comparison is not possible. A sample of Michigan Whites can be used to estimate gingival eruption times for the Ohio sample. Although the Michigan White group later published by Garn is a different population, an almost identical relation describes the difference between the averaged sex value for the Michigan White sample and the population average for gingival eruption in table $1: \mathrm{P}_{3} \cdot \mathrm{M}_{1}$ break the gum about a half year later in the population of European descent while $\mathbf{M}_{2}$ eruption is the same. In sum, within the other constraints of the analysis, the estimated average occlusal eruption times presented would seem to be valid.

\section{SOURCES OF ERROR}

\section{Eruption variation within populations}

Normal variations in eruption times result in an important source of error. Published variances in eruption times within populations are substantial (Hurme, '48: Friedlaender and Bailit, '69; Garn et al., '65). Moreover, demonstrable sex differences in average eruption times create an additional source of variation for samples in which sex is unknown.

Published ranges of eruption times are fairly similar between populations, when the range is expressed between the 0.05 and 0.95 confidence intervals. Ranges vary from 2.5 to 3.5 years within each sex; the canine, premolars, and second molar are generally the most variable. This variability introduces an unavoidable error when aging individuals, al. though the error tends to be self canceling for the sample statistics since as many individuals should be underaged as overaged if the mean is used. However, if this range of normal variation is added to the range of populational means presented in table 1 , the potential for considerable error in aging specific specimens of unknown genetic relationship to living populations cannot be overstated.

Regular sex differences in eruption times characterize all populations. Considering those samples used in constructing the populational average in table 1 , male eruption time almost inevitably follows females in all teeth except the third molar. In a few instances the times are the same, and in fewer still the female average time lags behind the male 

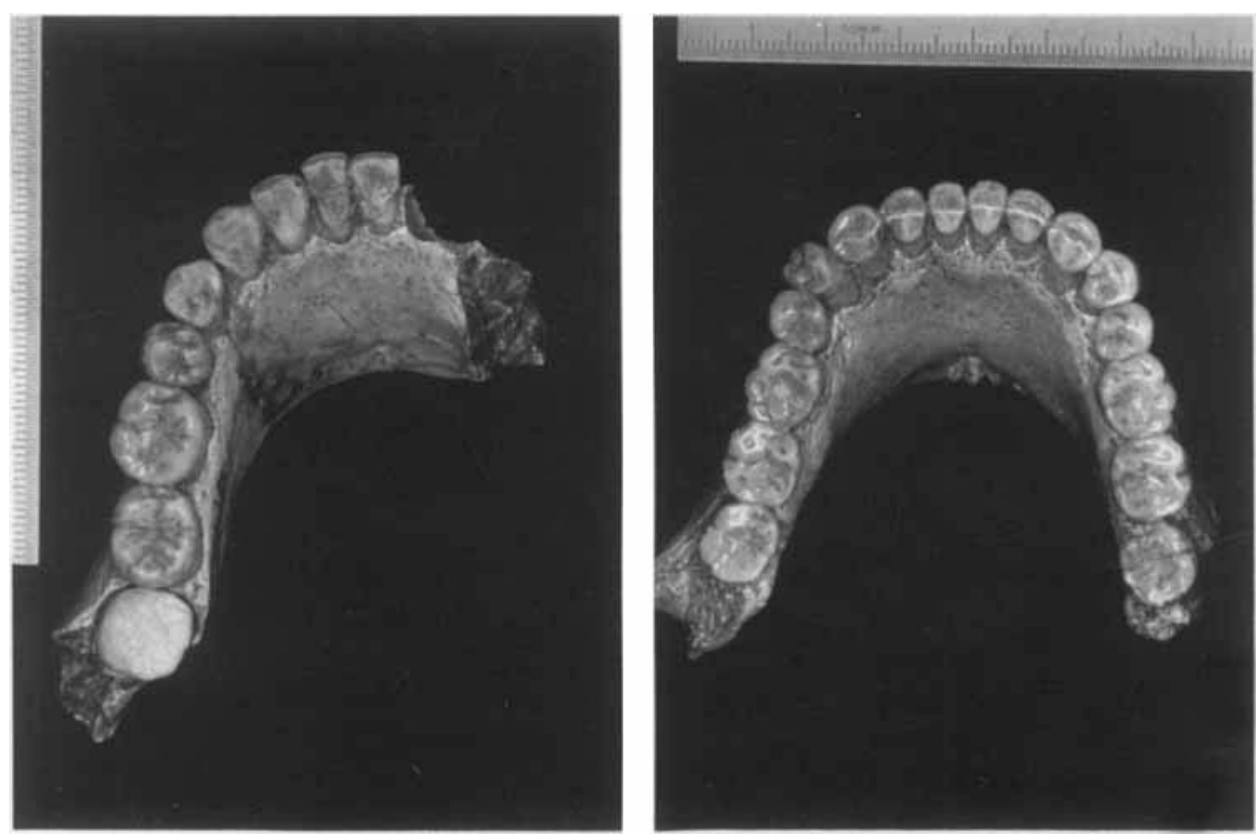

Fig. 1 Comparison of Krapina mandibles $\mathbf{E}$ (left) and $H$. An unerupted $\mathbf{M}_{3}$ fits exactly into the open socket in E. Note the similarity in the sequence of cusp removal and dentin exposure. The $\mathbf{M}_{2}$ wear in $\mathrm{H}$ is greater than the $M_{2}$ wear in $E$.

time. In the third molar, the more limited data suggest that while on the average male eruption times are later than those of females, the exceptions are more numerous and more dramatic.

The magnitude of the sex difference in eruption times seems linked with the age at eruption. Excluding the canine, the average sex differences for the populations in table 1 are lineally related to the time of eruption for each tooth with correlation coefficients of 0.995 in the maxilla and 0.972 in the mandible. The single exception is the canine, with an average sex difference 0.2 years greater than predicted by the linear regression based on the remaining teeth for the maxilla, and 0.5 years greater for the mandible. In the Krapina sam ple with specimens of unknown sex, it is consistent to apply average eruption data to the sample with the expectation that given the likelihood of an approximately equal representation of both sexes, the systematic errors introduced will be cancelled for the sample statistics.

In sum, variation in eruption times within populations is sufficiently great to introduce potential error in age determinations for individuals. However, since errors are evenly dis- tributed about the mean they will not markedly affect sample statistics based on the age distribution as long as the sample size is adequate.

\section{Uniform wear rates}

Consistency in wear pattern and rate for the individuals aged underlies any attempt to use this wear-based aging technique on isolated teeth, if not on more complete dentitions. Known variations in the pattern of wear are marked, and it is unlikely that interpretable results could be based on a sample lacking a fair degree of consistency in wear pattern as expressed for the full dentition. Fortunately, excluding obvious malocclusions and missing teeth, the wear patterns that have been observed are fairly consistent within populations (Lavelle, '70). However, between-population variation can be extreme (Molnar, '71a). This problem becomes critical in any fossil sample since it is likely that numerous different populations are represented.

At least one intrapopulational difference is fairly consistent. Sex differences in wear rates have been established by several workers (Molnar, '71b; Cechová and Titlbachová, '71; Campbell, '39). Another source of variation 

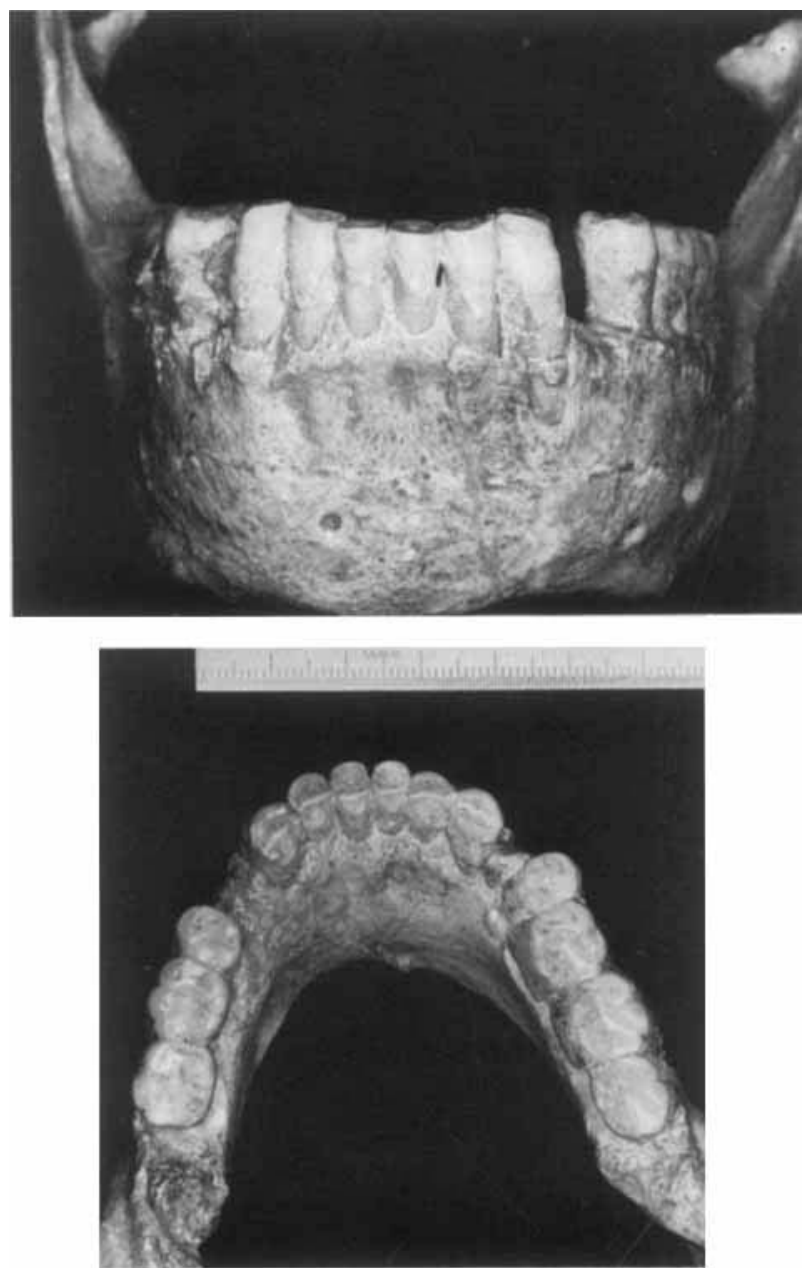

Fig. 2 Anterior and occlusal views of the mandible $J$ dentition. This specimen has the most marked expression of irregular and rounded incisor wear.

known to apply to living people and suspected for preindustrial populations is associated with occupational differences (Schour and Sarant, '42; Lous, '70).

The contribution of these factors to the aging procedure is almost certainly present, but its magnitude is unknown. Certainly, uniform sex differences will be self canceling for the sample statistics although along with possible occupational wear differences they surely contribute to individual age estimate errors.

\section{Age-independence of wear rate}

Even if wear pattern and rate are sufficiently consistent within a sample, a final problem concerns whether the same rate applies to all of the teeth of each class, and whether this rate is age independent. With regard to the first, several studies have indicated consistent bilateral wear differences, especially expressed in older age groups (Molnar, '71b; Murphy, '64). These differences seem to relate more to the form of wear than to its rate in relatively normal dentitions, although Molnar reports generally heavier wear on the left side of the mandibular posterior teeth for a California Amerind group ('71b). Interestingly, little bilateral wear asymmetry was found in the maxillae of this group. No comparative data are known and the potential importance of wear asymmetry cannot be 
determined. In the case of Krapina, marked wear asymmetry does not characterize the relatively complete dentitions.

The question of a possible age-dependence for wear rate in the teeth of each class is also yet to be answered. M1, for instance, constitutes a considerably greater proportion of the total occlusal surface when it is associated with the primary dentition than it does after the other two permanent molars have erupted. While there is presumably less mastication during the former timespan, the degree to which these are compensating factors is simply unknown. Moreover, one study indicates a more rapid wear rate in the second molar than in the first (Morris, '66) while another indicates the exact opposite (Murphy, '59).

The fact that differences in occlusal form can characterize the same tooth at various stages of wear (Butler, '72) confuses the application of wear criteria based on one tooth to the age assessment of another. Fortunately, the most marked changes in occlusal form occur during the older ages in living populations; equivalent ages are seldom attained in fossil samples.

In sum, consistency of wear pattern presents an empirical problem and in this case it is fortunate that the same basic wear pattern seems to characterize all of the complete Krapina specimens (fig. 1). For instance, in the mandibular molars wear proceeds more rapidly on the buccal side than on the lingual, and dentin exposure is almost always on the mesial buccal cusp, followed by the distal buccal cusp. Wear on the lingual side also proceeds from mesial to distal, but this side is inevitably less worn although the differences between buccal and lingual wear vary from marked (as in mandible $\mathrm{H}$ ) to minimal (as in $\mathrm{G}$ and J). It takes only a few years before the difference between sides is clearly visible. The pattern for $\mathrm{P}_{3}$ involves an initial flattening of the mesial buccal cusp, followed by the formation of distinct buccal-mesial and buccal-distal wear planes. This pattern evolves into a single flattened wear plane on the buccal surface which progressively increases in angulation until a fairly sharp mesial-distal edge is left on the occlusal surface of the tooth. Anterior wear is almost inevitably flat and level with the occlusal plane; only mandible J (fig. 2) shows the irregular wear plane and lingual rounding which has been interpreted to indicate non-masticatory functions for the anterior teeth (Brace, '62; Smith, '76).

\section{Error analysis}

Two main points emerge from the above discussion. First, a significant magnitude of error in aging the individual teeth in a fossil sample cannot be avoided. Second, for all but the oldest individuals in the fossil sample, the systematic nature of these errors results in partial self-cancelation for the sample statistics. The age-distributional data for the sample are likely to be more accurate than the individual ages themselves. Perhaps the most important criterion for deciding whether age estimates can be determined from dental wear in a fossil sample is the "nothing succeeds like success" principle. Tooth wear aging can be applied to the Krapina teeth because of the lack of significant wear pattern differences in the complete dentitions and the absence of notable bilateral wear asymmetry. Moreover, it is likely that many problems are avoided because of the absence of particularly old individuals. The most important point is that in the process of aging Krapina dentitions, no significant contradictions were encountered between age determinations for different teeth in the same dentitions (excepting M3 which will be discussed below).

The error involved in the age determination is both populational and individual. Populational level error refers to the possible departure of the age-based sample statistics from the "true" value. While a sex ratio significantly different from $50 / 50$ could cause such a departure, the main source of error is the fact that the eruption times are unknown and unknowable in a fossil sample. Based on Mann's ('75) analysis of hominids much more ancient than Krapina, it is likely that a living populational model can be applied, but there is no way to determine which of the possible living population schedules is the most valid. The procedure used here is to apply a populational mean schedule determined from the most wide ranging possible set of comparable schedules. If it is assumed that the true Krapina schedule falls within the range of these populational means, a maximum possible error can be estimated from this range. The average difference between maximum and minimum means for all teeth excepting M3 is 1.6 years; the standard error is 0.1 years and the range is 1.2 to 2.2 years. This would suggest that an estimated maximum error for the central tendency calculations not exceeding \pm 0.8 years is reasonable. 
Individual error is much more difficult to determine; at the maximum it is almost surely greater than the populational estimate. The major contributing factor to individual error is the intrapopulational variance in eruption times. Since the times for most teeth in large samples approach normality, $95 \%$ or $50 \%$ in tervals can be estimated from the normal curve, given the standard deviation. The $50 \%$ range is almost invariably below one year, while the $95 \%$ range is much greater. Thus, very different error estimates are obtained depending upon the amount of accuracy desired.

Other factors discussed above add to the potential for individual error; the magnitude of the additional error is simply impossible to ascertain. Given the apparent consistency in the observed Krapina wear rates and patterns, I believe that a \pm 1 year estimated error for each age approximates or overestimates the $50 \%$ range for this sample. The actual, or $95 \%$ range, is much larger and the potential for individual deviations from the estimated ages must be constantly in mind.

\section{KRAPINA AGES}

Age determinations for the Krapina sample were based on the occlusal eruption criteria (discussed above), and wherever possible the stage of crown calcification and root formation. The later could be observed for individual teeth, in fortuitious breaks of fragmentary specimens, and from a limited number of $\mathrm{X}$ rays available at the museum (some of these were published in Gorjanovic's monograph). Although both populational and individual variability in crown and root formation are substantial (Legoux, '66; Garn et al., '59), they are equivalent in eruption variability (Garn et al., '65). Average stages were determined and keyed to the occlusal eruption times of table 1.

\section{The younger mandibles}

The basic sequence for Krapina was initially determined from the mandibles. The dentition of mandible $\mathrm{B}$ (museum number 52) consists of a newly erupted $I_{2}$, a slightly worn $M_{1}$, and a well worn $\mathrm{dC}$ (fig. 3 ). The condition of the incisor indicated that since polishing wear extended over the entire crown surface, the tooth had been in occlusion for a short but significant time. The three unerupted teeth remaining $\left(C, P_{3}, P_{4}\right)$ appear to have complete crowns while the available $\mathrm{X}$-rays indicate slight root formation (especially visible on $\mathrm{P}_{4}$ ).

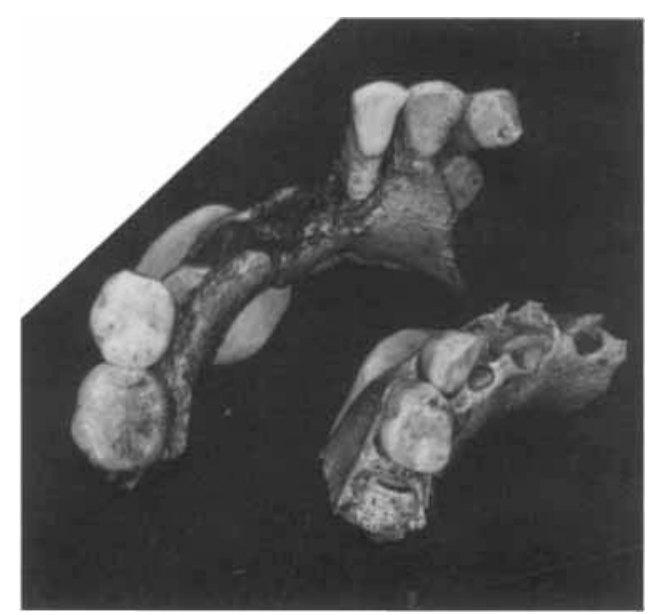

Fig. 3 Krapina juvenile mandibles $\mathrm{A}$ and $\mathrm{B}$ (right and left). The deciduous canine added to A fits exactly in the socket and the interproximal facets match. $A n I_{1}$ and $d_{2}$ are shown added to the specimen; the criteria are as above.

This fairly effectively brackets the age at death between seven and eight years (Garn et al., '59; Legoux, '66). Combined with the wear on the $\mathrm{I}_{2}$, these data suggest that the upper date, eight years, is the most likely. This would suggest approximately two years of occlusal wear for the molar; it exhibited only slight cusp polishing on the buccal side with no lingual facets and no distal interproximal facet.

Comparison of mandible A (No. 51) with B was not possible occlusally, since the only in situ erupted tooth is $\mathrm{dM}_{1}$. The tooth has a wide $(3.5 \mathrm{~mm})$ distal interproximal facet for the erupted $\mathrm{dM}_{2}$. Using the available X-ray, crown formation on the unerupted $\mathrm{P}_{3}$ is complete although the canine does not appear fully formed; neither tooth has root development. Both central and lateral incisors have fully developed crowns and the roots appear more than half complete. The alveoli are fully open and the crown tips are close to the alveolar level. The higher position of the central incisor suggests it is in the process of alveolar eruption. Taken together, these data indicate an age of six years for the A mandile.

The next youngest mandible is $\mathrm{C}$ (No. 53). $\mathrm{M}_{2}$ has just erupted with only the slightest cusp polishing and without any distinct facets; the wear is less than that of the mandible $\mathbf{B} \mathbf{M}_{1}$. The right $\mathbf{M}_{3}$ crown is visible in the crypt and the crown appears fully developed. Wear on the lateral incisor is moderate al. 

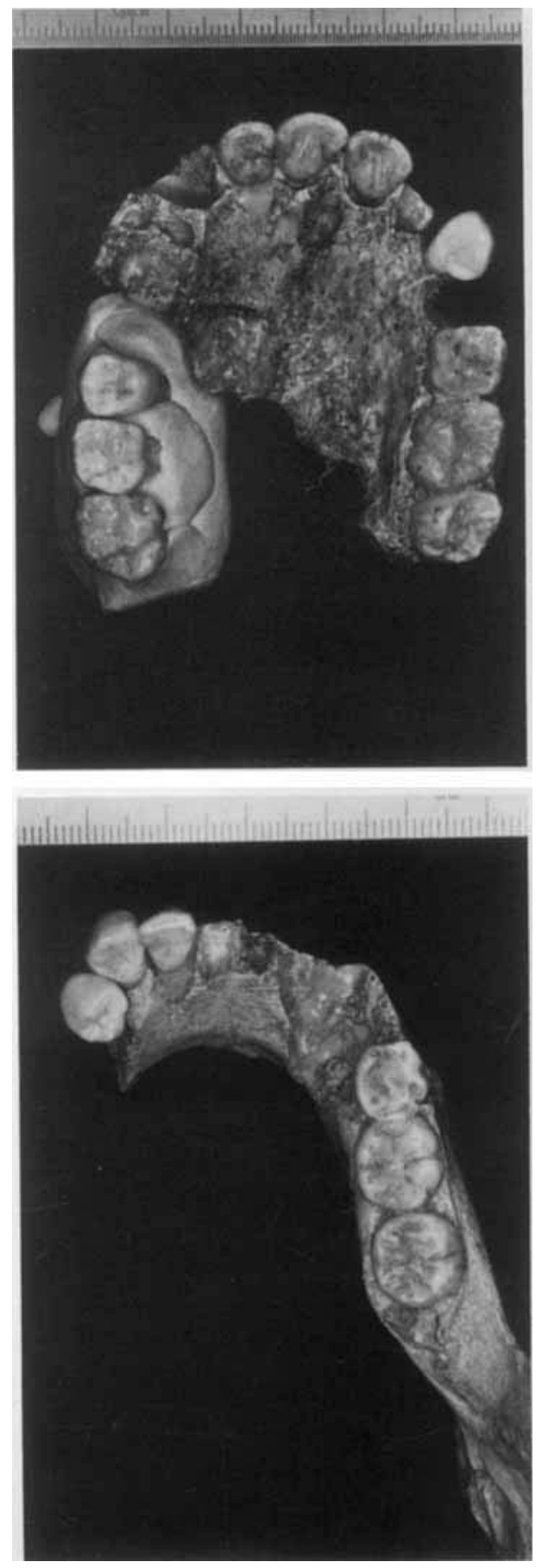

Figure 4 though dentin is exposed over virtually the entire crown surface (fig. 4). The $\mathrm{dM}_{2}$ is still present, although the position of $\mathrm{P}_{4}$ is high relative to the alveolar margin and the deciduous tooth would probably have been lost had the individual lived slightly longer. $P_{3}$ is broken through the alveolus but almost certainly had not erupted gingivally. The presence of $\mathrm{dM}_{2}$ would argue for an age younger than 11 while the wear on $\mathrm{M}_{2}$ argues for an older than 11 determination. Studies of the $\mathbf{P}_{4} / \mathbf{M}_{2}$ eruption sequence polymorphism (Garn and Lewis, '57; Garn and Koski, '57; Garn et al., '57) indicate that the $\mathbf{M}_{2}$ eruption is the more stable of the two. However, the fact is that neither the canine nor $\mathrm{P}_{3}$ (an equally stable tooth) have reached occlusion. An estimated age of 11 years for Krapina $C$ seems the best compromise. Mandible $\mathrm{C}$ thus provides a molar with five years wear, a $\mathrm{dM}_{2}$ with eight to nine years wear, a lateral incisor with three to four years wear and a molar $\left(\mathrm{M}_{2}\right)$ with one year or less wear. The observable wear on $\dot{M}_{2}$ conforms to the eruption sequence $\mathrm{M}_{2} \mathrm{P}_{4}$ inferred by Koski and Garn (57) on the basis of observable tooth positions. This is an unusual sequence for the known Neandertal children according to these authors.

Mandibles D (No. 54) and E (No. 55) appear to be the same age; $\mathrm{E}$ is easier to age because it is more complete (fig. 1). Lack of an interproximal facet on the distal border of the $\mathbf{E}$ $M_{2}$ shows that $M_{3}$ had not erupted although the size and excavation of the crypt indicated that root formation was partially complete; the long axis of the crypt, open at the top, is $18.3 \mathrm{~mm}$ from the alveolar margin. This led me first to believe that the individual was approximately 16 to 18 years of age, although the marked angulation of the crypt suggests that the $\mathrm{M}_{3}$ probably would have become impacted upon eruption (Molnar, personal communication), rendering the interpretation of root size more difficult. An age in the 16- to

Fig. 4 The C maxilla (above) and mandible. Age deter mination of these jaws is critical in both the maxillary and the mandibular sequence; the $\mathbf{M}_{2}$ shows slight occlusal wear while the $\mathbf{M}^{2}$ shows none. The $\mathrm{C}^{1}$ is an unerupted canine with virtually complete root formation which fit into the maxillary socket once the canine that had been plastered in (after Gorjanovic's time) was removed and the socket cleaned. $A$ right unerupted $P^{3}$, and antimeres for the $\mathrm{dM}^{1}$ and $\mathrm{M}^{1}$ are also shown (not in their symmetric position - displaced distally). The $C_{1}$ and $P_{s}$ shown fit exactly into the existing sockets; these teeth were in the process of erupting but neither was in occlusion at death. The canine was at a more advanced stage of eruption than the premolar. 
18-year range would require between five to seven years wear on the $\mathrm{M}_{2}$; the tooth should be at least as worn as the mandible $\mathrm{C} \mathrm{M}_{1}$ (5 years in occlusion). However, the $\mathrm{M}_{2}$ wear on $\mathrm{E}$ is very much less, approximating the $\mathrm{M}_{1}$ wear on mandible $B$ (2 years in occlusion) although slightly greater. Finally, the $\mathbf{M}_{1}$ wear is similar to the $\mathrm{dM}_{2}$ wear for mandible $C$. Thus, the erupted molars suggest an age no greater than 15 years. The $\mathrm{M}_{1}$ of mandible $\mathrm{D}$ (fig. 23) is very slightly less worn than the mandible $\mathrm{E} \mathrm{M}_{1}$. It is unlikely that this represents as much as a year's difference and the similarity in anterior tooth and premolar wear between these individuals indicates that they are the same approximate age.

\section{Older mandibles and the problem of $M_{3}$ eruption}

Mandible G (No. 57) has three worn molars in occlusion (fig. 5). $\mathrm{M}_{2}$ wear is slightly more than the $M_{1}$ wear in mandible $C$ ( 6 years in occlusion) but much less than the mandible $\mathrm{E}$ $\mathrm{M}_{1}$ wear (9 years in occlusion). This would indicate seven years on occlusion for the tooth, and an approximate age of 18 years. However, the $M_{3}$ wear exceeds the $M_{1}$ wear in mandible B (2 years in occlusion) although it is not as great as the $\mathbf{M}_{2}$ wear in mandible $\mathrm{E}$; if in occlusion for approximately three years an age of 20 to 21 years is indicated (table 1). A similar problem occurs with mandible $H$ (No. 58, fig. 1). The $M_{2}$ wear exceeds the $M_{1}$ wear in mandible $\mathrm{E}$ (9 years in occlusion) and most closely resembles the mandible $\mathrm{G}_{1}$ wear (12 years in occlusion according to $\mathrm{M}_{2}$ wear but 15 years in occlusion according to $M_{3}$ wear). As in mandible $G$, the $M_{3}$ wear suggests a different age. It very closely resembles the mandible $\mathrm{E}$ $\mathrm{M}_{1}$ wear ( 9 years in occlusion).

The same interpretive problem occurs in both mandibles; $\mathrm{M}_{3}$ wear gives an age which is three years older than that suggested by $\mathbf{M}_{2}$ wear if it is assumed that $M_{3}$ erupts at 18 years. The interpretations become interrelated because mandible $\mathrm{G}$ is especially useful in aging mandible $\mathrm{H}$. Whatever solution is taken, the two must be treated the same way.

Mandible J (No. 59) is the third fairly complete adult (fig. 2), in this case missing only the third premolars. Tooth wear is uniformly younger than $H$, although older than $G$. The $M_{1}$ is slightly more worn than the $M_{2}$ in $H$. $A$. better comparison is between the $\mathrm{M}_{2}$ and the first molar in $E$ (9 years in occlusion); these are virtually identical and the match is even

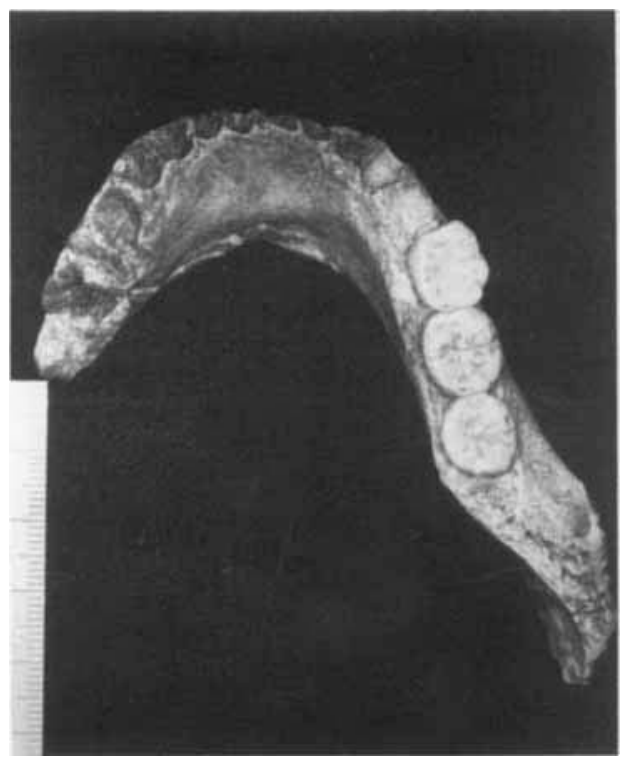

Fig. 5 Mandible $G$ in occlusal view. In spite of the socket cleaning that was allowed, no teeth were recovered which clearly could be associated with the mandible and no likely antimeres for the molars were found.

closer with the mandible $\mathrm{D} \mathrm{M}_{1}$. This would suggest an age of 20 to 21 years for the mandible, but again the $\mathrm{M}_{3}$ provides contradictory information. In this case it is similar in wear to the $\mathrm{M}_{1}$ of mandible $\mathrm{C}$ ( 6 years in occlusion), although slightly less worn.

In these three adult mandibles; one factor systematically underlies the problems in molar wear aging; the age based on the $\mathrm{M}_{3}$ appears to be two to three years older than the age based on the other molars. Combined with the condition of the $\mathbf{M}_{3}$ crypt in mandible $\mathbf{E}$, the simplest explanation is that the ages based on the other molars are correct and that the $M_{3}$ at Krapina erupts at approximately 15 years. This would result in similar ages for the molars of the three; $\mathrm{G}$ would be aged at $18, \mathrm{H}$ at 23 , and $J$ at 20 . I have utilized this simplifying hypothesis in all further work at the site, and although the evidence is only based on four specimens it would appear that an early $\mathbf{M}_{3}$ eruption characterizes this sample. Individual ages for the mandibles are presented in APPENDIX 2.

A 15-year estimate for the occlusal eruption is markedly in advance of some populational figures. However, it clearly falls within the range of individual data sampled from Africa (Chagula, '60; Houpt et al., '67; MacKay and 


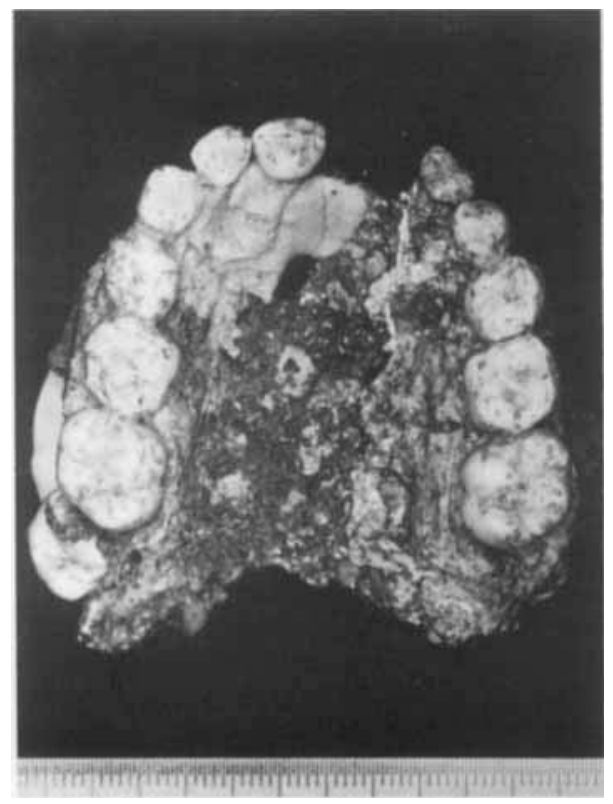

Fig. 6 Juvenile maxilla $B$.

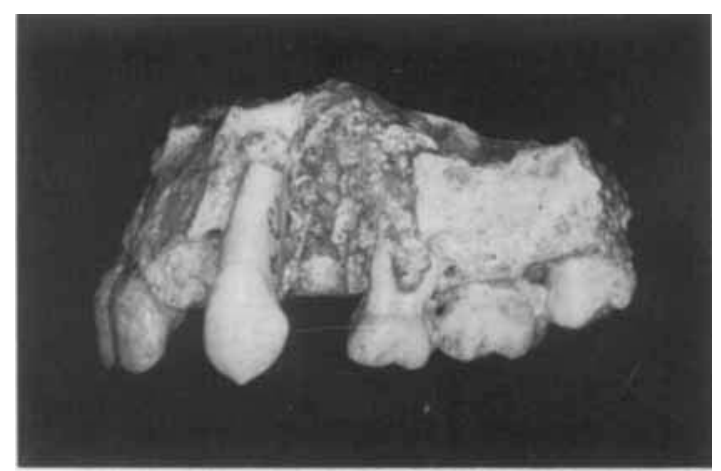

Fig. 7 Lateral view of the $C$ maxilla, showing the erupting canine that is associated with it on the basis of socket fit, developmental stage, and size.

Martin, '52), the Philippines (Suk, '19), India (Shourie, '46), and elsewhere. A 15-year average would seem to precede the earliest reported modern group by about two years.

\section{Individual mandibular teeth}

Using the sequences of aged teeth built up from the mandibles discussed above, the individual isolated mandibular teeth were aged. I felt that premolar, canine, and incisor wear was sufficiently consistent in these specimens to attempt age determinations for all of the isolated mandibular teeth, and in this respect
I departed from Mann's more conservative approach.

\section{The maxillary sample}

The sample for incompletely developed maxillas is smaller than the mandibular sample, and consequently determining an age sequence was more difficult. Application of the mandibular sequence is constrained by the fact that the wear patterns are not truly analogous (although they are complementary), and the demonstration that maxillary teeth tend to wear more rapidly than their mandibular counterparts (Molnar, '71b).

Maxilla B (No. 46, fig. 6) appears to be the best specimen to start with; a full deciduous dentition is in place and there is slight wear on the $\mathrm{M}^{1}$ which appeared to be no greater than the $M_{1}$ wear on the $B$ mandible (2 years in occlusion). This suggested an age of eight years which was confirmed when I was given permission to remove the unerupted $\mathrm{M}^{2}$ from its crypt. The $\mathrm{M}^{2}$ appeared to have completed enamel formation but there was virtually no root development; this stage is also indicative of an 8-year old age (Kronfeld, '54).

In comparison, the maxilla A (No. 45) deciduous molars are slightly less worn than the maxilla $B$ teeth, indicating an age of 7 years. A distal interproximal facet on $\mathrm{dM}^{2}$ indicated that the $\mathbf{M}^{1}$ had erupted.

Maxilla C (No. 47, fig. 4) provided the only other case of a mixed dentition in situ. The right $\mathrm{P}^{4}$ was at the alveolar margin while on the left the $d M^{2}$ remained. The central and lateral incisors were erupted and in occlusion and the second molar was in the process of erupting. It had not yet reached the occlusal plane and no wear appears on its occlusal surface (fig. 7). The molar may not yet have cut through the gum. The $\mathrm{P}^{4}$ and $\mathrm{M}^{2}$ are consistent with an age of ten to ten and one-half years and the retardation compared to mandible $\mathrm{C}$ is consistent with the hypothesis that these could represent the same individual with the same relative sequence of $\mathrm{P} 4 / \mathrm{M} 2$ eruption, although not proof of it (Garn et al., '57). I will return to this point. A canine plastered into the left socket, however, is inconsistent with this age estimation; the root formation had barely begun. Photographs of the specimen in Gorjanovic's monograph ('06) and X-rays on display at the Museum taken several decades later do not show this tooth, and it seems likely that the canine was later thought to be associated with the specimen 


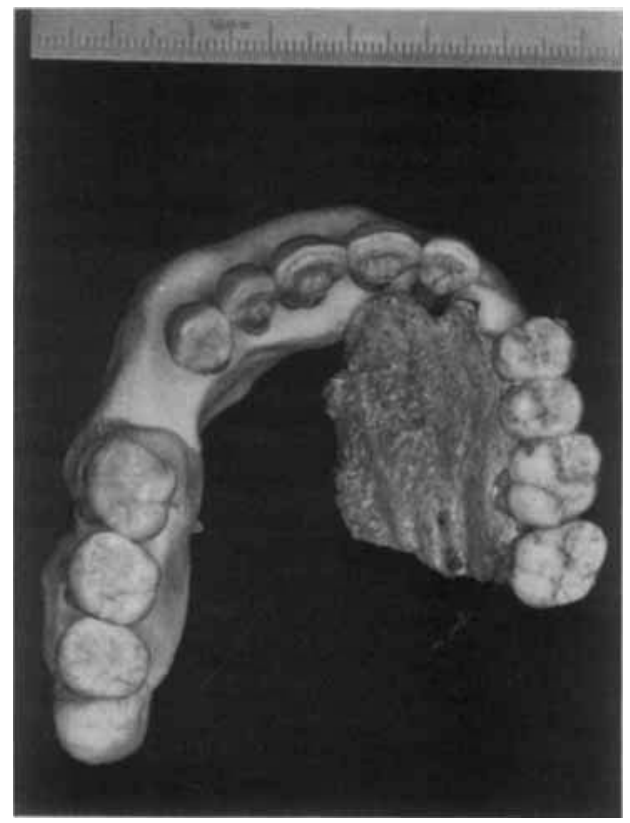

Fig. 8 Occlusal view of the $\mathrm{D}$ maxilla showing the as sociated anterior tooth set, the antimeres for the molars, and the $\mathbf{M}^{3}$ thought to belong to the specimen. Differences in angle between the maxilla and the teeth mounted in clay obscure the metric and morphological similarities of the antimeres. The four incisors were reported as an associated set by Kallay (69) and a canine was added because of occlusal and interproximal wear criteria. The interproximal facet on the distal left $\mathbf{M}^{2}$ shows that an $\mathbf{M}^{3}$ was erupting or erupted. The right $\mathbf{M}^{2}$ shows a similar slight facet which is matched by mesial face polishing on the $\mathbf{M}^{3}$. However, the facet position indicates that the tooth was not fully erupted and no occlusal wear occurs on the mesial occlusal surface. and consequently plastered into the existing socket. The tooth was removed and the socket was cleaned. Maxilla $\mathrm{C}$ thus provided a model for four years of molar occlusal wear.

Maxillas D and E are clearly older than C, based on comparisons of $\mathrm{M}^{1}$ wear the presence of wear on the premolars and $\mathrm{M}^{2}$. Only $\mathrm{D}$ (No. 48) has molars (fig. 8); a small distal interproximal facet on the $\mathrm{M}^{2}$ shows that $\mathrm{M}^{3}$ had erupted. This would make the specimen 15 years or older, using the early eruption age of M3 established by the mandibular analysis. On the other hand, the wear on $\mathrm{M}^{2}$ is between the $\mathrm{M}^{1}$ wear on maxilla $\mathrm{B}$ (2 years in occlusion) and maxilla $C$ (4 years in occlusion); it is most similar to the latter and is only slightly less worn indicating an age of 15 to 16 years. The lack of much more than cusp polishing on the premolars suggests the earlier age. In the E maxilla (No. 49), $\mathrm{P}^{3}$ wear matches $\mathrm{D}$ while $\mathrm{P}^{4}$ wear is slightly greater (fig. 9). An age of about 16 is indicated. Ages for the maxillas are in APPENDIX 2.

Maxilla F (No. 50) included two very worn incisors. Ultimately, it was shown that the specimen occluded with mandible $\mathrm{H}$ and is likely the same individual. This provides an age estimate of 23 , and with the other maxillas results in an excellent series of age-graded maxillary incisors.

\section{Individual maxillary teeth}

The smaller sample size for the incomplete maxillas makes the age sequence more problematic than the mandibular sequence. Non-

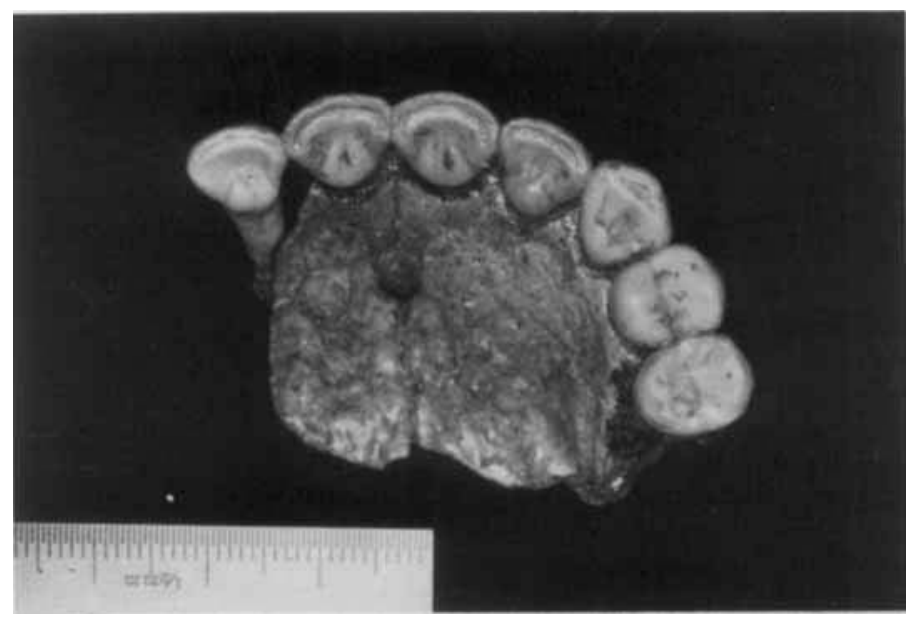

Fig. 9 Occlusal view of the E maxilla showing the single associated lateral incisor. Difference in coloration is due to the heavier shellac applied to the maxilla. 
etheless, ages were attempted for the individual maxillary teeth based on the molar occlusal wear sequence available $(2,4,5$, and 9 years), the degree of root formation and closure (when applicable), and the less certain premolar wear determined from maxilla $D$. The dependence on maxilla $D$ for both the molar and premolar wear models turned out to be fortunate because the excellent occlusal fit of mandible and maxilla D and the close correspondence of wear facets clearly indicates that they belong to the same individual. This helps confirm the 15-year estimate for the maxilla.

\section{INDIVIDUAL COUNT}

In the process of aging individual teeth, a number of specimens were found that showed marked similarity to each other. For instance, three mandibular molars (described by Kallay, '70) are characterized by a unique root robustness and thickening with marked taurdontism. In another case an apparent flake removed from the mesial surface of an $\mathbf{M}_{1}$ aligned with a similar flake from the distal surface of a $\mathrm{dM}_{2}$, completing what was in actuality a compression pit between two adja. cent teeth. However, the system established by Gorjanovic made it virtually impossible to compare different teeth. Teeth (usually) of the same type were stored in numbered boxes and then consecutively labeled; each isolated specimen was catalogued with a box $(\mathrm{Br})$ and individual number. However, only the individual number appeared on the tooth so that each box had a No. 1, No. 2, etc. This made it undesirable to mix the teeth of different boxes together for comparison, a procedure made even more difficult because of the apparent misclassification of some teeth. For instance, Br.92 generally contained upper premolars but No. 15 was found to be a $P_{4}$. Moreover, many of the teeth had lost their original numbers. To facilitate comparisons and identification, Director Crnolatac kindly allowed all of the isolated teeth to be recatalogued and renumbered with a unique number for each tooth. The resulting numbers along with the original box (Br) association and when possible the original number are presented in APPENDIX 2.

\section{Specimen associations}

One the renumbering was completed, an at. tempt was made to find isolated teeth that could be associated with the existing jaws,

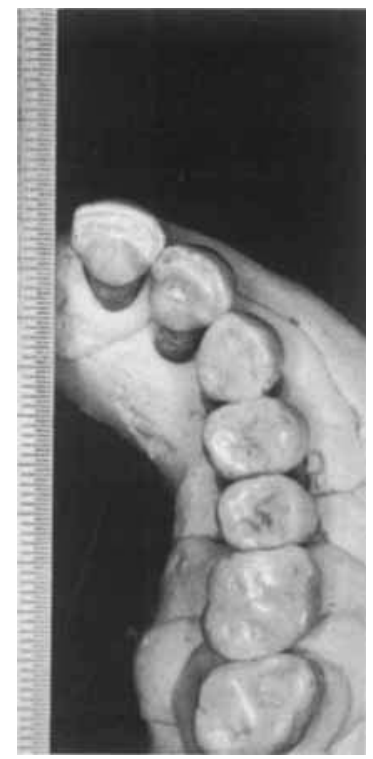

Fig. 10 The two antimere incisors of maxilla $F$ and the remaining maxillary dentition that was associated with them on the basis of matching interproximal facets, continuity of occlusal wear, and appropriate age relations. Note in particular the form of the wear facet between $\mathrm{P}^{4}$ and $\mathrm{M}^{1}$, and between the canine and $\mathrm{P}^{3}$. Age was helpful in the following manner; once the $\mathbf{M}^{1}$ was scored for approximately 15 to 17 years occlusal wear, an $\mathbf{M}^{2}$ was sought amongst the molars with 10 to 12 years occlusal wear. In most cases corresponding teeth were not found, and in those cases where possible associations were identified additional criteria necessary for acceptance in cluded (1) unambiguous fit of the interproximal facets, (2) continuity of occlusal wear including surface scratching, and (3) in this specific case evidence that the tooth was a second molar such as relative cusp sizes and root morphology.

and ultimately with each other, following Weidenreich's (37) treatment of the Choukoutien teeth. In some cases such as the $C$ mandible and maxilla, antimeres of the existing teeth were fairly obvious because of the near identity in morphology and wear. Antimeres were also established for the unerupted $B$ maxilla $\mathrm{M}^{2}$, the maxilla $\mathrm{D}$ molars, the exist ing E maxillary teeth, and the two maxilla $\mathrm{F}$ incisors.

The association of the isolated teeth is a more problematic procedure. Kallay ('69) associated a set of maxillary incisors (Nos. 153, 154,155 , and 160); these were ultimately shown to fit maxilla D (fig. 8) along with a right canine (No. 141). I did not attempt to utilize a "probability" scheme for these associations similar to Mann's, but instead only accepted cases which were clearly demonstra- 


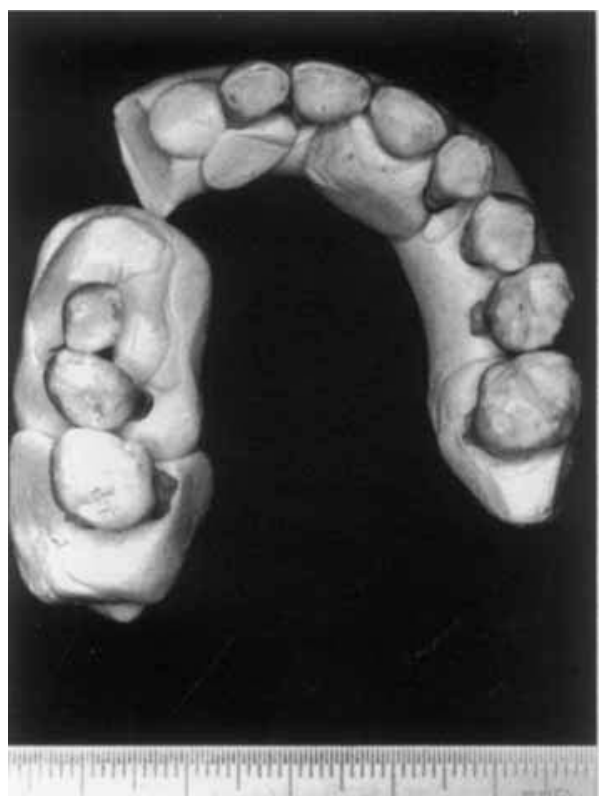

Fig. 11 Associated maxillary tooth set G. In this case occlusal wear, interproximal facet fits, and similarity of antimeres provide the basis for the association. The close facet relations on the right side separated slightly when the photograph was taken.

ble. The criteria used involved the fit of interproximal facets (fig. 10) the continuity of occlusal wear (fig. 11) and the appearance of unique features such as the completed pit discussed above (mandible set $P$ ), the marked hypoplasia in one dental set (fig. 12), a series of angled interproximal facets on a lower anterior series which shows dramatic incisor crowding (fig. 23), an interproximal facet relation showing impactation in an $\mathrm{M}_{3}$ (fig. 13) and in one case an anomalously occluded $\mathrm{P}^{3}$ (fig. 14).

Age was not a criterion for association but the fact that the teeth had been aged beforehand made the process much easier. As one would predict from the sources of potential error, not all associated tooth sets comprised teeth of the same age. However, in review it was reassuring to discover that in only two cases was a tooth as much as two years different in age than the others in the set; all other discrepancies were within one year of error. It was this fact, more than any single other, that provided a reasonable basis for accepting the otherwise less than secure maxillary age model. Individual ages were altered to be consistent within each associated specimen; these are listed in APPENDIX 1.
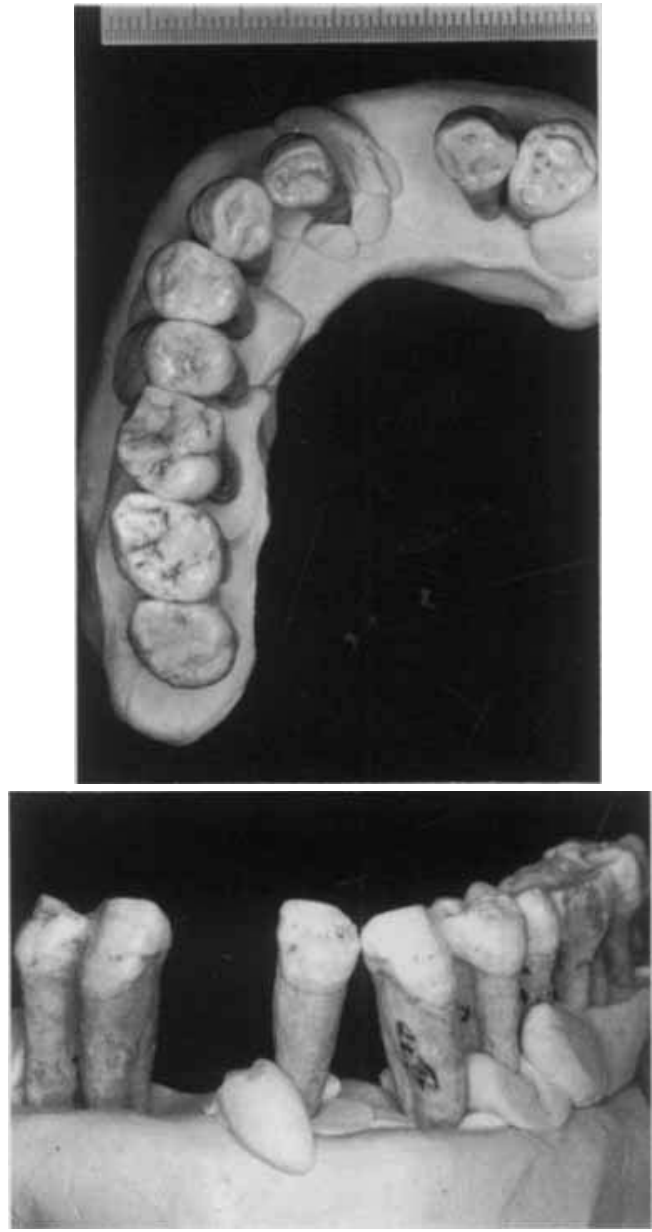

Fig. 12 Associated maxillary dentition M. The association was made on the basis of occlusal and interproximal wear. It was later discovered that the maxillary set included the teeth evincing the most marked linear hypoplasia at the site, and that the relative positions of this feature were consistent with the association.

At the same time associations were being attempted, possible associations which demonstrably did not go together were noted. These comprise teeth of the same age which could fit together but do not, such as an $\mathbf{M}_{1}$ and $M_{2}$ of 14 years with interproximal facets that did not match.

Associated sets of teeth that did not go with existing jaws were given additional letter designations; $G-R$ were added to the maxillas and $L-Q$ to the mandibles. Table 2 lists the specific teeth associated with these sets; APPENDIX 2 provides the numbers of the additional teeth associated with the original jaws, and 
TABLE 2

Letter codes given to additional Krapina tooth set associations, and maxillary-mandibular assaciations for the total sample. Tooth numbers are keyed to APPENDIXI

\begin{tabular}{|c|c|c|c|c|c|c|c|}
\hline Combinatio & & & & & & & \\
\hline & & & & & & & \\
\hline G & $\mathrm{H}$ & $I$ & $J$ & $\mathbf{K}$ & $\mathrm{L}$ & $\mathbf{M}$ & $\mathbf{N}$ \\
\hline 14 & 122 & 76 & 41 & 147 & 166 & 54 & 36 \\
\hline 15 & 123 & 128 & 135 & 156 & 177 & 55 & 38 \\
\hline 17 & & & 136 & 157 & 178 & 56 & 47 \\
\hline 21 & & & & 158 & & 57 & 127 \\
\hline 91 & & & & 159 & & 139 & 129 \\
\hline 93 & & & & & & 146 & \\
\hline 95 & & & & & & 167 & \\
\hline 183 & & & & & & 169 & \\
\hline 185 & & & & & & 170 & \\
\hline 23 & & & & & & & \\
\hline 0 & $\mathbf{P}$ & $Q$ & $\mathrm{R}$ & & & & \\
\hline 162 & 137 & 132 & 24 & & & & \\
\hline 172 & 176 & 148 & 181 & & & & \\
\hline & 179 & & 186 & & & & \\
\hline & & & 190 & & & & \\
\hline & & & & & & & \\
\hline $\mathrm{L}$ & $\mathbf{M}$ & $\mathbf{N}$ & 0 & $\mathbf{P}$ & $\mathrm{Q}$ & & \\
\hline 1 & 3 & 2 & 59 & 13 & 63 & & \\
\hline 7 & 5 & 28 & 60 & 18 & 168 & & \\
\hline 25 & 32 & 31 & & 64 & & & \\
\hline 27 & 82 & 84 & & 67 & & & \\
\hline 30 & & 145 & & 81 & & & \\
\hline 69 & & & & & & & \\
\hline 71 & & & & & & & \\
\hline 72 & & & & & & & \\
\hline 79 & & & & & & & \\
\hline 85 & & & & & & & \\
\hline 138 & & & & & & & \\
\hline 143 & & & & & & & \\
\hline 70 & & & & & & & \\
\hline Mandible & $=$ Maxilla & & & & & & \\
\hline N & $\mathrm{N}$ & & & & & & \\
\hline $\mathrm{D}$ & $\mathrm{D}$ & & & & & & \\
\hline B & A & & & & & & \\
\hline $\mathrm{H}$ & $F$ & & & & & & \\
\hline
\end{tabular}

the jaw-association (if any) for the isolated teeth is also indicated in APPENDIX 1.

Differences in identification within tooth fields between this analysis and previous works are difficult to establish. Many teeth were originally catalogued by type rather than by position, and only a few specimens have a particular position number written on them. Of these, several of the molars fitting in tooth sets are not the same. Similarly, a comparison with Smith's listing ('76) indicated that differences in identification occur for a small number of teeth. There are also some numbering differences between APPENDIX 1 and Smith's tables; under the circumstances these problems are inevitable and with the unambiguous numbers now attributed to the teeth they should not occur again.
These associations allowed determination of some position-related criteria which may be useful in future identifications of isolated teeth. For instance, in the mandibular molars the $\mathbf{M}_{1}$ has a broad mesial root which progressively narrows in $\mathbf{M}_{2}$ and $\mathbf{M}_{3}$. Root divergence is maximum in the $M_{1}$ and decreases posteriorly while lingual root fusion is unknown in $\mathbf{M}_{1}$, common in $\mathbf{M}_{2}$, and all the roots are generally fused in $\mathbf{M}_{3}$. Occlusally, the lingual mesial cusp is equal to or larger than the lingual distal cusp in $\mathbf{M}_{1}$, smaller or equal in $\mathbf{M}_{2}$, and much smaller in $\mathbf{M}_{3}$.

\section{Jaw associations}

Table 2 also indicates associations of mandibles and maxillas. These were determined after the association of individual teeth with 
jaws, and as in the former procedure only completely convincing cases are presented. The main criteria for jaw associations were occlusal fit, correspondence in wear facets, and

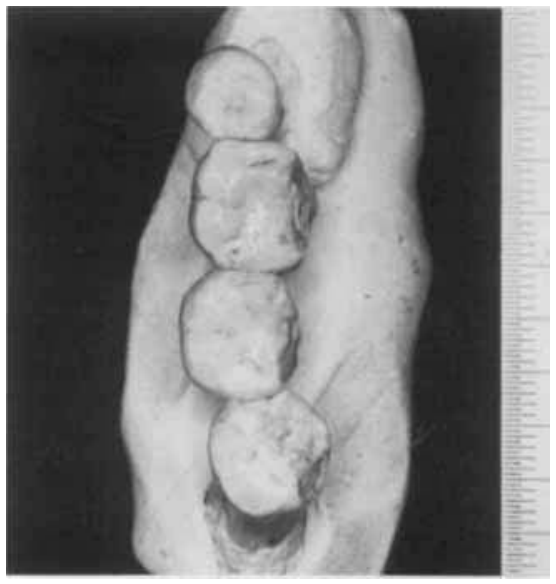

Fig. 13 Associated mandibular tooth set $\mathrm{M}$. The impacted $\mathbf{M}_{3}$ was partially erupted and the angled occlusal facet and the position of the interproximal facets helped establish this association. The $\mathbf{M}_{3}$ is worn on the buccal side, angling strongly to the tooth surface. The interproximal facet extends to the surface of the tooth. This matehes the very low lingually extended facet on the distal $M_{2}$ (the fit is perfect). It is possible that the $E$ mandible would have been similar had the individual died at an older age. similarity in age; no associated jaws had been aged more than one year apart. In one case, isolated tooth sets are suggested to represent the same individual. In specimen N (fig. 14) the anomalous position of the $\mathrm{P}^{3}$ corresponds to angled and unusual wear in the mandible and the apparent rotation of $\mathrm{P}_{3}$ as supported by the position of the distal proximal facet and the lack of a mesial one.

Mandible and maxilla $\mathrm{C}$ are not included in this list, although I feel that a reasonable case can be made for their association. The teeth in these jaws are among the largest at the site, and the corresponding stages of eruption are exactly what would be expected in jaws from the same individual; the maxilla is slightly retarded compared with the mandible. Unfortunately the specimens are broken in such a way to preclude occlusion (fig. 4). Moreover, information taken from Gorjanovic's notes by Malez ('70) indicates that the jaws came from different layers. The conservative procedure, then, is to not associate them. However, the similarities in size of the teeth, eruption stage, and eruption sequence (in both cases the $\mathrm{M} 2$ is in occlusion before either premolar or the canine had erupted) present a strong enough case for association to suggest anxiety with respect to the accuracy of Gorjanovic's notes in this instance. Independently, the fact

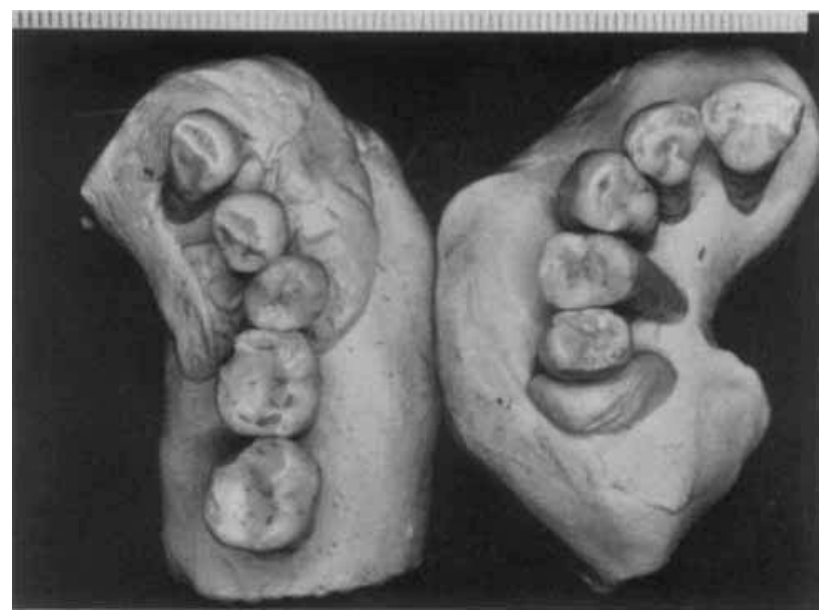

Fig. 14 The associated upper and lower dentitions of specimen $N$. In the lower dentition the $P_{3}$ is rotated counterclockwise as seen from above and displaced lingually; this is just the opposite of the clockwise rotation seen in the mandible $\mathrm{H}$ left $\mathrm{P}_{3}$ (fig. 1). The wear facet is on the buccal side of the tooth (but buccalmesial in the reconstructed arcade) and is strongly angled. In the maxillary dentition, the cause of this facet can be seen in the angulation of the $\mathrm{P}^{3}$ crown and the wear on the canine. These corresponding anomalies make the association likely. The lower canine is the only one in the Krapina set with marked occlusal wear and a mesial interproximal facet, that lacks a distal facet (as would be expected from the lack of a mesial facet on the $P_{3}$ ). 


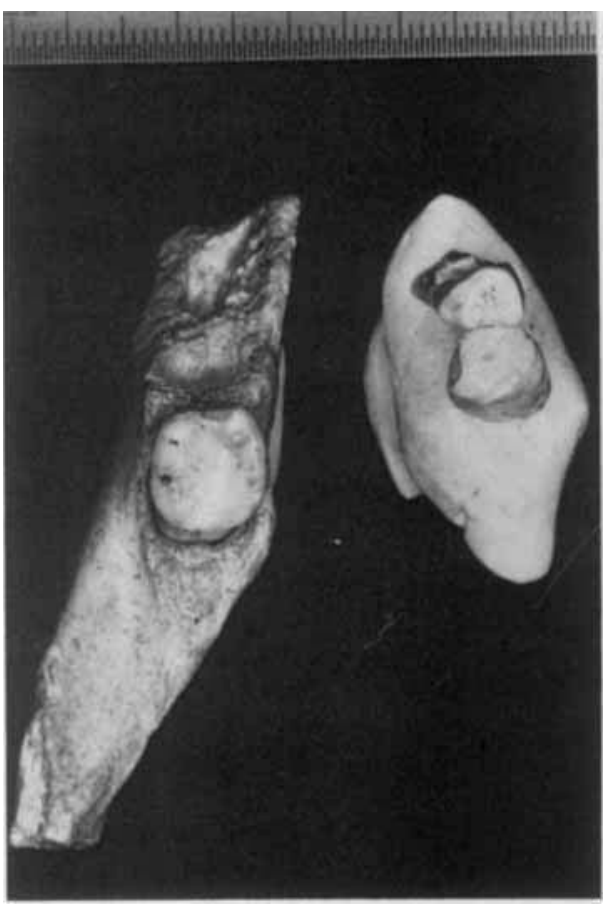

Fig. 15 Ramus 60 with an $M_{3}$ found to fit in the socket, and the associated $\mathrm{I}_{2}$ and $\mathrm{C}$ of specimen $\mathrm{O}$. These are the two oldest specimens at the site, and are an example of specimens which could belong to the same individual but for which no demonstration is possible.

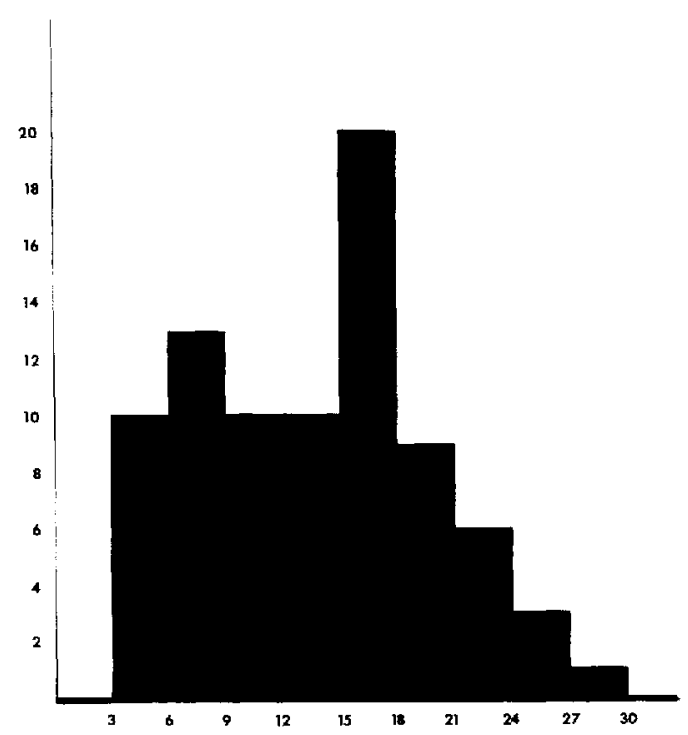

Fig. 16 Observed age at death distribution for the Krapina dental sample. Three-year intervals are given. that blasting was used to remove the apparently sterile layers (Malez, personal communication) provides a different basis for considering the possibility that the stratum associations may have been in error.

\section{Specimen count}

The procedure used here differs from that of Mann ('75) in that age information is taken into account. The data consist of the associated tooth sets and the remaining isolated teeth. These were placed in two categories, "demonstrably different" and "possibly different." The criteria for "demonstrable difference" are either ages that are more than two years apart, or in the case of ages within two years the determination that the teeth cannot belong to the same individual because interproximal facets or occlusal wear do not match (applicable only to adjacent teeth in the same jaw). The "demonstrably different" category makes up the great bulk of the specimens. The "possibly different" category comprises teeth (or tooth sets) which could belong to the same individual, but which are either not adjacent or are in opposite jaws so that no direct determination can be made (fig. 15). The minimum number of "possible" individ. uals in the latter category was determined by assuming that all specimens within two years of age belonged to one individual, and the maximum number was determined under the assumption that each specimen in the category represents a different indivudal. The maximum and minimum numbers at the site are sensitive only to variation in this (fortunately small) category and comprise, respectively, the maximum and minimum of the "possibly associated" specimens added to the number of "demonstrably different" specimens. The number of individuals at Krapina represented by dentitions can be bracketed between 75 and 82 . While this is markedly greater than the estimates usually made for the site, it is not much less than the maximum number (90) estimated from the lower limb remains by Trinkaus ('75).

\section{AGE DISTRIBUTION}

The determination of ages allows the age distribution of the sample to be ascertained. In this analysis, the maximum individual set (82) was used; it is more conservative to assume that associations should only be accepted if verified. Use of the $10 \%$ smaller mini- 


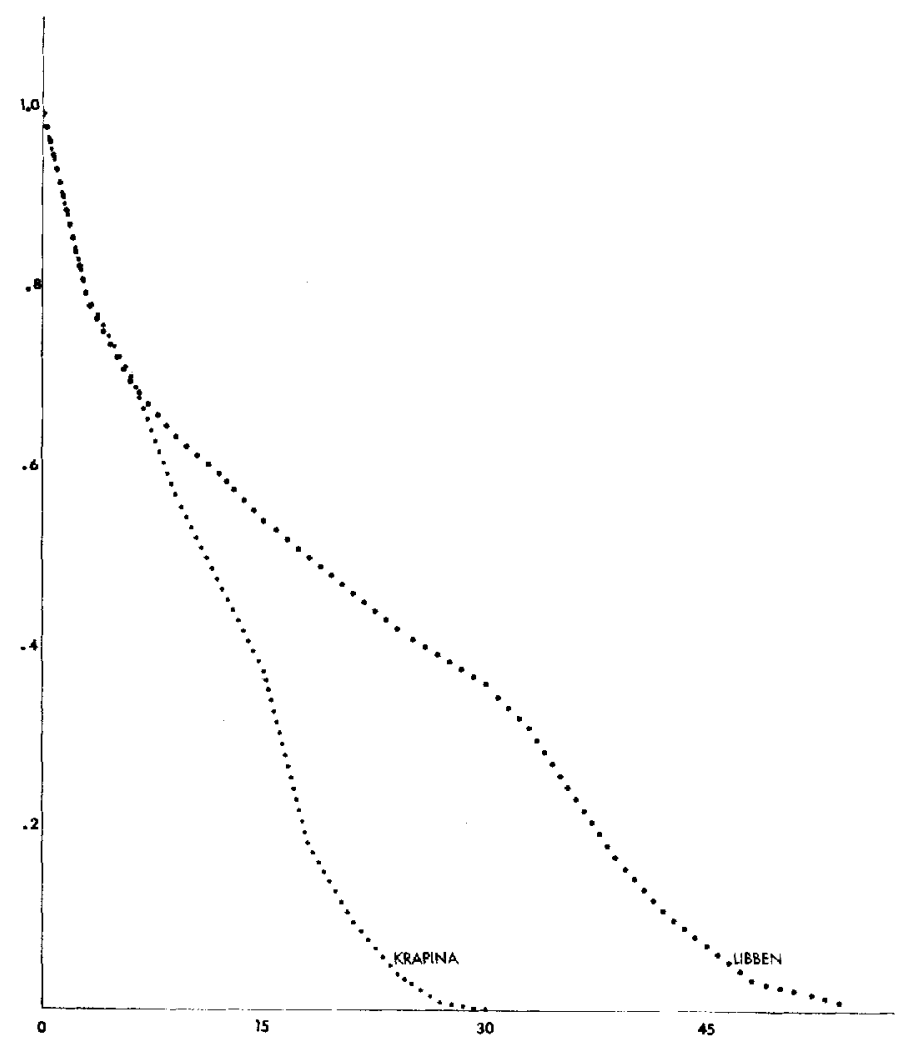

Fig. 17 Comparison of survivorship curves in 3-year intervals for the Krapina sample and the Libben Amerinds (data courtesy of $C$. O. Lovejoy). It is assumed that the $0-3$ age group at Krapina would be com prised of 21 individuals, or $25 \%$ of the sample.

mum set, however, would not substantially alter the conclusions.

The age distribution (fig. 16) indicates a maximum mortality between 15 and 18 . No individuals represent the 0 - to 3-year span, and the oldest individual is 27. The lack of individuals under three is almost certainly the result of preservation and excavation; a substantial number of individuals would be expected to die within that span (Weiss, '73). Analysis of the 1, 289 skeletons from the Libben Amerind aboriginal sample demonstrates that slightly more than $25 \%$ of the sample died before the age of three (data provided by C. O. Lovejoy). Even higher proportions of infant mortality are reported for post-contact samples (Weiss, '75; Neel and Weiss, '75).

The lack of older individuals is also unusual. At Libben almost $35 \%$ of the sample survived beyond 30 whereas no specimens older than 27 are known from Krapina. It is unlikely that this could be the result of either preservation, excavation technique, or any conceivable bias in collecting.

\section{Average age at death}

The average age at death for the known specimens is 13.3 years. While this is extraordinarily low for a human population (Keyfitz and Flieger, '71), it is probably too high when one takes the lack of known specimens younger than three into account (Moore et al., '75). Assuming that these represent $25 \%$ of the sample, as suggested by the Libben survivorship, and using the yearly survivorship percentages from Libben to approximate this span, the 21 expected missing individuals would depress the average age at death at Krapina to 10.8 years. The crude birth rate necessary to maintain the "population" would be 0.28 , and the calculated average interval between births (Smith, '54) would have to be 
TABLE 3

Descriptive statistics for the Krapina maxillary dentition. The mean is calculated for the total number of individuals rather than the total number of teeth; when antimeres are present the average of both is used

\begin{tabular}{|c|c|c|c|c|c|c|c|c|c|c|}
\hline & & \multicolumn{3}{|c|}{ Number of } & \multirow[b]{2}{*}{$\sigma$} & \multirow[b]{2}{*}{$\mathrm{CV}$} & \multirow[b]{2}{*}{ Maximum } & \multirow[b]{2}{*}{ Minimum } & \multirow[b]{2}{*}{ Skew } & \multirow[b]{2}{*}{ Kurtosis } \\
\hline & & $\overline{\mathrm{X}} \pm S \mathrm{E}_{\mathrm{m}}$ & Teeth & Individuals & & & & & & \\
\hline \multirow[t]{2}{*}{$I^{1}$} & $\mathrm{I}$ & $10.3 \pm 0.2$ & 17 & 11 & 0.54 & 5.2 & 11.1 & 9.4 & 0.1 & 1.6 \\
\hline & $\mathrm{B}$ & $8.9 \pm 0.2$ & 17 & 11 & 0.55 & 6.2 & 9.7 & 8.1 & 0.0 & 1.7 \\
\hline \multirow[t]{2}{*}{$I^{2}$} & $\mathrm{~L}$ & $8.4 \pm 0.1$ & 18 & $13^{\prime}$ & 0.51 & 6.0 & 9.3 & 7.4 & -0.4 & 2.6 \\
\hline & $\mathrm{B}$ & $8.9 \pm 0.2$ & 18 & 13 & 0.61 & 6.9 & 9.9 & 7.8 & -0.3 & 2.4 \\
\hline \multirow[t]{3}{*}{$\mathrm{C}^{4}$} & L & $9.2 \pm 0.1$ & 16 & 14 & 0.51 & 5.5 & 10.0 & 8.2 & -0.4 & 2.5 \\
\hline & $\mathrm{B}$ & $10.3 \pm 0.2$ & 16 & 14 & 0.65 & 6.3 & 11.4 & 9.5 & 0.3 & 1.7 \\
\hline & A & $95.0 \pm 2.6$ & 16 & 14 & 9.5 & 10.0 & 114.0 & 81.2 & 0.6 & 2.4 \\
\hline \multirow[t]{3}{*}{$P^{3}$} & L & $8.5 \pm 0.1$ & 13 & 10 & 0.42 & 5.0 & 9.3 & 8.0 & 0.9 & 2,4 \\
\hline & $B$ & $11.2 \pm 0.2$ & 12 & 9 & 0.55 & 4.9 & 11.9 & 10.1 & -1.1 & 3.1 \\
\hline & $\mathbf{A}$ & $95.7 \pm 3.1$ & 12 & 9 & 8.9 & 9.3 & 109.5 & 82.4 & -0.1 & 2.0 \\
\hline \multirow[t]{3}{*}{$\mathbf{P}^{4}$} & $\mathrm{~L}$ & $8.1 \pm 0.2$ & 13 & 12 & 0.60 & 7.4 & 8.8 & 6.8 & -0.8 & 2.8 \\
\hline & B & $10.9 \pm 0.1$ & 12 & 11 & 0.44 & 4.0 & 11.7 & 10.4 & 0.4 & 1.9 \\
\hline & A & $88.5 \pm 3.1$ & 12 & 11 & 9.7 & 11.0 & 103.0 & 70.4 & -0.4 & 2.3 \\
\hline \multirow[t]{3}{*}{$M^{1}$} & L & $12.4 \pm 0.3$ & 13 & 9 & 0.77 & 6.2 & 13.6 & 11.3 & 0.2 & 1.6 \\
\hline & $B$ & $12.6 \pm 0.3$ & 13 & 9 & 0.95 & 7.5 & 14.2 & 11.3 & 0.5 & 2.0 \\
\hline & A & $156.5 \pm 7.3$ & 13 & 9 & 20.6 & 13.2 & 185.3 & 127.7 & 0.3 & 1.6 \\
\hline \multirow[t]{3}{*}{$\mathbf{M}^{2}$} & $\mathrm{~L}$ & $11.3 \pm 0.4$ & 14 & $10^{2}$ & 1.16 & 10.2 & 13.1 & 10.0 & 0.5 & 1.9 \\
\hline & B & $12.8 \pm 0.2$ & 14 & 10 & 0.70 & 5.5 & 14.2 & 11.7 & 0.1 & 2.5 \\
\hline & A & $144.3 \pm 7.2$ & 14 & 10 & 21.6 & 14.9 & 174.9 & 117.7 & 0.4 & 1.7 \\
\hline \multirow[t]{3}{*}{$\mathbf{M}^{3}$} & $\mathrm{~L}$ & $10.4 \pm 0.2$ & 11 & 10 & 0.58 & 5.5 & 11.4 & 9.8 & 0.3 & 1.5 \\
\hline & $\mathrm{B}$ & $12.5 \pm 0.2$ & 9 & 9 & 0.60 & 4.8 & 13.5 & 11.7 & 0.4 & 2.1 \\
\hline & A & $130.3 \pm 4.2$ & 9 & 9 & 12.0 & 9.2 & 148.5 & 114.2 & 0.2 & 1.7 \\
\hline \multirow[t]{2}{*}{ dI! } & L & 8.3 & 3 & 2 & & & 8.6 & 7.9 & & \\
\hline & $\mathrm{B}$ & 6.7 & 3 & 2 & & & 6.9 & 6.6 & & \\
\hline \multirow[t]{2}{*}{$d I^{2}$} & $L$ & 7.1 & 5 & 8 & & & 7.4 & 6.8 & & \\
\hline & $\mathrm{B}$ & 5.9 & 5 & 3 & & & 6.3 & 5.8 & & \\
\hline \multirow[t]{3}{*}{$\mathrm{dC}^{\mathrm{b}}$} & $\mathrm{L}$ & 8.1 & 4 & 3 & & & 8.4 & 7.8 & & \\
\hline & $\mathrm{B}$ & 6.9 & 4 & 3 & & & 7.3 & 6.6 & & \\
\hline & A & 55.9 & 4 & 3 & & & 61.0 & 51.5 & & \\
\hline \multirow{3}{*}{$\mathrm{dM}^{1}$} & L. & 8.2 & 5 & 4 & & & 8.9 & 7.4 & & \\
\hline & B & $9.2 \pm 0.2$ & 6 & 5 & 0.48 & 5.2 & 9.9 & 8.6 & & \\
\hline & A & 76.1 & 5 & 4 & & & 92.4 & 78.7 & & \\
\hline \multirow{3}{*}{$\mathrm{dM}^{2}$} & $\mathrm{~L}$ & $10.5 \pm 0.3$ & 10 & 6 & 0.57 & 5.4 & 11.1 & 9.1 & & \\
\hline & $B$ & $10.9 \pm 0.3$ & 10 & 6 & 0.64 & 5.9 & 11.5 & 9.9 & & \\
\hline & A & $112.6 \pm 6.1$ & 10 & 6 & 13.7 & 12.2 & 126.0 & 90.1 & & \\
\hline
\end{tabular}

${ }^{1}$ Specimens 95 and 97 are not sufficiently developed for measurement to be used.

close to one year. By any estimate, it is unlikely that this life history summary would characterize an actual population. I do not believe that the sample represents the age distribution at death for any real population that lived in the cave (fig. 17).

\section{METRICS}

The basic metric descriptions of the Krapina dental sample are given in tables 3 and 4 . Length is the mesiodistal diameter, taken along the approximate midline of the tooth from the mesial to the distal edge. In cases where interproximal wear results in a length shortening, the midline dimension of the existing occlusal surface is used. Incisor lengths are almost always taken at the occlusal surface, but depending on the crown shape the length of some canines may be measured inferior to this surface. Breadth is the max imum dimension perpendicular to length in the horizontal plane and parallel to it in the vertical plane (for a more detailed discussion of technique, see Wolpoff, '71a: pp. 9-10). For most teeth with no more than moderate wear, this dimension is inferior to the existing occlusal plane; in the incisors and canines it is almost inevitably at the crown base. Area is the length times breadth approximation. It indicates the maximum occlusal area that can be attained for the postcanine teeth during life, generally at the latest stages of wear. Area of the canine approximates the occlusal surface when the crown is approximately half gone, but because maximum length of the incisors is at the most superior surface while 
TABLE 4

Descriptive statistics for the Krapina mandibular dentitions

\begin{tabular}{|c|c|c|c|c|c|c|c|c|c|c|}
\hline & & \multirow[b]{2}{*}{$\overline{\mathrm{X}} \pm S \mathrm{E}_{\mathrm{m}}$} & \multicolumn{2}{|c|}{ Number of } & \multirow[b]{2}{*}{$\sigma$} & \multirow[b]{2}{*}{$\mathrm{CV}$} & \multirow[b]{2}{*}{ Maximum } & \multirow[b]{2}{*}{ Minimum } & \multirow[b]{2}{*}{ Skew } & \multirow[b]{2}{*}{ Kurtosis } \\
\hline & & & Teeth & Individuals & & & & & & \\
\hline \multirow[t]{2}{*}{$I_{1}$} & L & $5.9 \pm 0.2$ & 10 & 6 & 0.42 & 7.1 & 6.3 & 5.2 & -0.6 & 1.6 \\
\hline & $\overline{\mathbf{B}}$ & $7.6 \pm 0.2$ & 10 & 7 & 0.50 & 6.6 & 8.2 & 6.8 & -0.7 & 2.2 \\
\hline \multirow[t]{2}{*}{$\mathrm{I}_{2}$} & $\mathbf{L}$ & $6.8 \pm 0.2$ & 12 & 9 & 0.48 & 7.0 & 7.5 & 6.1 & 0.1 & 1.9 \\
\hline & B & $8.0 \pm 0.2$ & 11 & 9 & 0.54 & 6.7 & 8.8 & 7.3 & 0.1 & 2.0 \\
\hline \multirow[t]{3}{*}{$\mathrm{C}_{1}$} & $\mathrm{~L}$ & $8.2 \pm 0.1$ & 14 & 11 & 0.36 & 4.5 & 8.8 & 7.6 & 0.2 & 2.0 \\
\hline & B & $9.4 \pm 0.2$ & 14 & 11 & 0.56 & 6.0 & 10.3 & 8.5 & -0.1 & 1.8 \\
\hline & A & $78.6 \pm 2.4$ & 13 & 11 & 7.5 & 9.8 & 90.1 & 63.1 & 0.0 & 2.7 \\
\hline \multirow[t]{3}{*}{$P_{3}$} & $\mathbf{L}$ & $8.3 \pm 0.1$ & 13 & 11 & 0.40 & 4.8 & 9.2 & 7.8 & 0.9 & 2.7 \\
\hline & B & $9.4 \pm 0.2$ & 11 & 10 & 0.50 & 5.3 & 10.3 & 8.7 & 0.6 & 2.5 \\
\hline & A & $78.1 \pm 2.6$ & 11 & 10 & 7.9 & 10.1 & 93.8 & 67.9 & 0.9 & 2.5 \\
\hline \multirow[t]{3}{*}{$\mathbf{P}_{4}$} & L & $8.1 \pm 0.2$ & 15 & 13 & 0.62 & 7.7 & 9.4 & 6.9 & 0.2 & 3.2 \\
\hline & B & $9.6 \pm 0.1$ & 14 & 13 & 0.48 & 5.0 & 10.5 & 8.8 & 0.3 & 2.4 \\
\hline & A & $77.5 \pm 1.9$ & 14 & 13 & 6.6 & 8.5 & 86.6 & 65.2 & -0.3 & 2.4 \\
\hline \multirow[t]{3}{*}{$\mathbf{M}_{1}$} & $\mathbf{L}$ & $12.5 \pm 0.2$ & 18 & $14^{1}$ & 0.77 & 6.2 & 13.6 & 11.4 & -0.1 & 1.8 \\
\hline & $\mathbf{B}$ & $11.5=0.3$ & 17 & 14 & 0.77 & 6.7 & 12.9 & 10.2 & 0.3 & 2.2 \\
\hline & A & $143.1 \pm 5.0$ & 17 & 14 & 17.9 & 12.5 & 174.8 & 116.3 & 0.2 & 2.0 \\
\hline \multirow[t]{3}{*}{$\mathrm{M}_{2}$} & $\mathbf{L}$ & $12.7 \pm 0.2$ & 15 & 12 & 0.77 & 6.1 & 14.0 & 11.5 & 0.3 & 2.2 \\
\hline & B & $11.5=0.2$ & 14 & 12 & 0.69 & 6.0 & 12.4 & 9.8 & -0.9 & 4.0 \\
\hline & A & $146.8 \pm 4.9$ & 14 & 12 & 16.1 & 11.0 & 172.4 & 112.7 & -0.2 & 3.2 \\
\hline \multirow[t]{3}{*}{$\mathrm{M}_{3}$} & $\mathrm{~L}$ & $12.2 \pm 0.2$ & 14 & 11 & 0.72 & 5.9 & 13.9 & 11.2 & 1.2 & 4.3 \\
\hline & $\mathbf{B}$ & $10.8 \pm 0.2$ & 13 & 10 & 0.46 & 4.3 & 11.4 & 9.8 & -0.7 & 2.7 \\
\hline & A & $132.2 \pm 3.6$ & 13 & 10 & 10.8 & 8.2 & 155.7 & 116.5 & 0.8 & 3.5 \\
\hline \multirow[t]{2}{*}{$\mathrm{dI}_{1}$} & $\mathbf{L}$ & 5.3 & 1 & 1 & & & & & & \\
\hline & $\mathbf{B}$ & 4.9 & 1 & 1 & & & & & & \\
\hline \multirow[t]{2}{*}{$\mathrm{d} \mathbf{I}_{2}$} & $\mathbf{L}$ & 5.8 & 3 & 3 & & & 6.0 & 5.7 & & \\
\hline & $\overline{\mathbf{B}}$ & 5.1 & 2 & 2 & & & 5.1 & 5.0 & & \\
\hline \multirow[t]{3}{*}{$\mathrm{dC}_{1}$} & $\mathbf{L}$ & 6.8 & 2 & 2 & & & 7.2 & 6.4 & & \\
\hline & $\overline{\mathbf{B}}$ & 5.9 & 2 & 2 & & & 5.9 & 5.9 & & \\
\hline & $\mathbf{A}$ & 47.4 & 2 & 2 & & & 56.9 & 37.8 & & \\
\hline \multirow[t]{3}{*}{$\mathbf{d} \mathbf{M}_{1}$} & $\mathbf{L}$ & 9.7 & 2 & 2 & & & 9.8 & 9.5 & & \\
\hline & $\overline{\mathbf{B}}$ & 8.1 & 2 & 2 & & & 8.2 & 7.9 & & \\
\hline & A & 77.7 & 2 & 2 & & & 77.9 & 77.4 & & \\
\hline \multirow[t]{3}{*}{$\mathrm{dM}_{2}$} & $\mathrm{~L}$ & $10.8 \pm 0.3$ & 7 & 6 & 0.67 & 6.2 & 11.5 & 9.9 & & \\
\hline & $\mathbf{B}$ & $9.5 \pm 0.3$ & 7 & 6 & 0.57 & 6.0 & 10.1 & 8.7 & & \\
\hline & A & $102.7 \pm 5.4$ & 7 & 6 & 12.0 & 11.7 & 115.6 & 82.5 & & \\
\hline
\end{tabular}

${ }^{1}$ Measurements of the 104 germ were not used.

maximum breadth is at the base, the area measure does not correspond to any occlusal surface that exists during life and consequently was not calculated.

\section{Distributional characteristics}

Generally, the Krapina teeth are characterized by moderate variance measurements (tables 3,4$)$. When compared with living biological populations (tables 5-7), differences in variation are best indicated by the application of an $F$ test to the square of the coefficient of variation (Lewontin, '66); a direct comparison of variance is confused by the large means for most of the Krapina teeth. The two modern groups used in this comparison are from the Central European site of Halimba, dated to the Eleventh Century (Török, '62), and an Australian aborigine population from Broadbeach. The former group represents a modern geographic counterpart to Krapina with dental characteristics prior to the final European reductions associated with the introduction of the knife-and-fork method of pre-oral food preparation (Brace and Mahler, "71). The Australian group, in contrast, represents one of the most megadont living human populations.

Using a liberal $10 \%$ probability criterion (i.e., only considering variance differences with a probability of significance greater than 0.90 ) reveals few cases when the Krapina variability is significantly different than the modern comparative populations. In virtually every one of these cases the Krapina tooth is less variable. For instance, four significant differences characterize the Halimba length, breadth, and area variance comparisons (not always the same teeth). Of these, only the maxillary first molar comparison shows 
MILFORD H. WOLPOFH

TARIL 5

Mean and variance in length for two modern human samples compared with Krapina (from tables 3 and 4 ). The modern groups are from the Hungarian eleventh Century site of Halimba, measured by the author, and the megadont Australian aborigine group from Broadbeach measured by C. L. Brace. Data compared are the ratio of means with Krapina (Krapina mean divided by comparative group mean, times 100;, and the results of a " $t$ " test between the means and an F test betueen the squared coefficients of variation expressed as probabilities

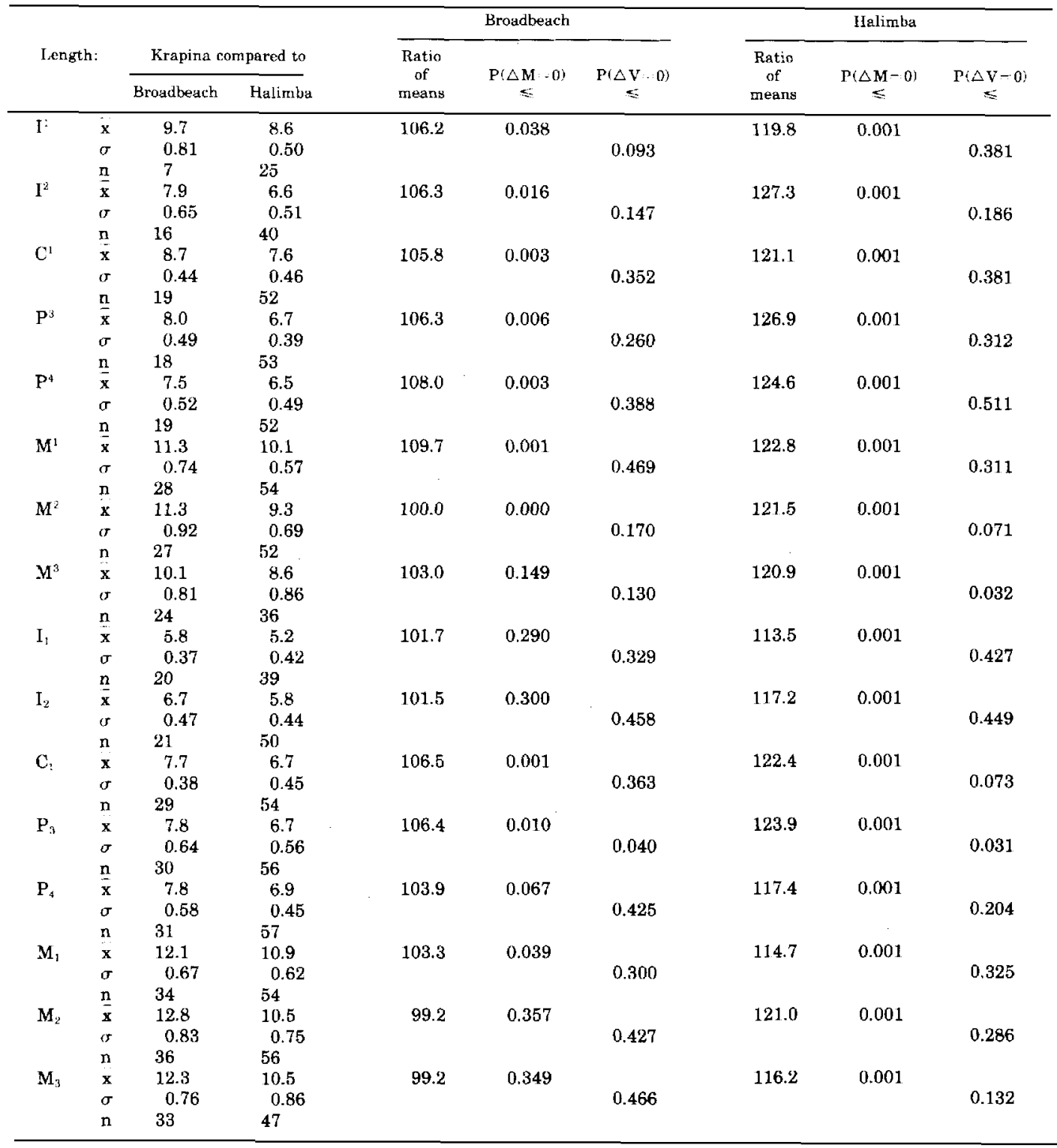

greater variation for Krapina and in no case does the significance probability exceed 0.95 . The Broadbeach comparisons result in fewer significant differences in length and area, but more for breadth (7). Similar to Halimba, only one comparison shows greater variation in a Krapina tooth; the breadth and area of $\mathbf{M}_{1}$, with respective significance of 0.93 and 0.91 . These comparisons suggest that while the Krapina first molars may be slightly more 
TABLE 6

Mean and variance in breadth for two modern human samples compared with Krapina (from tables 3 and 4)

\begin{tabular}{|c|c|c|c|c|c|c|c|c|c|}
\hline \multirow{2}{*}{\multicolumn{2}{|c|}{ Breadth: }} & \multirow{2}{*}{\multicolumn{2}{|c|}{ Krapina compared to }} & \multicolumn{3}{|c|}{ Broadbeach } & \multicolumn{3}{|c|}{ Halimba } \\
\hline & & & & \multirow{2}{*}{$\begin{array}{c}\text { Ratio } \\
\text { of } \\
\text { means }\end{array}$} & \multirow{2}{*}{$\begin{array}{c}P(\Delta M=0) \\
\leqslant\end{array}$} & \multirow{2}{*}{$\begin{array}{c}\mathrm{P}(\Delta \mathrm{V}=0) \\
\leqslant\end{array}$} & \multirow{2}{*}{$\begin{array}{c}\text { Ratio } \\
\text { of } \\
\text { means }\end{array}$} & \multirow{2}{*}{$\begin{array}{c}P(\Delta M=0) \\
\quad \leqslant\end{array}$} & \multirow{2}{*}{$\begin{array}{c}P(\Delta V=0) \\
\leq\end{array}$} \\
\hline & & Broadbeach & Halimba & & & & & & \\
\hline \multirow[t]{3}{*}{$I^{\prime}$} & $\overline{\mathbf{x}}$ & 8.1 & 7.3 & 109.9 & 0.006 & & 121.9 & 0.001 & \\
\hline & $\sigma$ & 0.65 & 0.45 & & & 0.222 & & & 0.467 \\
\hline & $\mathrm{n}$ & 7 & 25 & & & & & & \\
\hline \multirow[t]{3}{*}{$\mathrm{I}^{2}$} & $\bar{x}$ & 7.1 & 6.4 & 125.4 & 0.001 & & 139.1 & 0.001 & \\
\hline & $\sigma$ & 0.36 & 0.42 & & & 0.135 & & & 0.394 \\
\hline & $\mathbf{n}$ & 16 & 41 & & & & & & \\
\hline \multirow[t]{3}{*}{ C } & $\overline{\mathbf{x}}$ & 9.1 & 8.3 & 113.2 & 0.001 & & 124.1 & 0.001 & \\
\hline & or & 0.82 & 0.68 & & & 0.098 & & & 0.152 \\
\hline & $\underline{\mathbf{n}}$ & 19 & 54 & & & & & & \\
\hline \multirow[t]{3}{*}{$\mathrm{P}^{3}$} & $\overline{\mathbf{x}}$ & 10.7 & 8.8 & 104.7 & 0.041 & & 127.3 & 0.001 & \\
\hline & $\sigma$ & 0.73 & 0.60 & & & 0.173 & & & 0.163 \\
\hline & $\mathrm{n}$ & 18 & 53 & & & & & & \\
\hline \multirow[t]{3}{*}{$\mathrm{P}^{4}$} & $\bar{x}$ & 10.5 & 9.1 & 103.8 & 0.071 & & 119.8 & 0.001 & \\
\hline & $\sigma$ & 0.81 & 0.55 & & & 0.021 & & & 0.084 \\
\hline & $\mathrm{n}$ & 19 & 52 & & & & & & \\
\hline \multirow[t]{3}{*}{$M^{1}$} & $\bar{x}$ & 12.8 & 11.4 & 98.4 & 0.263 & & 110.5 & 0.001 & \\
\hline & $\sigma$ & 0.78 & 0.60 & & & 0.193 & & & 0.058 \\
\hline & $\underline{\mathrm{n}}$ & 28 & 53 & & & & & & \\
\hline \multirow[t]{3}{*}{$\mathbf{M}^{2}$} & $\bar{x}$ & 13.1 & 11.4 & 97.8 & 0.220 & & 112.3 & 0.001 & \\
\hline & $\sigma$ & 1.14 & 0.82 & & & 0.074 & & & 0.191 \\
\hline & $\underline{\mathbf{n}}$ & 27 & 52 & & & & & & \\
\hline \multirow[t]{3}{*}{$\mathbf{M}^{3}$} & $\overline{\mathrm{x}}$ & 12.8 & 10.9 & 97.7 & 0.206 & & 114.7 & 0.001 & \\
\hline & $\sigma$ & 1.01 & 0.96 & & & 0.074 & & & 0.038 \\
\hline & $\mathrm{n}$ & 24 & 36 & & & & & & \\
\hline \multirow[t]{3}{*}{$\mathrm{I}_{1}$} & $\overline{\mathrm{x}}$ & 6.4 & 6.0 & 118.8 & 0.001 & & 126.7 & 0.001 & \\
\hline & $\sigma$ & 0.42 & 0.40 & & & 0.464 & & & 0.544 \\
\hline & $\underline{\mathrm{n}}$ & 20 & 40 & & & & & & \\
\hline $\mathrm{I}_{2}$ & $\overline{\mathbf{x}}$ & 6.7 & 6.4 & 119.4 & 0.001 & & 125.0 & 0.001 & \\
\hline & $\sigma$ & 0.52 & 0.42 & & & 0.356 & & & 0.407 \\
\hline & $\underline{\mathrm{n}}$ & 21 & 52 & & & & & & \\
\hline $\mathrm{C}_{1}$ & $\bar{x}$ & 8.3 & 7.7 & 113.2 & 0.001 & & 122.1 & 0.001 & \\
\hline & $\sigma$ & 0.67 & 0.56 & & & 0.157 & & & 0.254 \\
\hline & $\underline{\mathrm{n}}$ & 29 & 53 & & & & & & \\
\hline$P_{3}$ & $\overline{\mathbf{x}}$ & 8.9 & 7.6 & 105.6 & 0.009 & & 123.7 & 0.001 & \\
\hline & $\sigma$ & 0.57 & 0.57 & & & 0.288 & & & 0.134 \\
\hline & $\mathrm{n}$ & 30 & 55 & & & & & & \\
\hline$P_{4}$ & $\overline{\mathbf{x}}$ & 9.2 & 8.1 & 104.4 & 0.028 & & 118.5 & 0.001 & \\
\hline & $\sigma$ & 0.66 & 0.57 & & & 0.093 & & & 0.097 \\
\hline & $\underline{n}$ & 31 & 56 & & & & & & \\
\hline$M_{1}$ & $\bar{x}$ & 12.1 & 10.4 & 95.0 & 0.003 & & 110.6 & 0.001 & \\
\hline & $\sigma$ & 0.59 & 0.59 & & & 0.071 & & & 0.195 \\
\hline & $\underline{\mathbf{n}}$ & 34 & 53 & & & & & & \\
\hline $\mathbf{M}_{2}$ & $\overline{\mathbf{x}}$ & 11.8 & 10.1 & 97.5 & 0.100 & & 113.9 & 0.001 & \\
\hline & $\sigma$ & 0.69 & 0.63 & & & 0.425 & & & 0.476 \\
\hline & $\mathrm{n}$ & 36 & 55 & & & & & & \\
\hline $\mathbf{M}_{3}$ & $\overline{\mathbf{x}}$ & 11.3 & 9.7 & 95.6 & 0.024 & & 111.3 & 0.001 & \\
\hline & $\sigma$ & 0.73 & 0.74 & & & 0.094 & & & 0.033 \\
\hline & $\mathbf{n}$ & 33 & 46 & & & & & & \\
\hline
\end{tabular}

variable than is normal within living human populations, in general the dentitions are equally if not less variable than the modern interbreeding groups.

Moreover, Krapina is not particularly variable when compared with roughly contemporary European sites. The dental sample from the Riss cave of Arago (de Lumley and de
Lumley, '71) is much smaller than the Krapina sample and yet the dimensions of the two most complete mandibles fall at and beyond the Krapina extremes. A greater range is encompassed by a much smaller sample size (fig. 18).

Other distributional characteristics include moderate skew in some of the teeth and the 
TABLE 7

Mean and variance in occlusal area (length times breadth) in two modern human groups compared with Krapina (from tables 3 and 4)

\begin{tabular}{|c|c|c|c|c|c|c|c|c|c|}
\hline & \multirow{3}{*}{ Area: } & & & \multicolumn{3}{|c|}{ Broadbeach } & \multicolumn{3}{|c|}{ Halimba } \\
\hline & & \multicolumn{2}{|c|}{ Krapina compared to } & \multirow{2}{*}{$\begin{array}{l}\text { Ratio } \\
\text { of } \\
\text { means }\end{array}$} & \multirow{2}{*}{$\begin{array}{c}\mathrm{P}(\Delta \mathrm{M}=0) \\
\leqslant\end{array}$} & \multirow{2}{*}{$\begin{array}{c}\mathrm{P}(\Delta \mathrm{V}=0) \\
\leqslant\end{array}$} & \multirow{2}{*}{$\begin{array}{c}\text { Ratio } \\
\text { of } \\
\text { means }\end{array}$} & \multirow{2}{*}{$\begin{array}{c}P(\Delta M=0) \\
\leqslant\end{array}$} & \multirow{2}{*}{$\begin{array}{c}P(\Delta V=0) \\
\leqslant\end{array}$} \\
\hline & & Broadbeach & Halimba & & & & & & \\
\hline \multirow[t]{5}{*}{$\mathrm{C}^{\mathrm{I}}$} & $\overline{\mathbf{x}}$ & 79.3 & 63.1 & 119.8 & 0.001 & & 150.6 & 0.001 & \\
\hline & $\sigma$ & 9.7 & 8.0 & & & 0.232 & & & 0.176 \\
\hline & $\mathbf{n}$ & 19 & 52 & & & & & & \\
\hline & $\min$ & 60.0 & 48.6 & & & & & & \\
\hline & $\max$ & 96.8 & 78.4 & & & & & & \\
\hline \multirow[t]{5}{*}{$\mathbf{P}^{3}$} & $\bar{x}$ & 85.7 & 59.5 & 111.7 & 0.010 & & 160.8 & 0.001 & \\
\hline & $\sigma$ & 10.3 & 7.4 & & & 0.234 & & & 0.194 \\
\hline & $\mathbf{n}$ & 18 & 53 & & & & & & \\
\hline & min & 60.7 & 43.7 & & & & & & \\
\hline & $\max$ & 98.0 & 83.0 & & & & & & \\
\hline \multirow[t]{5}{*}{$\mathbf{P}^{4}$} & $\overline{\mathbf{x}}$ & 78.9 & 58.3 & 112.2 & 0.009 & & 151.8 & 0.001 & \\
\hline & $\sigma$ & 10.2 & 7.5 & & & 0.302 & & & 0.303 \\
\hline & $\mathrm{n}$ & 19 & 52 & & & & & & \\
\hline & $\min$ & 59.8 & 41.9 & & & & & & \\
\hline & $\max$ & 95.1 & 71.1 & & & & & & \\
\hline $\mathbf{M}^{\mathbf{L}}$ & $\overline{\mathbf{x}}$ & 145.1 & 114.3 & 107.9 & 0.051 & & 136.9 & 0.001 & \\
\hline & $\sigma$ & 16.7 & 11.2 & & & 0.281 & & & 0.098 \\
\hline & $\mathbf{n}$ & 28 & 52 & & & & & & \\
\hline & $\min$ & 104.2 & 90.7 & & & & & & \\
\hline & $\max$ & 169.4 & 143.2 & & & & & & \\
\hline $\mathbf{M}^{2}$ & $\overline{\mathrm{x}}$ & 149.3 & 105.9 & 96.7 & 0.276 & & 136.3 & 0.001 & \\
\hline & $\sigma$ & 22.7 & 13.2 & & & 0.513 & & & 0.195 \\
\hline & $n$ & 27 & 52 & & & & & & \\
\hline & $\min$ & 96.8 & 80.0 & & & & & & \\
\hline & $\max$ & 179.4 & 134.8 & & & & & & \\
\hline $\mathbf{M}^{3}$ & $\bar{x}$ & 130.6 & 92.7 & 99.8 & 0.480 & & 140.6 & 0.001 & \\
\hline & $\sigma$ & 18.2 & 15.6 & & & 0.113 & & & 0.039 \\
\hline & $\mathbf{n}$ & 24 & 36 & & & & & & \\
\hline & $\min$ & 92.9 & 68.8 & & & & & & \\
\hline & $\max$ & 155.5 & 126.0 & & & & & & \\
\hline $\mathrm{C}_{2}$ & $\overline{\mathbf{x}}$ & 63.9 & 52.2 & 123.0 & 0.001 & & 150.6 & 0.001 & \\
\hline & $\sigma$ & 7.0 & 6.8 & & & 0.334 & & & 0.144 \\
\hline & $\mathbf{n}$ & 29 & 53 & & & & & & \\
\hline & $\min$ & 44.9 & 41.1 & & & & & & \\
\hline & $\max$ & 78.3 & 67.1 & & & & & & \\
\hline$P_{3}$ & $\overline{\mathbf{x}}$ & 69.4 & 50.7 & 112.5 & 0.004 & & 154.0 & 0.001 & \\
\hline & $\boldsymbol{v}$ & 8.7 & 6.8 & & & 0.255 & & & 0.183 \\
\hline & n & 30 & 55 & & & & & & \\
\hline & $\min$ & 45,3 & 38.6 & & & & & & \\
\hline & $\max$ & 84.6 & 67.5 & & & & & & \\
\hline$P_{4}$ & $\overline{\mathbf{x}}$ & 72.1 & 56.8 & 107.5 & 0.038 & & 136.4 & 0.001 & \\
\hline & $\sigma$ & 9.8 & 7.3 & & & 0.044 & & & 0.093 \\
\hline & $\mathbf{n}$ & 31 & 56 & & & & & & \\
\hline & $\min$ & 53.2 & 38.9 & & & & & & \\
\hline & $\max$ & 91.9 & 70.1 & & & & & & \\
\hline $\mathbf{M}_{1}$ & $\bar{x}$ & 147.6 & 113.8 & 97.0 & 0.176 & & 125.8 & 0.001 & \\
\hline & $\sigma$ & 13.8 & 11.3 & & & 0.086 & & & 0.119 \\
\hline & $\mathbf{n}$ & 34 & 53 & & & & & & \\
\hline & $\min$ & 118.8 & 85.5 & & & & & & \\
\hline & $\max$ & 174.8 & 139.2 & & & & & & \\
\hline $\mathrm{M}_{2}$ & $\overline{\mathbf{x}}$ & 151.6 & 104.5 & 96.8 & 0.203 & & 140.5 & 0.001 & \\
\hline & $\sigma$ & 17.4 & 12.4 & & & 0.461 & & & 0.411 \\
\hline & $\mathbf{n}$ & 36 & 55 & & & & & & \\
\hline & $\min$ & 110.3 & 80.1 & & & & & & \\
\hline & $\max$ & 192.6 & 133.4 & & & & & & \\
\hline $\mathbf{M}_{3}$ & $\bar{x}$ & 139.0 & 102.6 & 95.1 & 0.104 & & 128.9 & 0.001 & \\
\hline & $\sigma$ & 15.6 & 14.2 & & & 0.158 & & & 0.047 \\
\hline & $\mathbf{n}$ & 33 & 46 & & & & & & \\
\hline & $\min$ & 103.8 & 71.1 & & & & & & \\
\hline & $\max$ & 177.9 & 136.7 & & & & & & \\
\hline
\end{tabular}




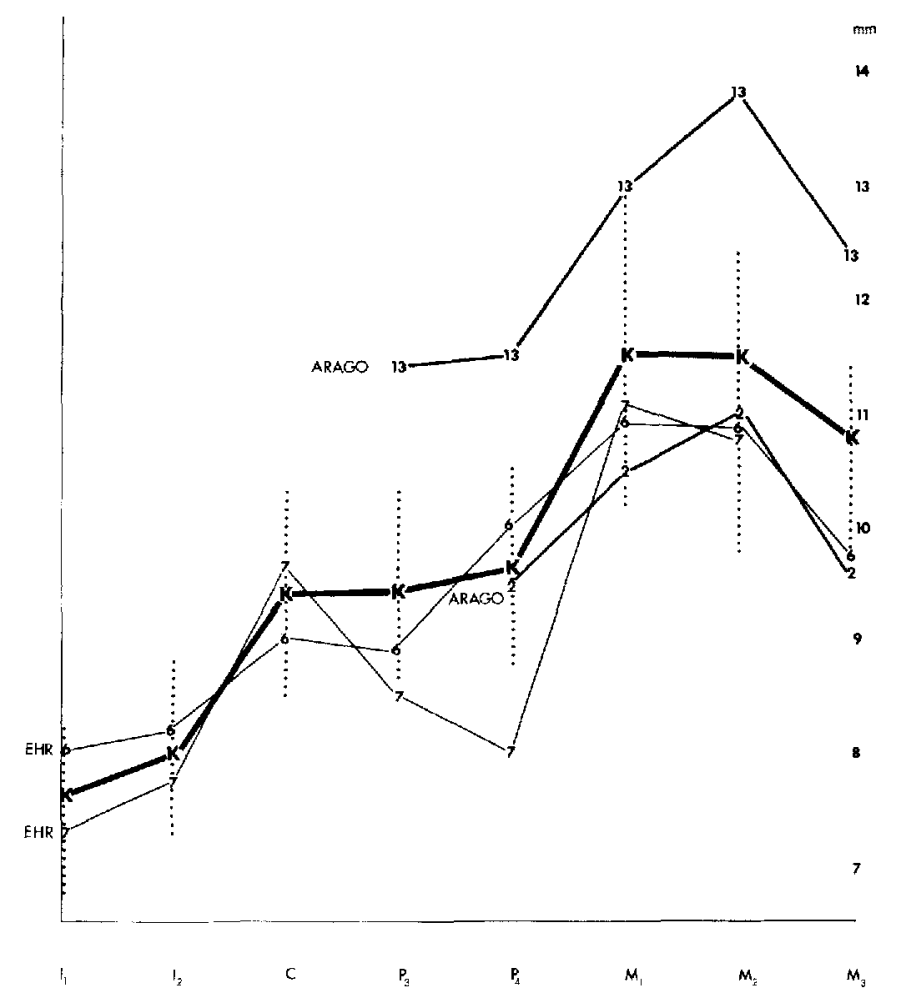

Fig. 18 Comparison of transverse breadths for the mandibular teeth from Krapina (mean and range) with the two Ehringsdorf and Arago mandibles. The Ehringsdorf data are from Patte ('62) and Twiesselmann ('73) and the Arago data were provided by H. de Lumley. Measurements are in millimeters.

general flattening of the central peaks when compared to normal distributions (tables 3,4 ). Skewing is much more often positive than negative, indicating that greater displacements tend to occur below the mean. In the maxilla all of the negative skews occur anterior to the molars. No other pattern characterizes the skew distribution; for instance, the large negative skew in $\mathrm{P}^{3}$ breadth is almost exactly matched by the positive skew in length. Skewing in the mandible is more evenly distributed through the tooth row; negative values characterize the anterior incisors and the posterior molars. The greatest skew magnitudes seem to correspond with the smallest sample sizes which seems reasonable given the sensitivity of the higher moments about the mean to small sample size. Variation in the kurtosis values is more systematic; almost every case is below the expected value of 3 for a normal distribution suggesting that the Krapina distributions tend to have flattened peaks. The few values that approach or exceed 3 tend to have high skewness, indicating that these higher peaks do not occur in otherwise normal distributions.

\section{Relative sizes in associated dentitions}

Relative incisor sizes are best compared using labiolingual breadth since this dimension remains unchanged with occlusal wear. In the mandible the lateral incisor is always greater than the central (table 8); at the maximum these are virtually identical in size. The maxilla, in contrast, differs from the usual condition (Wolpoff, '71a) in living humans ( $\mathrm{I}^{1}$ $>\mathrm{I}^{2}$ ) in 5 of the 13 cases. The size relations are asymmetric in maxillas $\mathrm{D}$ and $\mathrm{E}$; lateral incisor size is greater on the left side of $D$ and the right side of $\mathrm{E}$. The tendency for a notable number of Krapina lateral incisors to exceed the centrals in breadth is an extension of the Middle Pleistocene hominid trend toward expansion of the anterior teeth, first visible at Choukoutien (Weidenriech, '37) where the average $I^{2}$ breadth exceeds the $I^{1}$ breadth average.

Molar size progression in living groups has 
TABLE 8

Relative incisor breadths and the breadth sequence distribution for Krapina jaws

\begin{tabular}{ccc}
\hline Breadth & Maxilla & Mandible \\
\hline$\overline{\mathrm{X}}(100 \cdot \mathrm{I} 1 / \mathrm{I} 2)$ & 105.5 & 95.1 \\
$\mathrm{~N}$ & 9 & 6 \\
$\mathrm{CV}$ & 15.4 & 2.5 \\
Maximum & 145.8 & 98.8 \\
Minimum & 88.9 & 92.5 \\
$\mathrm{I} 1>\mathrm{I} 2$ & $\mathrm{D}_{\mathrm{R}}, \mathrm{N}, \mathrm{C}, \mathrm{E}_{\mathrm{L}}, \mathrm{G}, \mathbf{H}, \mathrm{K}_{\mathrm{L}}, \mathrm{K}_{\mathrm{R}}$ & \\
$\mathrm{I} 1=\mathrm{I} 2$ & $\mathrm{D}_{\mathrm{L}}, \mathrm{F}_{\mathrm{L}}, \mathrm{F}_{\mathrm{R}}, \mathbf{E}_{\mathrm{R}}, \mathrm{Q}$ & $\mathrm{B}, \mathrm{C}, \mathrm{E}, \mathrm{H}, \mathrm{J}, \mathrm{L}$ \\
$\mathrm{I} 2>\mathrm{I} 1$ &
\end{tabular}

TABLE 9

Relative molar size progressions for length and breadth in Krapina maxillas, and length, breadth, and area for the mandibles. Only specimens with all three molars are considered

\begin{tabular}{|c|c|c|c|c|c|c|c|}
\hline & & & \multicolumn{5}{|c|}{ Molar size progression (largest to smallest) } \\
\hline & & & \multicolumn{2}{|c|}{ Maxilla } & \multicolumn{3}{|c|}{ Mandible } \\
\hline & & & Length & Breadth & Length & Breadth & Area \\
\hline M1 & $\mathbf{M} 2$ & M3 & $\mathrm{H}, \mathrm{M}$, Average & $\mathrm{L}$ & $\mathbf{E}, \mathbf{G}, \mathbf{M}$ & $\mathbf{E}, \mathrm{L}$ & $\mathbf{E}, \mathbf{L}, \mathbf{M}$ \\
\hline M1 & M3 & M2 & & & & $\mathbf{M}$ & \\
\hline M2 & M1 & M3 & $\mathbf{L}$ & Average, $\mathrm{H}, \mathrm{M}$ & L, Average & $\mathbf{G}, \mathbf{H}_{\mathrm{L}}$, Average & Average, $\mathrm{G}$ \\
\hline M2 & M3 & M1 & & & $\vec{J}$ & $\mathbf{H}_{\mathbf{R}}, \mathbf{J}$ & $\mathrm{J}, \mathrm{H}_{\mathrm{L}}, \mathrm{H}_{\mathrm{R}}$ \\
\hline M3 & M2 & M1 & & & $\mathrm{H}_{\mathrm{L}}$ & & \\
\hline M3 & M1 & $\mathrm{M} 2$ & & & $\mathrm{H}_{\mathrm{R}}$ & & \\
\hline
\end{tabular}

been reported for only mesiodistal length (Garn et al., '63) and crown area (Moorrees, '57) although age affects both measures because of length reduction from interproximal attrition (Wolpoff, '71b). This makes them poor indicators of the underlying genetics of relative size. In the maxilla (table 9) the Krapina length data are virtually identical to that reported for living populations; the first molar is smaller than the second $67 \%$ of the time and larger $33 \%(n=3)$. The mandibular sample is larger $(n=7)$ and exhibits a higher frequency of $\mathrm{M}_{1}$ size dominance and a lower frequency of the reverse. For instance, in Pima Indians and modern "Ohio whites" the $\mathrm{M}_{1}$ length is larger three-fourths of the time or more while at Krapina this fraction barely exceeds one-half. The area-based progressions, in contrast, are virtually identical to those reported for the Aleuts by Moorrees ('57) for the mandible while the Aleut maxillas are generally characterized by $\mathbf{M}^{1}$ size dominance.

Comparison with a wider range of modern groups (Wolpoff, '71a; Selmer-Olsen, '49) indicates a tendency for the Krapina mandibular second molars to exceed the first with greater magnitude than ever occurs today, whether length, breadth, or area are considered. In no living group does the $\mathbf{M}_{2}$ average breadth exceed the $\mathbf{M}_{1}$ average while at Krapina $\mathbf{M}_{2}$ is larger on the average, as well as in more than half the cases where these two teeth can be compared (a larger sample than indicated in table 9 which presents data for only specimens with all three molars). A larger sample would be necessary to determine a reasonably accurate estimate of the Krapina molar size progression. Nonetheless, the known data indicate that this progression differs from that in any living human population in its average characteristics, although the overlap of individuals is complete.

\section{Central tendencies}

Krapina has always been described as a megadont sample. The average tooth sizes, however, are probably best understood in an evolutionary context. Given the small sample size for European dentitions dating earlier than Krapina, the ancestral condition for the site is probably best sought in the Middle Pleistocene sample of Homo erectus. This sample is better represented by mandibles than maxillas so most comparisons will be restricted to the lower jaw. The Homo erectus mandibular sample from the Middle Pleisto- 


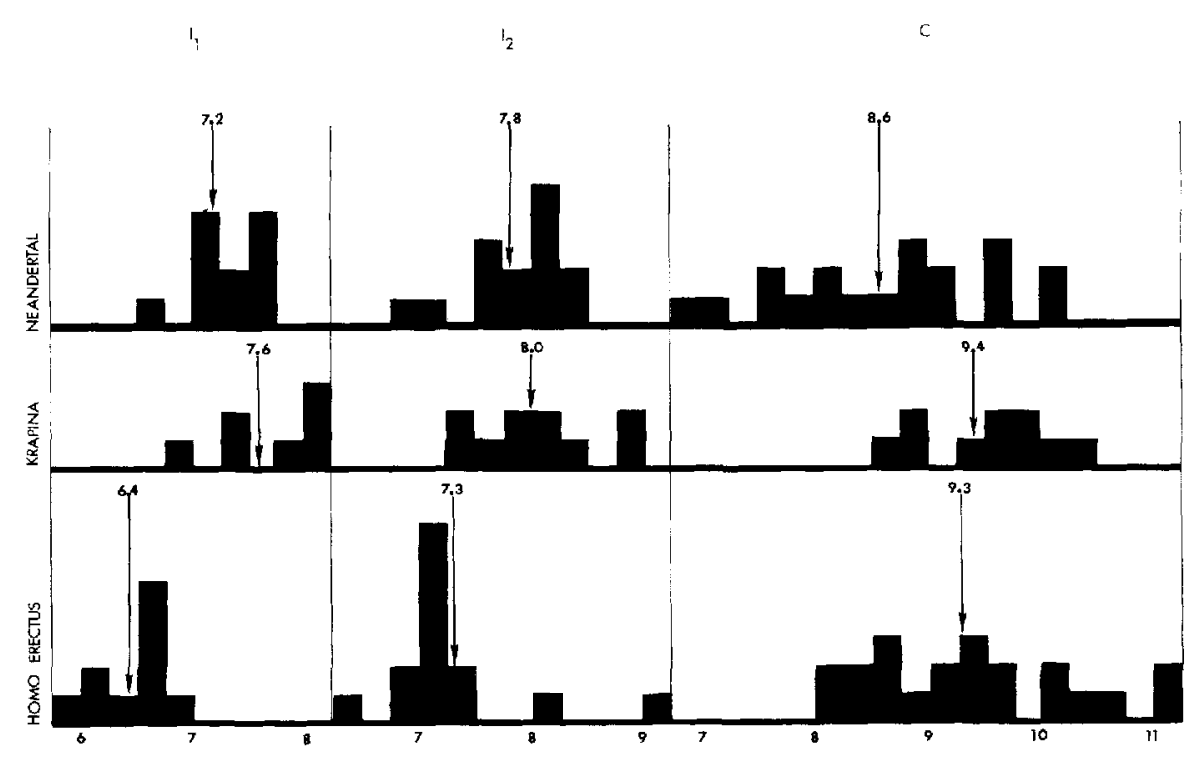

Fig. 19 Changes in anterior mandibular tooth breadths comparing the Homo erectus, Krapina, and European Würm Neandertal samples. Frequency distributions are given using a $0.25-\mathrm{mm}$ interval, and the position and value of the mean are indicated in each case.

cene available for comparison includes the following: The three Ternifine mandibles and isolated teeth (Arambourg, '63), Thomas (Sausse, '75), the Turkana mandibles and mandibular teeth ER 730, 806, 820,992 (measured by the author), ER 1805 (Day et al.,'76), Omo K7 (Coppens, '71), Olduvai hominids 22 and 23 (measured by the author), Baringo (measured by the author), SK (Swartkrans) 15 and 43 (measured by the author), Mauer (Howell, '60), Sangiran 1, 5, and 6 (Weidenreich, '45), Sangiran 8, 9, 11a (Jacob, '73), isolated mandibular teeth from the People's Republic of China (von Koenigswald, '57; Gao, '75), Lantian (Woo, '64), and the Choukoutien mandibular teeth (Weidenreich, '37, '45; Woo, '56; Woo and Chia, '54; Woo and Chao, '59).

A student's " $t$ " test shows the Krapina mandibular incisors are significantly greater in breadth than the Homo erectus ones at the 0.01 level, although the canines are virtually identical (fig. 19). Expansion in the centrals is approximately twice as great as in the laterals; with one exception every Krapina central incisor falls above the Homo erectus range. There is somewhat more overlap in the lateral incisors, but the same pattern clearly applies. In fact, the Krapina incisors of both jaws are broader than the incisors of any fossil or living hominid group. Even when compared with the
Pliocene hominids from the Afar (Johanson and Taieb, '76) and Laetolil (White, '77), sites with anterior teeth which are larger than any of the Pleistocene australopithecine samples and which retain many features of the ancestral condition, the Krapina maxillary incisors (table 3 ) are broader and the canine average is only $0.2 \mathrm{~mm}$ less. Lengths in the Laetolil 3 maxillary $\mathrm{I}^{1}$ and $\mathrm{C}^{1}$, however, fall above the Krapina range.

The Homo erectus maxillary anterior sample consists of specimens from Choukoutien ( 6 central incisors, 3 lateral, and 6 canines) published in sources described above, an isolated Sangiran central incisor (von Koenigswald and Weidenreich, '39) and canines from Sangiran 4 (Weidenreich, '45) and 17 (Jacob, '73), North African specimens from Ternifine (Arambourg, '63) and the Thomas quarry (Ennouchi, '72), the Omo F-18 lateral incisor (Coppens, '73), Turkana specimens ER 1805, 803 , and $808^{*}$ (the first published by Day et al., '76, and the remainder measured by the author), and the Olduvai Bed III JK central incisor OH 29 (measured by the author). Compared with Homo erectus, the Krapina anterior maxillary teeth (table 3) are markedly larger; $10.6 \%$ for $I^{1}$ ( $n=10$ for Homo erectus), $20.7 \%$ for $\mathrm{I}^{2}(\mathrm{n}=8)$, and $4.7 \%$ for $\mathrm{C}^{1}(\mathrm{n}=12)$. The breadth expansion in the Krapina incisors 

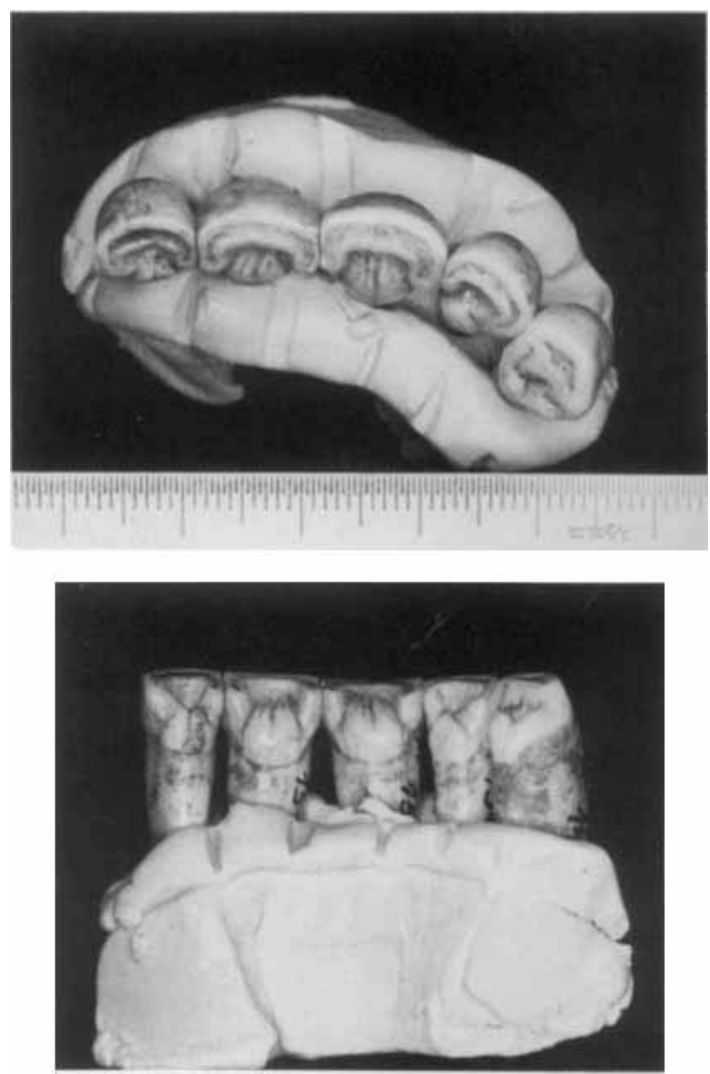

Fig. 20 Occlusal and lingual views of the $\mathrm{K}$ maxillary anterior set, comprising four incisors associated by Kallay ('69) and a canine. Note the strong expression of shoveling on the incisors and the marked basal tubercle development on all the teeth.

and canines is partially the result of pronounced basal tubercle development (fig. 20). Lingual tubercle expression is more marked in maxillary than in mandibular incisors and canines.

Comparison with the European Würm Neandertal mandibles is also appropriate, especially in view of the problems concerning how these two samples are related, and whether the Neandertals represent a lineage evolving away from the direction of modern Homo sapiens. Mandibles with measurable anterior teeth include the following: Arcysur-cure 8 (Leroi-Gourhan, '58), Hortus 2, 4, 6 (de Lumley, '72; personal communication; de Lumley and Piveteau, '69), Jersey (Keith, '12), the Suard cave of La Chaise (David, '60), La Ferrassie 1 (Heim, '76), Le Portel (Brabant and Sahly, '64), La Quina 5 (Henri-Martin,
'23) and 9 (Henri-Martin, '26), Le Moustier (Weinert, '25), Monsempron (Vallois, '52), Montgaudier (Duport and Vandermeersch, '76), Regourdou (Piveteau, '64), Šipka (Vlček, '69), Spy 1 and 2 (Twiesselmann, '73), Teshik Tash (Okladnikov et al., '49), Zaskalnaya (Kolossov et al., '75), Mt. Circeo 3 (measured by D. W. Frayer), Ochoz (measured by F. H. Smith), Subalyuk and Vindija 206 (measured by the author). It is likely that this sample is later than most of the Krapina specimens.

Average Krapina canine and incisor size is larger than that of the European Würm Neandertals, although the $I_{2}$ difference is not significant. That the Würm Neandertal anterior teeth are reduced compared with Krapina indicates an evolutionary trend in the direction of living populations, although the Neandertal anteriors are still much larger than those in any living group. Compared with the Central European Eleventh Century group (tables 5,6), length reductions range from $17 \%$ to $22 \%$ in the mandible and up to $27 \%$ in the maxilla while the breadth reductions are even greater (between 22\% and 39\%). The differences are less marked when compared with the megadont Australian aborigine group but even in this sample with molars generally larger than Krapina, the anterior breadth ranges from between $10 \%$ and $25 \%$ smaller in both jaws and marks the greatest dental difference between this extreme of the living Homo sapiens range and the Krapina sample. The Krapina pattern is characteristically different from any living group.

In contrast to the anterior teeth, the Krapina postcanines show marked reduction when compared with the Middle Pleistocene Homo erectus sample (fig. 21). Using occlusal areas, the Krapina mandibular premolars are $90 \%$ and $88 \%$ of the $H$. erectus value, while the molar reduction is respectively $95 \%, 92 \%$, and $93 \%$. Reduction is least in the earliest erupting teeth in the molar and premolar fields, although the differences within each field are not great.

Between P4 and M3 in both jaws, Krapina tooth size falls at the extreme of the living human range; $\mathrm{P} 3$ and the canine, however, are well above the living human populational maximum (table 7). Even so, the posterior area sum exceeds Broadbeach by only $3 \%$ in the maxilla, and is identical in the mandible.

However, within the European sequence Krapina contrasts with living populations and is well above the living European population 


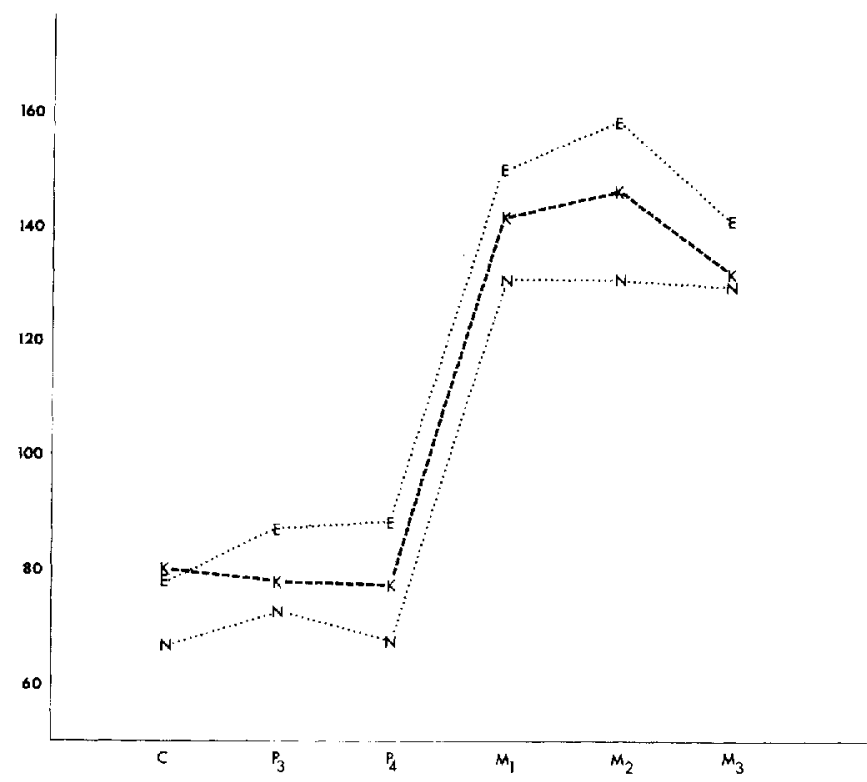

Fig. 21 Comparison of average mandibular tooth areas (length $\times$ breadth) for the middle Pleistocene Homo erectus sample (E), Krapina (K), and the European Wurm Neandertals (N). Areas are in $\mathrm{mm}^{2}$. See text for further details and sample composition.

extreme. The Krapina average areas exceed Halimba by percentages ranging from $36 \%$ to $61 \%$ in the maxilla, and $26 \%$ to $54 \%$ in the mandible. The Halimba posterior area sum reduction is $60 \%$ the Krapina value in the maxilla and $74 \%$ in the mandible. To place this reduction in context, the Krapina maxillary posterior area sum represents a $69 \%$ reduction from the australopithecine mean (excluding the hyper-robusts). One way to look at this places Krapina midway between the australopithecines and living Europeans in posterior tooth size, but another aspect is that the earlier reduction took approximately 2,000,000 years while the later required only 100,000 !

Comparison with the later Würm Neandertals is again appropriate. Besides specimens from the sites listed above, the sample for Neandertal mandibular postcanine teeth includes the following: Bombarrel (Twiesselmann, '73), Combe Grenal (Piveteau, '57), La Croze del Dua (Genet-Varcin, '66), Le Placard (Genet-Varcin, '62), Mascassargues (Piveteau, '51), Camerota (Palma di Cesnola and Messeri, '67), Petit-Puymoyen 3 (Siffre, '08), Vergisson 2 and 3 (Genet-Varcin, '62), and Castel-Merle and the Gibraltar child (measured by the author). As in the anteriors, the European Würm Neandertal posteriors are reduced compared with Krapina. In the mandi- ble, premolars reduce to about $90 \%$ the Krapina value as do the anterior molars while the third molar remains virtually identical.

\section{The deciduous dentitions}

The Krapina dentitions are sufficiently well represented to be placed in an evolutionary context. Deciduous teeth from any time period are fairly rare; for instance, the entire Homo erectus maxillary sample consists of five teeth. There is a dc ${ }^{1}$ from Vergranne (Campy et al., '74), two central incisors from ER (L. Turkana) 808 (measured by the author), and two firsts and a second deciduous molar from Ternifine (Arambourg, '63). Fortunately, the mandibular sample is larger, if specimens from the entire $H$. erectus time range are used. Mandibular deciduous dentitions consist of the following: 11 teeth from Choukoutien (Weidenreich, '37), Vértesszöllös ( $\mathrm{dc}_{1}$ measured by the author), and ER 820 (dc- $\mathrm{dm}_{2}$, measured by the author). The Würm Neandertal sample available for comparison is much larger. Specimens with deciduous teeth include the following: Archy (measured by D. W. Frayer), Combe Grenal (Piveteau, '57), Chateuneuf (Genet-Varein, '74), Gibraltar child (measured by the author), Hortus 15 (de Lumley, '72), Kulna (4 specimens, measured by F. H. Smith), Les Peyrards (Genet-Varein, 


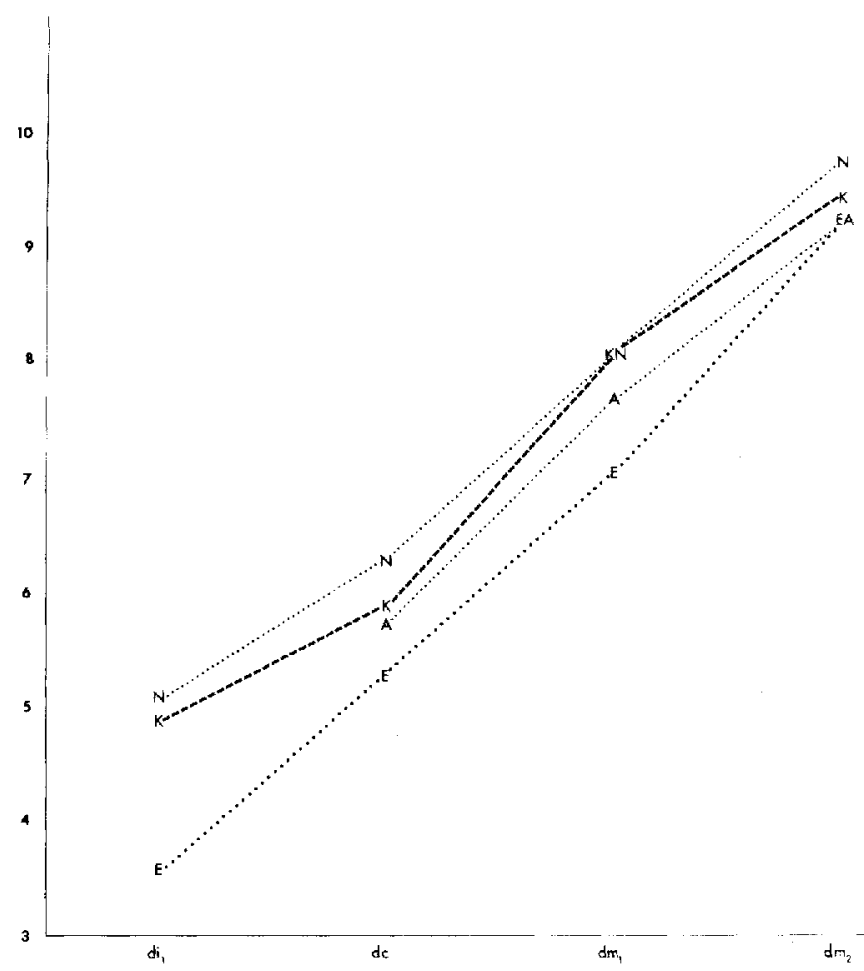

Fig. 22 Comparison of mandibular deciduous trangverse breadths for Middle and Lower Pleistocene Homo erectus (E), the European archaic Homo sapiens sample older than Krapina (A), Krapina (K), and the European Würm Neandertal sample $(\mathrm{N})$. Breadth is used to allow comparison of anterior and posterior teeth; measurements are in $\mathrm{mm}$. See text for sample composition and further details.

'74), Portel (Brabant and Sahly, '64), La Quina 18 (Henri-Martin, '23), La Vienne (Patte, '60), Camerota a, b, and c (Palma di Cesnola and Messeri, '67), Pech de l'Aze (Patte, '57), Roc Marsal (Genet-Varcin, '74), Salemas (Ferembach, '62), Subalyuk child (measured by the author), Teshik-Tash (Okladnikov et al., '49), and Staroselje (Roginskij, '54).

Uncertainty due to small sample size for the earlier specimens is somewhat mitigated by the presence of what appears to be a consistent evolutionary trend in the deciduous mandibular teeth (fig. 22). The Krapina dentitions are consistently larger than Homo erectus; moreover, the small pre-Krapina European sample consisting of Arago (measurements courtesy of $\mathrm{H}$. de Lumley) and La Chaise 13 (Piveteau, '57) is midway between the two. What is more surprising is that the later European Würm Neandertal dentitions are even larger yet. In sum, there appears to be a consistent trend for size increase in the deciduous mandibular teeth through the Middle Pleistocene and up to the Würm glaciation. This is quite different from the evolutionary trends in the permanent teeth: expansion and then reduction in the incisors and consistent reduction in the postcanines.

The Homo erectus maxillary sample is too small for any comparisons. A slightly larger sample can be constructed if it is added to the pre-Krapina European sample from Arago and La Chaise 37 (Genet-Varcin, '74). Even this combination is probably too small for comparisons; $n=3$ for $\mathrm{dI}^{1}$ and $\mathrm{dC}$, and $\mathrm{n}=2$ for the deciduous molars. The Krapina $\mathrm{dI}^{1}$ is larger, while the canine and molars are virtually identical. Of more interest is the comparison of the Krapina deciduous maxillary teeth with those of the Würm Neandertals, since the sample sizes are generally much larger. In contrast to the reduction observed in the permanent teeth of these later Europeans, maxillary deciduous tooth size is virtually identical and clearly indistinguishable in a statistical sense.

\section{Sexual dimorphism}

Generally, expectations are that the Kra- 
pina sexual dimorphism was likely marked (Gorjanovic-Kramberger, '06). This contention is supported by evidence of considerable postcranial size dimorphism in the Würm Neandertals (Heim, '74), and the presence of pronounced mandibular dimorphism in the skeletally sexed Near Eastern archaic Homo sapiens sample (Wolpoff, '75a). Yet, analysis of the Krapina dimorphism is constrained by the difficulties in sexing individual specimens. Mandibular corpus variation exceeds dental variation (fig. 23) and it is likely that mandibles at the extremes can be accurately sexed. Amongst the adults, $\mathrm{H}$ and $J$ are likely males, and $\mathrm{G}$ is a likely female.

However, neither the canines nor any other teeth show evidence of bimodality; sexing procedures applicable in the australopithecine sample (Wolpoff, ' $76 a$ ) cannot be used here. In living humans, canines below the female mean are almost always females, and males above the male mean are almost always male (Wolpoff, '76b). One might expect that at Krapina the probability is that specimens with the largest canines are male, and those with the smallest are female. However, such a "rule of thumb" cannot be applied with accuracy. For instance, the mandible with the largest corpus $(\mathrm{H})$ has one of the smallest canines.

In the Near Eastern archaic Homo sapiens sample that can be skeletally sexed, dental dimorphism does not differ from living humans while dimorphism in the dimensions of the mandibular corpus is generally much greater than in living humans and at the symphysis closely approaches the australopithecine values (Wolpoff, '75a). The meager evidence available suggests substantially the same pattern in the Krapina sample.

Fig. 23 Variation at the extremes of the range for the more complete Krapina mandibles. Above are adult mandibles $\mathrm{G}$ (the smaller) and $\mathrm{H}$ in lateral view, and below are occlusal views of $L$ (left) and D. Usual comparisons of the mandibular corpus that include the $D$ and $E$ juveniles (Vlček, '69) provide a misleading estimate of the variability present. The second molar added to mandible $D$ fits the existing socket (after cleaning) and matches the in terproximal facet on the $M_{1}$. The $\mathrm{L}$ dental set is comprised of teeth showing continuity of wear striations and exact matches for the interproximal facets. The anterior crowding in this megadont specimen is of particular interest. The lateral incisors are displaced lingually, although not rotated; the left is more displaced than the right. Two grooves appear on the labial face of this tooth, slightly centralward from the edge, showing the contact facets on the canine and $I_{1}$. The facets on these teeth $\left(C_{1}\right.$ and $\left.I_{1}\right)$ are set correspondingly on the lingual corners. The central in cisors meet normally, but on the right the mesial contact facet on $I_{2}$ also appears on the labial face. The remaining contact facets are not unusual.

\section{AGE RELATED CHANGES}

The most obvious effect of increasing age is occlusal wear. As discussed above, the wear rates within each dental field were found to be reasonably consistent, and provided the bases for age determinations. No formal comparison of wear rates with those of other sites was attempted. Based on my own experience with large dental samples, I suspect that little if any difference in the rate of occlusal wear dis-
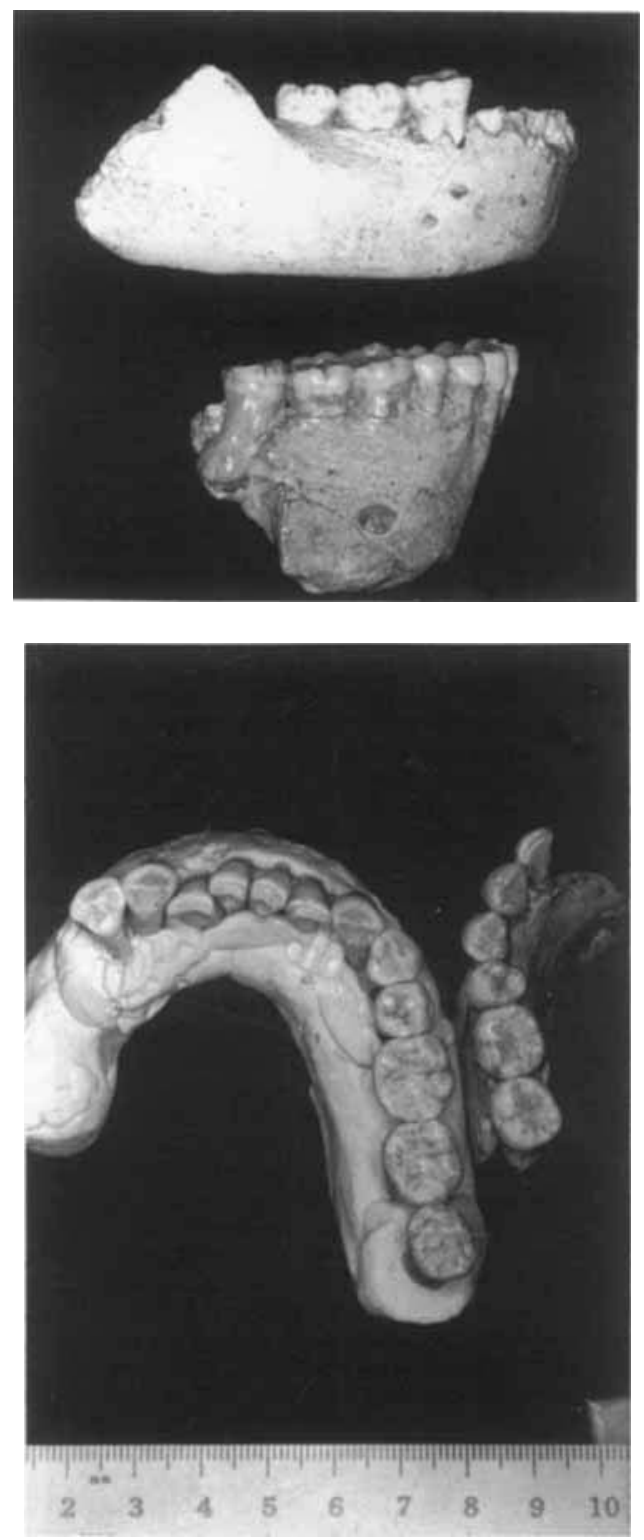

Figure 23 
TABLE 10

Krapina transverse breadths as a function of age. Data presented include the slope ( $m$ ) and the intercept of the least squares regression $(\mathrm{B})$, the correlation ( $r$ )and the probability that it is equal to 0 , and the sample size ( $n$ ). When antimeres for a tooth are present, the average is used in the calculations

\begin{tabular}{|c|c|c|c|c|c|}
\hline & \multicolumn{5}{|c|}{ Breadth as a function of age } \\
\hline & $\mathrm{m}$ & B & $\mathbf{r}$ & $\begin{array}{c}\mathrm{P}(\mathbf{r}=0) \\
\leqslant\end{array}$ & $\mathrm{n}$ \\
\hline $\mathrm{I}^{1}$ & 0.03 & 8.6 & 0.331 & 0.19 & 11 \\
\hline$I^{2}$ & 0.05 & 8.1 & D.335 & 0.13 & 13 \\
\hline $\mathrm{C}$ & 0.02 & 10.0 & 0.171 & 0.28 & 14 \\
\hline $\mathbf{P}^{3}$ & 0.01 & 11.1 & 0.052 & 0.45 & 9 \\
\hline $\mathbf{P}^{4}$ & -0.01 & 11.1 & -0.127 & 0.35 & 11 \\
\hline $\mathbf{M}^{3}$ & 0.05 & 12.0 & -0.294 & 0.22 & 9 \\
\hline $\mathbf{M}^{2}$ & 0.00 & 12.8 & 0.005 & 0.49 & 10 \\
\hline $\mathrm{M}^{3}$ & -0.06 & 13.5 & -0.409 & 0.14 & 9 \\
\hline $\mathrm{dM}^{2}$ & -0.01 & 10.9 & -0.046 & 0.47 & 6 \\
\hline $\mathbf{I}_{1}$ & -0.00 & 7.7 & -0.039 & 0.47 & 7 \\
\hline $\mathrm{I}_{2}$ & -0.02 & 7.6 & -0.295 & 0.22 & 9 \\
\hline $\mathrm{C}$ & -0.02 & 9.7 & -0.171 & 0.31 & 11 \\
\hline $\mathrm{P}_{3}$ & -0.03 & 9.8 & -0.235 & 0.26 & 10 \\
\hline$P_{4}$ & 0.05 & 8.9 & 0.453 & 0.06 & 13 \\
\hline $\mathbf{M}_{1}$ & -0.01 & 11.6 & -0.059 & 0.42 & 14 \\
\hline $\mathrm{M}_{2}$ & -0.03 & 12.0 & -0.167 & 0.30 & 12 \\
\hline $\mathbf{M}_{3}$ & -0.03 & 11.4 & -0.219 & 0.27 & 10 \\
\hline $\mathrm{dM}_{2}$ & 0.02 & 9.4 & 0.121 & 0.41 & 6 \\
\hline
\end{tabular}

tinguishes the Krapina teeth from samples as disparate as the South African australopithecines or the Libben Amerinds. In all three, marked wear is evident on most teeth by the approximate age of 20 and crown destruction is well advanced if not completed by about 30 . Two other age related changes were examined: differential survivorship for tooth size and length loss rates due to interproximal attrition.

\section{Tooth size differential survivorship}

Differential survivorship in tooth size provides a means of directly examining the differential mortality aspect of selection. Various attempts have been made to demonstrate the action of selection through differential tooth size survivorship in Cave Bears (Kurtén, '57), fossil horses (Van Valen, '63, '65), australopithecines (Wolpoff, '76c), and living humans (Perzigian, '75).

Since mesiodistal length, and consequently occlusal area, change through life as a result of interproximal attrition, differential survivorship is best sought in transverse breadth. Linear correlations and regressions were attempted for the breadth of each Krapina tooth type and age (table 10). The correlations were low, and half were negative (the majority of these in the mandible). However, only one correlation could be shown significantly different from 0 at less than the $10 \%$ level (the 0.453 correlation for $\left.\mathrm{P}_{4} ; \mathrm{p}(\mathrm{r}=0) \leqq 0.06\right)$. The low correlations and lack of significance provide no evidence for a demonstrable size trend in differential survivorship. No directional selection due to differential mortality can be ascertained for this sample. The sample sizes are too small for the variance comparisons necessary to determine whether there was stabilizing selection.

\section{Interproximal attrition}

Interproximal attrition rates were determined by reduced major axis regressions of the dental index (length $\times 100 /$ breadth) as a function of age (table 11). The dental index is used instead of length to compensate for size differences between the teeth; rates of change for this index can be transformed into average length loss rates through multiplication by the average breadth. Given the absence of systematic bread th differences with age, no additional alterations in the rates are necessary.

Correlations of dental index and age (table 11) are significant at the $10 \%$ level for only one maxillary tooth $\left(\mathrm{M}^{1}\right)$ and the three mandibular molars. The correlations and rates of dental index change are lowest in the premolars and canine. When transformed to length loss rates, the maxillary values are more uniform although the mandibular teeth vary from the virtual absence of length loss in the canine to the posterior molar values which ex- 
TABLE 11

Krapina mesiodistal length loss determinations. The dental index is examined as a function of age and the slope $(m)$ and intercept $(B)$ of the reduced major axis regression are presented, along with the correlation ( $r$ ) and the probability that it is equal to 0 . Using the regression, the dental index at eruption (from ages in table 1 ) is determined, and the mesiodistal length loss per year is calculated by multiplying the slope times the average trans. verse breadth. Comparative data for the australopithecines are from Wolpoff ('71b)

\begin{tabular}{|c|c|c|c|c|c|c|c|c|}
\hline & \multirow[b]{2}{*}{$\mathbf{m}$} & \multirow[b]{2}{*}{$\mathrm{B}$} & \multirow[b]{2}{*}{$r$} & \multirow[b]{2}{*}{$\begin{array}{c}\mathrm{P}(r=0) \\
\quad \leqslant\end{array}$} & \multirow[b]{2}{*}{$\mathbf{n}$} & \multicolumn{2}{|c|}{ Estimated Krapina } & \multirow{2}{*}{$\begin{array}{c}\text { Australopithecine } \\
\text { Length loss } \\
\text { (mm/year) }\end{array}$} \\
\hline & & & & & & $\begin{array}{l}\text { Index } \\
\text { eruption }\end{array}$ & $\begin{array}{l}\text { Length loss } \\
\text { (mm/year) }\end{array}$ & \\
\hline $\mathrm{C}^{1}$ & -0.38 & 95.4 & -0.352 & 0.11 & 14 & 91.2 & 0.04 & \\
\hline $\mathrm{P}^{3}$ & -0.20 & 79.1 & -0.294 & 0.22 & 9 & 77.1 & 0.02 & \\
\hline $\mathrm{P}^{4}$ & -0.23 & 77.8 & -0.209 & 0.27 & 11 & 75.3 & 0.03 & \\
\hline $\mathbf{M}^{1}$ & -0.32 & 103.5 & -0.526 & 0.07 & 9 & 101.6 & 0.04 & 0.11 \\
\hline $\mathbf{M}^{2}$ & -0.35 & 93.5 & -0.295 & 0.20 & 10 & 89.6 & 0.04 & \\
\hline $\mathbf{M}^{3}$ & -0.43 & 90.9 & -0.388 & 0.15 & 9 & 84.5 & 0.05 & 0.16 \\
\hline $\mathrm{C}_{1}$ & -0.03 & 87.3 & -0.050 & 0.44 & 11 & 87.0 & 0.002 & \\
\hline $\mathrm{P}_{3}$ & -0.13 & 90.5 & -0.257 & 0.25 & 10 & 89.2 & 0.01 & 0.12 \\
\hline$P_{4}$ & -0.69 & 95.4 & -0.379 & 0.11 & 12 & 87.8 & 0.07 & 0.17 \\
\hline $\mathbf{M}_{1}$ & -0.38 & 113.7 & -0.530 & 0.03 & 13 & 119.3 & 0.04 & 0.13 \\
\hline $\mathbf{M}_{2}$ & -0.63 & 121.3 & -0.519 & 0.04 & 12 & 114.3 & 0.07 & \\
\hline $\mathbf{M}_{3}$ & -1.16 & 136.3 & -0.475 & 0.08 & 10 & 118.9 & 0.13 & 0.12 \\
\hline
\end{tabular}

ceed any in the maxilla. While these data establish the presence of length loss with age in the molars, the effect of age on canine and premolar lengths is less systematic.

The length loss rates are very low when compared to values obtained for the australopithecines (Wolpoff, '71b); except for the $M_{3}$, australopithecine length loss varies between being 2.5 and 12 times more rapid (table 11 ). Even these lower rates can have a considerable effect on tooth size in the older Krapina individuals; to some extent the low average age at death of the sample acts to elevate the average tooth areas when compared with samples having an older average age at death. However, the wear rates are not rapid enough for this to be critical. For instance, Vallois ('60) estimates an average age at death of 19.9 years for the European Neandertals while Weiss ('73) revises this to 18 years using data smoothing techniques. The difference in mandibular posterior area sums, when compared with Krapina, is $46 \mathrm{~mm}^{2}$; only $10 \mathrm{~mm}^{2}$ could be accounted for by the average age difference (i.e., if the average age at death for the Krapina sample was about 20 years, interproximal wear rates predict an average mandibular posterior area sum $10 \mathrm{~mm}^{2}$ less than observed). The average age at death for the Krapina sample would have to be 30 years for the mandibular posterior area sum to be reduced to the European Neandertal value through interproximal attrition.

\section{DISCUSSION AND SUMMARY}

Seen in an evolutionary context, the metric characteristics of the Krapina dental sample represent an extension of the trends visible in the earlier archaic Homo sapiens sample and Homo erectus. If no specimens dating to the Riss/Würm were known, analysis of the earlier specimens would predict the presence of larger permanent anterior and smaller posterior teeth for this timespan. It is the later Würm Neandertal sample from Europe that appears unusual, since these specimens show the results of both posterior and anterior tooth size reduction.

\section{Evolutionary models}

A number of authors have related the middle Pleistocene reduction in posterior tooth size and expansion in anterior tooth size to aspects of the hominid cultural adaptation (Brace, '64, '68; Brose and Wolpoff, '71; Greene, '70). Posterior reduction over this period would seem to correspond to the effects of cooking and food preparation on the amount of mastication (time, power, and effect on occlusal wear) necessary to reduce foods to digestability. It is unlikely that any worldwide uniform Middle Pleistocene dietary shift could account for this reduction, given the likelihood of markedly different diets for the affected populations. One insight into the differences in the masticatory requirements of the diet that evolved is suggested by a comparison of Krapina and the australopithecines. The occlusal wear rates of these samples are similar. However among the australopith ecines, the wear is distributed over a much larger occlusal surface, indicating that much 
more masticatory work was sustained; this could be the result of somewhat more force expressed over a longer chewing time, much more force expressed over the same chewing time, or most likely some (differing) combination of these. A more direct measure of the applied forces can be seen in the more rapid rates of australopithecine interproximal wear. These data suggest that the reduction in masticatory work resulting in the Krapina condition was at least as great as the reduction in occlusal area.

Anterior tooth expansion has been equally marked, although its explanation is somewhat more controversial (cf., Wallace, '75). In the continuing discussion over the importance of anterior tooth use for environmental manipulation, central focus must be maintained on the fact that these teeth increase markedly in size through the entire Pleistocene up to approximately 100,000 years ago. This same period is characterized by the most dramatic increases in the complexity of the material aspects of culture (Bordes, ' 68 ; Isaac, '72). If a simple model of shifting food preparation from the inside to the outside of the mouth (Campbell, '39; Wallace, '75) is applied to the anterior teeth, the expected evolutionary trend would be size reduction. That marked size increase occurs instead indicates that a rather different explanation is required.

No explanation other than the suggested use of these teeth as part of the tool kit has ever been put forward; while one worker has suggested that normal abrasion could account for the wear on some Neandertal teeth (Wallace, '75), the author seems to admit that his hypothesis does not bear on the more general evolutionary question of why the teeth and the surrounding stress-bearing portion of the maxilla have been subjected to continuous expansion. Apart from the question of how much positive tooth wear evidence supports this model (Brace, '75), or for that matter whether any particular pattern of macroscopic wear can clearly distinguish masticatory from non-masticatory function (Barrett and Brown, '75), a number of features indicate the progressive adaptation of the anterior face to a pattern of incisor and canine loading at a significant angle to the long axes of these teeth (Wolpoff, '75b). The complex of features which show expansion throughout the span of earlier archaic Homo sapiens preceding Krapina include anterior tooth breadths, the frequency of shoveling and basal tubercle de- velopment, incisor root size, and the maxillary expansion and thickening which leads to the loss of the canine fossa. In the absence of any other hypothesis explaining the evolution of this complex, anterior loading for purposes other than masticating food remains the most likely hypothesis.

The parallel expansion of the deciduous teeth through the latest archaic Homo sapiens samples probably represents different selection than for either the posterior or the anterior permanent teeth. No explanation is testable without further study of the deciduous teeth. However, in the context of pos. terior reduction in the permanent teeth of the same samples, constraints for the possible explanations can be suggested. The size expansion probably is a response to a longer period of wear for the deciduous dentition. This could result from more delayed eruption for the permanent dentition, although Mann's ('75) demonstration of delayed eruption in the australopithecines limits the time over which additional delay could be expressed to only a few years. Another possibility could be a tendency for earlier weaning to reduce the birth spacing, which seems rather great in the australopithecines (McKinley, '71). Reduced birth spacing provides an effective means of expanding the net rate of population increase when there is high adult mortality; such an increase might be expected to accompany the dramatic habitat expansions of the Upper Pleistocene hominids. Earlier weaning would result in earlier and more rapid reduction of the deciduous tooth surfaces, and its presence could be ascertained through a demonstration of earlier and more rapid wear on the deciduous teeth.

\section{Position of the Krapina sample}

With regard to the Middle and Upper Pleistocene evolutionary trends for the deciduous and posterior permanent teeth, Krapina lies between Homo erectus and the later European Würm Neandertals. In the permanent anteriors, however, Krapina is the largest sample representing the timespan for which size is maximized. Other European hominids from the Riss and Riss/Würm also show this anterior expansion (Ehringsdorf, Arago, Bourgeois-Delaunay), indicating that it is part of a continent-wide trend and not a unique feature of the Krapina sample (fig. 18).

Since anterior tooth size is maximized at Krapina, one might expect to find indications 
of the change(s) in selection that resulted in the subsequent reduction. While an analysis of differential survivorship in anterior tooth size provides no evidence for directional selection, one hint of a possible selective agency might lie in the observed anterior tooth crowding. Under the hypothesis that tooth reduction occurs as the developing proliferation of special purpose tools in Middle Paleolithic industries results in less use of the anterior teeth as part of the tool kit (Brose and Wolpoff, '71), it is possible that with less strain upon the jaws there is a reduction of bone growth during life. Crowding could be the result of this process, and subsequently provide selection for dental reduction following the gnathic reduction. Another explanation allowable under the same circumstances is the mutation accumulation hypothesis (Brace, '63). With reduced use of the anterior teeth comes relaxation of the selection maintaining their large size. According to this hypothesis, size reduction is the most likely consequence of the mutations that could accumulate with selection relaxation (Wolpoff, ' 69 , '75c). In either case, the conditions allowing reduction are the same; technology provided an effective means of reducing the use of the anterior teeth.

\section{Summary}

A number of points have emerged from this discussion. These can be summarized under four broad categories.

\section{(1) Dental aging of the specimens}

(a) Of the assumptions necessary to apply a dental aging technique to a fossil sample, none can be unquestionably satisfied although in most cases it can be reasonably argued that they are probably valid.

(b) Accuracy in age determination based on eruption is limited by observed genetic differences in eruption times between human populations, normal variation within populations, and the lack of comparative data for occlusal eruption.

(c) An occlusal eruption schedule was determined by calculating an average for comparable gingival eruption schedules representing modern geographic variation as evenly as possible, and adding to this an estimate of the time lag between gingival and occlusal eruption based on a more limited sample.

(d) Since most of the variation within populations is systematically distributed about the mean eruption times, the age based distributional statistics for a fossil sample are likely more accurate than the individual ages. A 50\% range for individual age estimates is determined at \pm 1 year or less.

(e) However, there is no way to be sure which modern eruption schedule validly applies to a fossil sample; using the mean described above minimized the likelihood of major error but provided no basis for estimating the error probabilities. The maximum error range for the mean values of all teeth except M3 is estimated at \pm 0.8 years.

\section{(2) Krapina ages and demography}

(a) Renumbering and reidentification of the 191 isolated Krapina teeth allowed the first full-sample comparison of these specimens with each other and with the 90 teeth remaining in jaws.

(b) The occlusal eruption sequence was used to provide ages for specimens with mixed dentitions. These ages were used to determine age-based wear models for each tooth class, which were applied to the older jaws and the isolated teeth. In the former case, aging based on individual teeth was found to be consistent within one year (in virtually all cases) except for M3.

(c) A hypothesis of occlusal eruption for M3 at 15 years resulted in age determinations which were consistent with the other teeth.

(d) A number of additional teeth were found to fit the existing jaws.

(e) A number of the remaining teeth were found to go together on the basis of interproximal facets and features of the occlusal surface. The resulting dental sets were identified and labeled in those cases when the teeth could be demonstrably (rather than probabilistically) shown to go together. In reviewing the individually determined ages of the teeth in these sets, in only two cases was there as much as a two year discrepancy in ages. In a few cases, upper and lower jaws were found to represent a single individual and in one instance this information could be determined for isolated tooth sets because of a dental anomaly in both jaws.

(f) A maximum and minimum estimate of individuals represented by dentitions was found by taking the number of demonstrably different individuals and adding respectively the maximum and minimum number of additional individuals that could be represented 
by the remaining teeth. The number of individuals was bracketed between 75 and 82 .

(g) The age distribution of the sample is unusual in the absence of individuals under three and the virtual absence of individuals over 20 . The highest observed mortality was between the ages of 15 and 18 .

(h) The average age at death was 13.3 years for the observed sample. Assuming that the missing individuals in the 0- to 3-year span represent $25 \%$ of the sample, the average age at death is reduced to 10.8 years.

(i) Analysis of the birth rate necessary to maintain a real population with this age-atdeath distribution indicated that the sample could not represent an actual biological population; an unknown but significant number of adults are missing from the Krapina remains.

\section{(3) Metric characteristics}

(a) The dental sample in general is represented by skewed and almost always flattened distributions. The skewing is much more often positive than negative.

(b) Variability, as measured by the coefficient of variation, is equal to or smaller than variability within skeletal samples representing recent biological populations. The diminutive dental variability contrasts with the marked size differences between the relatively few complete individuals.

(c) The relative size sequence of the mandibular incisors fit the modern human pattern: $I_{2}>I_{1}$ for the labiolingual breadth. In the maxillas, however, 5 out of 13 cases differ from the $\mathrm{I}^{1}>\mathrm{I}^{2}$ sequence.

(d) While the different individual molar size progressions within the Krapina sample fall within the living human range, unlike any living population the average breadth relation is $\mathbf{M}_{2}>\mathbf{M}_{1}$. The progressions based on tooth areas are more similar to the living human populational averages.

(e) The Krapina anterior teeth are larger, on the average, than any other Pleistocene hominid group whether earlier or later in time. The maxillary incisors are even broader than those of the Pliocene hominids, and the canines only slightly smaller.

(f) The posterior teeth, in contrast, are a consistent part of the trend for size reduction; they are smaller than the earlier Homo erectus sample and larger than the European Würm Neandertal sample.

(g) The deciduous teeth are included in a general trend for size expansion; the Krapina averages are generally larger in size than Homo erectus and smaller or equal to the European Neandertal averages.

(h) Comparison with living populations shows the presence of marked tooth size reduction in recent Europeans, equaling in percentage the amount of reduction between the australopithecine sample and Krapina but expressed over one-twentieth the time. Comparison with a megadont Australian aborigine population with molars of approximately equal size to Krapina throws the relatively large size of the Krapina anteriors, and to a lesser extent also the premolars, into contrast.

(i) While sexual dimorphism at Krapina was likely marked, no dental evidence can be used to sex specimens or provide estimates of the degree of dimorphism.

(j) No consistent pattern of differential survivorship can be found for age independent size characteristics. The interproximal wear rates are generally low.

\section{(4) Evolutionary trends}

(a) The trend for permanent premolar and molar reduction is more likely related to changes in food preparation technology than to any worldwide dietary change spanning the Middle and Upper Pleistocene.

(b) The expansion of deciduous tooth size may be due to a progressive delay in permanent tooth eruption over this timespan, but more likely responds to earlier use of the deciduous teeth as the result of earlier weaning.

(c) The large anterior teeth occur at a time when selection for expanding anterior tooth size is in the process of changing to selection (or its absence) resulting in anterior reduction. Reduced jaw growth and subsequent anterior crowding is one mechanism which could account for this reduction, while another pos. sibility is mutation accumulation allowed when selection to maintain large teeth is relaxed.

\section{ACKNOWLEDGMENTS}

The Krapina material was studied with the permission and enthusiastic cooperation of Doctor I. Crnolatac, director of the GeoloskoPaleontoloski Muzej in Zagreb. I offer Doctor Crnolatac and the staff of the museum my most profound gratitude for their help, encouragement, and hospitality during my visit, and gratefully acknowledge permission to use Doctor J. Kallay's laboratory at the Institute for Paleontology and Quarternary Geology to 
prepare the C maxilla. I thank the Croatian Academy of Sciences for their cooperation and for permission to participate in the exchange program. I am grateful to Doctor T. Toth of the Természettudományi Múzeum in Budapest for permission to study the Halimba material and Doctor C. L. Brace, Doctor D. W. Frayer, Doctor H. de Lumley, and Doctor F. H. Smith for providing much of the comparative data discussed in the text. I thank Doctor T. White for help in preparing this manuscript.

\section{LITERATURE CITED}

Adler, P. 1958 Studies on the eruption of permanent teeth. IV. The effect upon the eruption of permanent teeth of caries in the deciduous dentition, and of urbanization. Acta. Genet., 8: 78-91.

Adloff, P. 1907 Die Zähne des Homo primigenius von Krapina. Anat. Anz, 31: 273-282.

__ 1908 Das Gebiss des Menschen und der Anthropomorphen. Springer, Berlin.

1909 Zur Frage der systematischen Stellung des Menschen von Krapina. Anat. Anz, 34: 105-110.

1910 Neue Studien über das Gebiss der diluvialen und rezenten Menschenrassen. Dtsch. Mtschr.f. Zhd., 28: $134-159$.

1927 Das Gebiss des Menschen und der Anthropoiden und das Abstammungsproblem. Z. Morphol. Anthrop., 26: 431-449.

Arambourg, C. 1963 Le gisement de Ternifine. Arch. Inst. Paleont. Hum., Mem. 32.

Bailit, H. L., P. L. Workman, J. D. Niswander and C. J. Mac Lean 1970 Dental asymmetry as an indicator of genetic and environmental conditions in human populations. Hum. Biol., 42: 626-638.

Bambach, M., R. Saracci and H. B. Young 1973 Emergence of deciduous teeth in Tunisian children in relation to sex and social class. Hum. Biol., 45: 435-444.

Banerjee, P., and S. Mukherjee 1967 Eruption of deciduous teeth among Bengalee children. Am. J. Phys. Anthrop., 26: $357-358$

Barrett, M. J., and T. Brown 1975 Comment on: "Did La Ferrassie 1 use his teeth as a tool?" by J. A. Wallace. Cur. Anthrop., 16: 396 .

Bean, R. B. 1914 The stature and eruption of the permanent teeth of American, German-American and Filipino children. Am. J. Anat, 17: 113-160.

Begg, P. R. 1954 Stone age man's dentition. Am. J. Orthodont., 40: 298-312, 373-383, 462-475, 517-531.

Boas, F. 1927 The eruption of deciduous teeth among Hebrew infants. J. Dent. Res., 7: 245-253.

Bordes, F. 1968 The Old Stone Age. McGraw-Hill, New York.

Boutourline, E., and G. Tesi 1972 Deciduous tooth eruption in a region of Southern Tunisia. Hum. Biol., 44: 433-442.

Brabant, H., and A. Sahly 1964 Étude des dents néanderthaliennes découvertes dans la Grotte du Portel en Ariège. Bull. G. Int. Rech. Sc. Stomat., 7: 237-254.

Brace, C. L. 1962 Cultural factors in the evolution of the human dentition. In: Culture and the Evolution of Man. M. F. A. Montagu, ed. Oxford, New York, pp. 343-353.

1963 Structural reduction in evolution. Am. Natural., 97: $39-49$.

1964 The fate of the "Classic" Neanderthals: a consideration of hominid catastrophism. Cur. Anthrop. 5: 3-43; 7: 204-214.
1967 Tooth form and size in the Pleistocene. $J$

Dent. Res., 46: 809-816.

1968 Neandertal. Nat. Hist., 77(5): 38-45.

1975 Comment on: "Did La Ferrassie 1 use his teeth as a tool?" by J. A. Wallace. Cur. Anthrop. I6 396-397.

Brace, C. L., and P. E. Mahler 1971 Post-Pleistocene changes in the human dentition. Am. J. Phys. Anthrop., 34: $191-204$

Brose, D. S., and M. H. Wolpoff 1971 Early Upper Pleistocene man and late Middle Paleolithic tools. Am. Anthropol., 73: 1156-1194.

Butler, R. J. 1972 Age-related variability in ocelusal wear planes. Am. J. Phys. Anthrop., 36: 381-390.

Campbell, T. D. 1925 Dentition and palate of the Austra lian aboriginal. Hassell, Adelaide.

- 1939 Food food values, and food habits of the Australian aborigines in relation to their dental condi tions. Aust. J. Dent., 43: 1-15, 45-55, 73-87, 141-156, 177-198.

Campy, M., J. Chaline, C. Guérin, and B. Vandermeersch 1974 Une canine humaine associé à une faune Mindel récent dans le replissage de l'Aven de Vergranne (Doubs) C. R. Acad. Sci., Série D, 278: 3187-3190.

Carlson, H. 1944 Studies on the rate and amount of eruption of certain human teeth. Am. J. Orthodont. Oral. Surg., 30: 575-588

Cechová, L., and S. Titlbachová 1971 Attrition of teeth. In: Proceedings of the Czechslovak Academy of Sciences An thropological Congress dedicated to Ales Hrdlicka. V. V Novotny, ed. Czechslovak Academy of Sciences, Prague, pp. 395-404

Chagula, W. K. 1960 The age at eruption of third perma nent molarg in male East Africans. Am. J. Phys. An throp., 18: 77-82.

Clements, E. M. B., E. Davies-Thomas and K. G. Pickett 1953 Time of eruption of permanent teeth in British children. Brit. Med. J., 1: 1421-1424.

Coppens, Y. 1971 Les restes d'Hominidés des séries supérieures des formations plio-villafranchiennes de l'Omo en Ethiopie. C. R. Acad. Sci., Série D, 272: 36-39.

- 1973 Les restes d'Hominidées des séries supé rieures des formations plio-villafranchiennes de l'Omo en Ethiopie (récoltes 1970, 1971, et 1972). C. R. Acad. Sci., Série D, 276: 1981-1984.

Dahlberg, A. A., and R. M. Menegaz-Bock 1958 Emergence of the permanent teeth in Pima Indian children. J. Dent. Res., 37: 1123-1140.

David, P. 1960 Etude de 2 dents neanderthaliennes découvertes à la Chaise. Bull. Soc. Preh. Fr., 57: 424-427.

Day, M. H., R. E. F. Leakey, A. C. Walker and B. A. Wood 1976 New hominids from East Turkana, Kenya. Am. J Phys. Anthrop., 45: 369-436.

Duport, L., and C. Vandermeersch 1976 La mandibule moustérienne de Montgaudier. C. R. Acad. Sci., Série D. 238: 1161-1164.

Ennouchi, E. 1972 Nouvelle découverte d'un archanthropien au Maroc. C. R. Acad. Sci., Série D, 274: 3088-3090.

Eveleth, P. B. 1966 Eruption of permanent dentition and menarche of American children living in the tropics. Hum. Biol., 38: 60-70

Eveleth, P. B., and J. A. de Souza Freitas 1969 Tooth eruption and menarche of Brazilian-born children of Japanese ancestry. Hum. Biol., 41: 176-184.

Ferembach, D. 1962 La deuxieme molaire deciduale inferieure de la grotte de Salemas (Portugal). Com. Servs. Geol. Port., 46: 177-187.

Ferguson, A. D., R. B. Scott and H. Bakwin 1957 Growth and development of Negro children. VIII, comparison of 
the deciduous dentitions in Negros and White infants. J. Pediat., 50: 327-331.

Finney, D. J. 1952 Probit Analysis. Cambridge University, Cambridge.

Friedlaender, J. S., and H. L. Bailit 1969 Eruption times of the deciduous and permanent teeth of natives on Bougainville Island, Territory of New Guinea: a study of racial variation. Hum. Biol., 41: 51.65.

Gao, J. 1975 Australopithecine teeth associated with Gigantopithecus. Vertebr. Palasiat., 13: 81-88.

Garn, S. M., and K. Koski 1957 Tooth eruption sequence in recent and fossil man. Nature, 180: 442-443.

Garn, S. M., K. Koski and A. B. Lewis 1957 Problems in determining tooth eruption sequence in fossil and recent man. Am. J. Phys. Anthrop., 15: 313-331.

Garn, S. M., and A. B. Lewis 1957 Relationship between the sequence of calcification and the sequence of eruption of the mandibular molar and premolar teeth. J. Dent. Res., 36: $992-995$.

Garn, S. M., A. B. Lewis and R. S. Kerewsky 1963 Molar size sequences and fossil taxonomy. Science, 142: 1060.

1965 Genetic, nutritional, and maturational correlates of dental development. J. Dent. Res., 44 : 228-242.

Garn, S. M., A. B. Lewis and D. L. Polacheck 1959 Vari ability of tooth formation. J. Dent. Res., 38: 135-148. 1960 Sibling similarities in dental developmen tal. J. Dent. Res., 39: 170-175.

Garn, S. M., J. M. Nagy, S. T. Sandusky and F. Trowbridge 1973 Economic impact on tooth emergence. Am. J. Phys. Anthrop., 39: 233.238.

Garn, S. M., and A. L. Russell 1971 The effect of nutritional extremes on dental development. Am. J. Clin. Nutr., 24. 285-286.

Garn, S. M., F. Wertheimer, S. T. Sandusky and M. B. McCann 1972 Advanced tooth emergence in Negro individuals. J. Dent. Res., 51: 1506.

Gates, R. E. 1966 Computation of the median age of eruption of permanent teeth using probit analysis and an electronic computer. J. Dent. Res., 45: 1024-1028.

Genet-Varcin, E. 1962 Evolution de la couronne de la second premolarie. Ann. Paleont., 48: 59-82.

- 1966 Etude des dents permanentes prouvenant du Gisement Mousterien de la Croze del Dua. Ann. Paleont. Vert., 52: 89-114.

1974 Etude de dents humaines isolées prove nant des Grottes de La Chaise de Vouthon. I. Bull. Mém. Soc. Anthrop. Paris, Série 13, 1: 373-384.

Genovés, S. 1963 Estimation of age and mortality. In: Environment and Archaeology. D. Brothwell and E. Higgs, eds. Basic Books, New York, pp. 353-364.

Gorjanovic-Kramberger, D. 1901 Der Paläolische Mensch und sein Zeitgnossen aus dem Diluvium von Kra pina in Kroatien I. Mitt. Anthrop. Ges. Wien, 31: 164-197. 1902 Der Puläolische Mensch und sein Zeitgnossen aus dem Diluvium von Krapina in Kroatien II. Mitt. Anthrop. Ges. Wien, 32: 189-216.

1904 Der Paläolische Mensch und sein Zeitgnossen aus dem Diluvium von Krapina in Kroatien III. Mitt. Anthrop. Ges. Wien, 34: 187-199.

1905 Der Paläolische Mensch und sein Zeit. gnossen aus dem Diluvium von Krapina in Kroatien IV. Mitt. Anthrop. Ges. Wien, 35: 197-229.

1906 Der Diluviale Mensch von Krapina in Kroatien: ein Beitrag zur Paläoanthropologie. Weisbaden, Kriedel.

1907 Die Kronen und Wurzeln der Mahlzähne des Homo primigenisus und ihre genetische Bedeutung. Anat. Anz., 31: 97-138.
- 1908a Bemerkungen zu: Adloff: Die Zähne des Homo primigenius von Krapina. Anat. Anz., 32: 145-156. 1908b Uber prismatische Molarwurzehn re zenter und diuvialer Menschen. Anat. Anz., 32 401-413.

1909 Der vordere Unterkieferabschnitt des al tdiluvialen Menschen in seinem gennetischen Verhältnis zum Unterkiefer des rezenten Menschen und dem der Anthropoiden. Ein Beitrag zur Entwicklungsgeschichte des Menschen. Zeitschr. f. induktive Abstammungs- und Vererbungslehre, 12: 411-439.

1910 Die Verwandschaftlichen Beiziehungen zwischen dem Homo Heidelbergensis aus Maur und dem Homo primigenisus aus Krapina in Kroatien. Anat. Anz. 34: 359-364.

Greene, D. L. 1970 Environmental influences on Pleistocene hominid dental evolution. Biosci., 20: $276 \cdot 279$.

Hatton, M. E. 1955 A measure of the effects of heredity and environment on the eruption of the deciduous teeth. J. Dent. Res., 34: 397-401.

Hayes, R., and N. Mantel 1958 Procedure for computing the mean age of eruption of human teeth. J. Dent. Res. 37: $938-947$.

Heim, J. L. 1974 Les hommes fossiles de La Ferrassie (Dordogne) et le problème de la définition des Neandertaliens classiques. L'Anthrop., 78: 81-112, 321-378.

- 1976 Les hommes fossiles de Ia Ferrassie. I. Arch. Inst. Paleont. Hum. Mem., 35: 1-331.

Hellman, M. 1923 Nutrition, growth, and dentition. Dent. Cosmos, 65: 34-49.

1943 The phase of development concerned with erupting the permanent teeth. Am. J. Orthod. Oral. Surg., 29: $507-526$.

Henri-Martin, G. 1923 L'homme fossile de La Quina. Arch. Morph. Gén. Exp., 15: 1-253.

1926 Màchoire humaine moustérienne. L'Homme Préh., 13: 4-21.

Houpt, M. I., S. Adu-Aryee and S. Grainger 1967 Eruption times of permanent teeth in the Brong Ahafo region of Ghana. Am. J. Orthodont., 53: 95-99.

Howell, F. C. 1960 European and Northwest African Middle Pleistocene hominids. Cur. Anthrop., 1: 195-232.

Hrdlička, A. 1923 Variations in the dimensions of the lower molars in man and anthropoid apes. Am. J. Phys. Anthrop., 6: 423-438.

1924 New data on the teeth of early man and certain European fossil apes. Am. J. Phys. Anthrop., 7: 109-137.

1930 The skeletal remains of early man. Smithsonian Miscellaneous Collections, Volume 83

Hunt, E. E. 1961 Malocclusion and civilization. Am. J. Orthodont., 47: 406-422.

Hurme, V. O. 1948 Standards of variation in the erup tion of the first six permanent teeth. Child Dev., 19. 213-231.

Isaac, G. L. 1972 Chronology and the tempo change during the Pleistocene. In: Calibration of Hominoid Evolution. W. W. Bishop and J. A. Miller, eds. Scottish Academic Press, University of Toronto Press, Edinburgh, pp. $381-430$.

Jacob, T. 1973 Paleoanthropological discoveries in Indonesia with special reference to the finds of the last two decades. J. Hum. Ev., 2; 473-486.

James, W. W., and A. T. Pitts 1912 Some notes on the ages of eruption in 4,850 children aged under 12 . Proc. Roy. Soc. Med., Odontol., Sec., 5: 80-101.

Johanson, D. C., and M. Taieb 1976 Plio-Pleistocene hominid discoveries in Hadar, Ethiopia. Nature, 260: 293-297. 
Kallay, J. 1949 Einige Besonderheiten der Premolaren bei Homo diluvialis e Krapina. Fol. Stomatol, 2: 25-36. 1955 Krapina Unterkeifer I und Paradentose im Pleistozän. Ostr. Zeitschr. Stomatol., 2: 57-63.

1969 Two sets of upper incisors of two Neandertalers from Krapina. Bull. Scient., 14: 71-72.

1970 Osobitosti Zubi Krapinskih Neander talaca. In: Krapina 1899-1969. M. Malez, ed. Jugosiavenske Akademije Znanosti i Unjetnosti, Zagreb, pp. 165-174.

Kamalanathan, G. S., H. M. Hauck and C. Kottiveja 1960 Dental development of children in a Siamese village, Bang Chan, 1953. J. Dent. Res., 39: 455 461 .

Keith, A. 1912 Description of the teeth of the Paleolithic man from Jersey. J. Anat. Physiol., 46: 12-27.

Keyfitz, N., and W. Flieger 1971 Population Facts and Methods of Demography. Freeman, San Francisco.

Klein, H., C. E. Palmer and M. Kramer 1938 Studies in den tal caries II. The use of the normal curve of expressing the age distribution of eruption of the permanent teeth Growth, 1: 385-394.

von Koenigswald, G. H. R. 1957 Remarks on Gigantopithecus and other hominid remains from Southern China. Konink. Akad. Wet. Amst., Series B, 60: 153-159. von Koenigswald, G. H. R., and F. Weidenreich 1939 The re lationship between Pithecanthropus and Sinanthropus. Nature, 144: 926-929.

Kolossov, Yu. G., V. M. Kharitonov and V. P. Yakimov 1975 Palaeoanthropic specimens from the site Zaskalnaya VI in the Crimea. In: Paleoanthropology. Morphology and Paleoecology. R. H. Tuttle, ed. Mouton, The Hague, pp. 419-428.

Koski, K., and S. M. Garn 1957 Tooth eruption sequence in fossil and modern man. Am. J. Phys. Anthrop., 15: 469-488.

Kronfeld, R. 1954 Development and calcification of the human deciduous and permanent dentition. In: Basic Readings on the Identification of Human Skeletons. T. D. Stewart and M. Trotter, eds. Wenner-Gren Foundation, New York, pp. 3-10.

Krumholt, L., B. Roed-Petersen and J. J. Pindborg 1971 Eruption times in the permanent teeth in 622 Ugandan children. Arch. Oral Biol., 16: 1281-1288

Kurtén, B. 1957 A case of Darwinian selection in bears. Evol, 11: 412-416.

Lavelle, C. L. B, 1970 Analysis of attrition in adult human molars. J. Dent. Res., 49: 822-828.

Lee, M. M. C., W. D. Low and K. S. F. Chang 1965 Eruption of the permanent dentition of Southern Chinese children in Hong Kong. Arch. Oral Biol., 10: 849-861.

Legoux, P. 1966 Détermination de l'age dentaire de fossiles de la ligneé humaine. Librairie Maloine. Société Anonyme d'Éditions Medicales et Scientifiques, Paris.

Leroi-Gourhan, A. 1958 Étude des restes humains fossiles prouvenant des Grottes d'Arcy-sur-Cure. Ann. Paléont., 44: 87-148.

Lewis, A. B., and S. M. Garn 1960 The relationship between tooth formation and other maturational factors. Angle Orthod., 30: 70-77.

Lewontin, R. C. 1966 On the measurement of relative variability. Syst. Zool., 15: 141-142.

Lous, I. 1970 The masticatory system as a tool. Dent. Abstr., 15: 457-458.

de Lumley, H., and M.-A. de Lumley 1971 Découverte de restes humains anténéandertaliens datés du debút Riss à la Caure de l'Arago (Tautaval, Pyrénées -Orientales). C. R. Acad. Sci., Série D, 272: 1739-1742.

de Lumley, M.A. 1972 Les Néandertaliens de la grotte de l'Hortus. Et. Quaternaires, Mém., 1: 375-385.

de Lumley, M.-A., and J. Piveteau 1969 Les restes humains de la grotte du Lazaret (Nice, Alpes-Maritimes), Mém. Soc. Préh. Fr., 7; 223-232.

MacKay, D. H., and W. J. Martin 1952 Dentition and phy. sique of Bantu children. J. Trop. Med., 55: 265-275.

Malez, M. 1970 A new look at the stratigraphy of the Krapina prehistoric site. In: Krapina 1899-1969. M. Malez, ed. Jugoslavenske Akademije Znanosti i Umjetnosti, Zagreb, pp. 13-44.

Mann, A. 1975 Paleodemographic aspects of the South African Australopithecines. University of Pennsylvania Publications in Anthropology Number 1, Philadelphia.

McKinley, K. 1971 Survivorship in gracile and robust australopithecines: a demographic comparison and a proposed birth model. Am. J. Phys. Anthrop., 34: 417-426.

Meredith, H. V. 1946 Order and age of eruption for the deciduous dentition. I. Dent. Res., 25; 43-66.

Miles, A. E. W. 1963 The dentition in the assessment of individual age in skeletal material. In: Dental Anthropology. D. R. Brothwell, ed. Pergamon, Oxford, pp. 191-209.

Møller, I. J. 1965 Dental Fluorosis and Caries. International Science publishers, Copenhagen.

Molnar, S. 1971a Human tooth wear, tooth function, and cultural variability. Am. J. Phys. Anthrop., 34: 175-190. $1971 \mathrm{~b}$ Sex, age, and tooth position as factors in the production of tooth wear. Am. Antiq., 36: 182-188.

Moore, J. A., A. C. Swedlund and G. J. Armelagos 1975 The use of life tables in paleodemography. Am. Antiq., $40(2$ part 2): $57-70$.

Moorrees, C. F. A. 1957 The Aleut Dentition. Harvard University, Cambridge.

Morris, D. H. 1966 Morphological analysis and age in the permanent dentitions of young American Indians. Am. J. Phys. Anthrop., 25: 91-96.

Murphy, T. 1959 Gradients of dentine exposure in human molar tooth attrition. Am. J. Phys. Anthrop., 17 179-186.

1964 The relationship between attritional facets and occlusal plane in aboriginal Australians. Arch Oral Biol., 9: 269-280.

Neel, J. V., and K. M. Weiss 1975 The genetic structure of a tribal population, the Yanomama Indians. XII Biodemographic Studies. Am. J. Phys. Anthrop., 42. 25-52.

Okladnikov, A. P., et al. 1949 Teshik-Tash: Paleolithicheskii Chelovek. Trudy Nauchno-Issledovatelskogo Instituta Anthropologii, Moscow.

Palma di Cesnola, A., and P. Messeri 1967 Quatre dents humaines Paléolithiques Trouvées dans des cavernes de l'Italie Meridionale. L'Anth., 71: 249-261.

Panek, S. 1965 Eruption of the permanent teeth in Egyptian children and youth. Pub. Joint Arabic-Polish Anthropol. Exp., 2: 189-199.

Patte, E. 1957 L'Enfant Néanderthalien du Pech de L'Aze. Masson, Paris.

1960 Découverte d'un néandertalien dans la Vienne. L'Anthrop., 64: 512-517.

1962 La Dentition des Neanderthaliens. Masson et Cie, Paris.

Perzigian, A.J. 1975 Natural selection on the dentition of an Arikara population. Am. J. Phys. Anthrop., 42: 63-70.

Piveteau, J. 1951 Restes humains de la Grotte de la Verrerie a Macassargues (Gard). Ann. Paleont., 37: 175-183. 1957 Traité de Paléontologie. Vol. 7, Les Primates et l'Homme. Masson, Paris.

1964 La grotte de Regourdou (II). Ann. Paléont. (Vertébr.), 50: 155-194.

Rhoads, T. F., M. Rappaport, R. Kennedy and J. Stokes 1945 Studies on the growth and development of male children receiving evaporated milk. II. Physical growth, dentition, 
and intelligence of White and Negro children through the first four years as influenced by vitamin supplements. J. Pediat., 26: 415-454.

Richardson, A., S. Akpata, J. Ana and R. Franklin 1976 A comparison of tooth eruption ages in European and West African children. Trans. Eur. Orthod. Soc., 1975: 161-167.

Roginskij, Y. 1954 Morphological features of the skull of the child from the late Mousterian level of the cave of Staroselje. Sov. Etnogr., 1: 27-41.

Sandler, H. C. 1944 The eruption of the deciduous teeth. J. Paediat., 25: 104-147.

Sausse, F. 1975 La mandibule Atlanthropienne de la Carrière Thomas I (Casablanca). L'Anthrop., 79: 81-112.

Schour, I., and B. G. Sarnat 1942 Oral manifestations of occupational origins. J. Am. Med. Assoc., 120: 1197-1201.

Selmer-Olsen, R. 1949 An odontometric study of the Norwegian Lapps. Skift. Nor. Videnskaps-Akad. I (Oslo), Mathematisk-Naturvidensk. Kl, 65: 1-168.

Short, E. M. 1944 Domestic water and dental caries VI. The relation of fluoride domestic waters to permanent tooth eruption. J. Dent. Res., 23: 247-255.

Shourie, K. L. 1946 Eruption age of teeth in India. Ind. J. Med. Res., 34: 105-118.

Siffre, A. 1908 Etude des dents humaines du Petit. Puymoyen. Rev. Ec. D'Anthrop., 18: 66-72.

Smith, F. E. 1954 Quantitative aspects of population growth. In: Dynamics of Growth Processes. E. J. Boell, ed. Princeton University Press, Princeton, pp. 277-294.

Smith, F. H. 1976 The Neandertal Remains from Krapina. A Descriptive and Comparative Study. The University of Tennessee Report of Investigations Number 15, Knoxville.

Steggerda, M., and T. J. Hill 1942 Eruption time of teeth among Whites, Negroes and Indians. Am. J. Orthodont., 28: $361-370$.

Suk, V. 1919 Eruption and decay of permanent teeth in Whites and Negroes. Am. J. Phys. Anthrop., 2: 351-388.

de Terra, M. 1903 Mitteilungen zum Krapina-Fund unter besonderer. Berücksichtigung der Zähne. Schw. Vjschr. F. Zahnh., 13: 11-13.

Török, G. 1962 Die Bewöhner von Halimba im 10. und 11. Jahrhundert. Ungar. Akad. Wissensch., Budapest. Archaeol. Hungar., 39: 1-169.

Trinkaus, E. 1975 The Neandertals from Krapina, northern Yugoslavia: an inventory of the lower limb remains. Z. Morph. Anthrop., 67: 44-59.

Twiesselmann, F. 1973 Evolution des dimensions et de la forme de la mandibule, du palais et des dents de l'homme. Ann. Paléont. (Vertébr.), 59: 173-277.

Vallois, H. 1952 Les restes humains du gisement Mousterien de Monsempron. Ann. Paleont., 38: 100-120. 11960 Vital statistics in prehistoric population as determined from archaeological data. In: The Application of Quantitative Methods in Archaeology. R. F. Heizer and S. F. Cook, eds. Viking Fund Publ. in Anthrop., 28: 181-222.

Van Valen, L. 1963 Selection in natural populations: Merychippus primus, a fossil horse. Nature, 197; 1181-1183.

-1965 Selection in natural populations. III. Measurement and estimation. Evol., 19: 514-528.
Vlček, E, 1969 Neandertaler der Tschechoslowakei. Prague: Verlag der Tschechoslowakischen Akademie die Wissenschaften, Prague.

Wallace, J. A. 1975 Did La Ferrassie 1 use his teeth as a tool? Cur. Anthrop., 16: 393-401.

1977 Gingival eruption sequences of permanent teeth in early hominids. Am. J. Phys. Anthrop., 46: 483-494.

Weidenreich, F. 1937 The dentition of Sinanthropus pekinensis: a comparative odontography of the hominids Paleont. Sinica, New Series D, 1 (Whole Series 101): 1-180.

- 1945 Giant early man from Java and South China. Anth. Pap. Am. Mus. Nat. Hist, 40: 1-134.

Weinert, H. 1925 Der Schädel des eiszeitlichen Menschen von Le Moustier. Springer, Berlin.

Weiss, K. M. 1973 Demographic Models for Anthropology. Mem. Soc. Am. Anthrop. 27.

1975 Demographic disturbance and the use of life tables in anthropology. Am. Antiq., 40 (2, part 2): 46-56.

White, T. D. 1977 New fossil hominids from Laetolil Tanzania. Am. J. Phys. Anthrop., 46: 197-230.

Wolpoff, M. H. 1969 The effect of mutations under conditions of reduced selection. Soc. Biol., 16: 11-23.

- 1971a Metric Trends in Hominid Dental Evolution. Case Western Reserve Studies in Anthropology 2. Case Western Reserve University, Cleveland.

- 1971b Interstitial wear. Am. J. Phys. Anthrop., 34: 205-228.

1975a Some aspects of human mandibular evolution. In: Determinants of Mandibular Form and Growth. J. A. McNamara, Jr., ed. Center for Human Growth and Development, University of Michigan, Ann Arbor, pp. 1-64.

1975b Comment on: "Did La Ferrassie I use his teeth as a tool?" by J. A. Wallace. Cur. Anthrop., 16: 399. 1975 c Dental reduction and the probable mutation effect. Am. J. Phys. Anthrop., 43: 307-308. 1976a Some aspects of the evolution of early hominid sexual dimorphism. Cur. Anthrop., 17: 579-606. 1976b Primate models for australopithecine sexual dimorphism. Am. J. Phys. Anthrop., 45: 497-510. $1976 \mathrm{c}$ Evolutionary aspects of hominid tooth size reduction and early hominid dental variation. In: Les Plus Anciens Hominidés. P. V. Tobias and Y. Coppens, eds. CNRS, Paris, pp. 318-406.

Woo, J.-K. 1956 Human fossils found in China and their significance in human evolution. Scient. Sinica, 5: 389-398.

1964 Mandible of the Sinanthropus-type discovered at Lantian, Shensi. Vertebr. Palasiat., 8: 1-12.

Woo, J.-K., and L.-P. Chia 1954 New discoveries about Sinanthropus Pekinensis in Choukoutien. Scient. Sinica, 3: $335-358$.

Woo, J.-K, and T.-K. Chao 1959 New discovery of Sinanthropus mandible from Choukoutien. Vertebr. Palusiat., 3: 169-172.

Yun, J. D. 1957 Eruption of primary teeth in Korean rural children. Am. J. Phys. Anthrop.; 15: 261-268. 
APPENDIX 1

Catalog of the isolated Krapina teeth and dental fragments by the new numbering. The information presented includes the original box (br) association and the number within the box when known. The author's tooth identification and side are followed by length and breadth measurements and the estimated age at death. Associations refer to the original maxillas and mandibles (APPENDIX 2) or the newly associated dental sets (table 2)

\begin{tabular}{|c|c|c|c|c|c|c|c|c|}
\hline \multirow{3}{*}{$\begin{array}{c}\begin{array}{c}\text { New } \\
\text { number }\end{array} \\
1\end{array}$} & \multicolumn{2}{|c|}{$\begin{array}{c}\text { Old } \\
\text { designation }\end{array}$} & & & \multirow[b]{2}{*}{ Length } & \multirow[b]{2}{*}{ Breadth } & \multirow{2}{*}{$\begin{array}{l}\text { Estimated } \\
\text { age }\end{array}$} & \multirow{2}{*}{$\begin{array}{l}\text { Associated } \\
\text { with }\end{array}$} \\
\hline & $\mathrm{Br}$ & No & \multicolumn{2}{|c|}{$\begin{array}{l}\text { Tooth and } \\
\text { side }\end{array}$} & & & & \\
\hline & 96 & 1 & $\mathbf{M}_{2}$ & $\mathrm{R}$ & 13.9 & 12.4 & 16 & $\mathbf{L}_{1}$ \\
\hline 2 & 96 & 2 & $\mathbf{M}_{2}$ & $\mathbf{R}$ & 12.3 & 11.5 & 20 & $\mathrm{~N}_{1}$ \\
\hline 3 & 96 & 3 & $\mathbf{M}_{2}$ & L & 12.65 & 11.3 & 19 & $\mathbf{M}_{1}$ \\
\hline 4 & 96 & 4 & $M_{3}$ & L & 12.1 & 10.6 & 26 & $\mathrm{~K}_{\mathrm{I}}=$ Ramus 60 \\
\hline 5 & 96 & 5 & $\mathbf{M}_{3}$ & $\mathrm{~L}$ & 12.35 & 11.4 & 19 & $\mathbf{M}_{i}$ \\
\hline 6 & 96 & 6 & $\mathbf{M}_{2}$ & L & 12.35 & 11.0 & 12 & \\
\hline 7 & 96 & 7 & $\mathbf{M}_{3}$ & $\mathbf{R}$ & 12.25 & 10.0 & 16 & $\mathbf{L}_{1}$ \\
\hline 8 & 96 & 8 & $\mathbf{M}_{3}$ & $\mathrm{R}$ & 13.9 & 11.2 & 18 & \\
\hline 9 & 96 & 9 & $\mathbf{M}_{3}$ & L & 11.7 & 10.7 & 20 & \\
\hline 10 & 96 & 10 & $\mathrm{M}_{2}$ & $\mathbf{R}$ & 13.3 & 11,65 & 15 & $\mathbf{E}_{1}$ \\
\hline 11 & 79 & & $\mathrm{dI}_{2}$ & R & 6.0 & & 5 & \\
\hline 12 & 79 & & $\mathrm{dI}^{2}$ & $\mathbf{R}$ & 7.4 & 5.8 & 8 & $\mathrm{~A}^{1}$ \\
\hline 13 & 79 & & $\mathrm{dI}_{2}$ & L & 5.8 & 5.1 & 7 & $\mathbf{P}_{1}$ \\
\hline 14 & 79 & & $\mathrm{dI}^{2}$ & $\mathrm{R}$ & 6.9 & 6.25 & 4 & $G^{1}$ \\
\hline 15 & 79 & & $\mathrm{dI}^{2}$ & $\mathrm{~L}$ & 6.75 & 6.25 & 4 & $\mathrm{G}^{\mathrm{i}}$ \\
\hline 16 & 79 & & $\mathrm{dI}_{2}$ & $\overline{\mathbf{R}}$ & 5.65 & 5.0 & 4 & \\
\hline 17 & 79 & & $\mathrm{dI}^{\mathrm{I}}$ & L & 8.6 & 6.9 & 4 & $\mathrm{G}^{1}$ \\
\hline 18 & 79 & & $\mathrm{dI}_{1}$ & $\bar{L}$ & 5.3 & 4.9 & 7 & $P_{1}$ \\
\hline 19 & 79 & & Roo & $\mathrm{rag}$ & & & & \\
\hline 20 & 79 & & Roo & rag & & & & \\
\hline 21 & 79 & & $\mathrm{dI}^{\prime}$ & $\mathbf{R}$ & 8.6 & 6.75 & 4 & $\mathrm{G}^{\prime}$ \\
\hline 22 & 80 & & $\mathrm{dC}_{\mathrm{I}}$ & $\mathrm{L}$ & 7.2 & 5.9 & 6 & $A_{1}$ \\
\hline 23 & 80 & & $\mathrm{dC}^{\mathrm{i}}$ & L & 8.35 & 7.3 & 4 & $G^{2}$ \\
\hline 24 & 80 & & $\mathrm{dC}^{\prime}$ & $\mathrm{R}$ & 7.75 & 6.65 & 3 & $\mathbf{R}^{\prime}$ \\
\hline 25 & 92.1 & 1 & $P_{3}$ & $\mathrm{R}$ & 9.0 & 9.9 & 16 & $\mathrm{~L}_{1}$ \\
\hline 26 & 92.1 & 7 & $\mathrm{P}_{4}$ & $\mathbf{R}$ & 8.3 & 8.8 & 12 & \\
\hline 27 & 92.1 & 5 & $P_{3}$ & $\mathrm{~L}$ & 9.2 & 10.2 & 16 & $\mathrm{~L}_{1}$ \\
\hline 28 & 92.1 & 2 & $P_{3}$ & $\mathbf{R}$ & 8.15 & 9.2 & 20 & \\
\hline 29 & 92.1 & 6 & $\mathbf{P}_{3}$ & $\mathbf{R}$ & 8.4 & 8.85 & 17 & \\
\hline 30 & 92.1 & 4 & $P_{4}$ & $\mathbf{R}$ & 8.5 & 9.9 & 16 & $\mathrm{~L}_{1}$ \\
\hline 31 & 92.1 & 3 & $P_{4}$ & $\mathbf{R}$ & 7.85 & 9.7 & 20 & $\mathrm{~N}_{1}$ \\
\hline 32 & 92.1 & 8 & $P_{4}$ & $\mathrm{~L}$ & 9.4 & 9.2 & 19 & $\mathbf{M}_{2}$ \\
\hline 33 & 92.1 & 9 & $P_{3}$ & L & 8.0 & 9.1 & 11 & \\
\hline 34 & 92.1 & 12 & $\mathbf{P}_{3}$ & $\mathbf{R}$ & 8.5 & 9.6 & 15 & \\
\hline 35 & 92.1 & $1 \overline{1}$ & $P_{4}$ & $\mathbf{R}$ & 7.8 & 10.05 & 18 & \\
\hline 36 & 91 & 3 & $\mathrm{C}^{\mathrm{i}}$ & $\mathbf{R}$ & 8.5 & 11.1 & 20 & $\mathbf{N}^{1}$ \\
\hline 37 & 91 & & $\mathrm{C}^{\mathrm{I}}$ & L & 9.8 & 10.9 & 15 & \\
\hline 38 & 92.2 & 3 & $\mathrm{P}^{3}$ & $\mathrm{R}$ & 8.3 & 11.5 & 20 & $\mathbf{N}^{1}$ \\
\hline 39 & 92.2 & 21 & $\mathrm{P}^{3}$ & $\mathbf{R}$ & 8.25 & 11.5 & 14 & \\
\hline 40 & 92.2 & 15 & $\mathrm{P}^{4}$ & $\mathrm{~L}$ & 8.2 & & 21 & \\
\hline 41 & 92.2 & 13 & $\mathrm{P}^{4}$ & L & 8.8 & 11.7 & 16 & $\mathrm{~J}^{\prime}$ \\
\hline 42 & 92.2 & 9 & $P^{4}$ & $\mathbf{R}$ & 7.4 & 10.5 & 14 & \\
\hline 43 & 92.2 & 14 & $P^{4}$ & $\mathrm{R}$ & 8.7 & 11.3 & 17 & \\
\hline 44 & 92.2 & 10 & $\mathbf{P}^{4}$ & $\mathbf{R}$ & 8.1 & 10.8 & 12 & \\
\hline 45 & 92.2 & 12 & $\mathbf{P}^{3}$ & $\mathrm{~L}$ & 8.2 & 11.15 & 23 & $F^{2}$ \\
\hline 46 & 92.2 & 11 & $\mathrm{P}^{4}$ & $\mathbf{R}$ & 8.45 & 11.0 & 17 & $\mathbf{M}^{1}$ \\
\hline 47 & 92.2 & 8 & $\mathrm{P}^{4}$ & $\mathrm{R}$ & 6.8 & 10.35 & 20 & $\mathbf{N}^{\mathrm{T}}$ \\
\hline 48 & 92.2 & 6 & $\mathrm{P}^{3}$ & $\mathbf{R}$ & 8.2 & 11.0 & 23 & $\mathrm{~F}^{2}$ \\
\hline 49 & 92.2 & 16 & $\mathrm{P}^{4}$ & $\mathrm{~L}$ & 7.6 & 10.5 & 23 & $\mathrm{~F}^{\mathrm{I}}$ \\
\hline 50 & 92.1 & 15 & $\mathbf{P}_{4}$ & L & 7.5 & 9.0 & 11 & \\
\hline 51 & 92.2 & 5 & $P^{3}$ & $\mathrm{R}$ & 8.5 & & 16 & \\
\hline 52 & 92.2 & 7 & $\mathbf{P}^{4}$ & L & 8.3 & 11.4 & 16 & \\
\hline 53 & 92.2 & 18 & $\mathbf{P}^{3}$ & $\mathrm{R}$ & 9.3 & 11.55 & 11 & $\mathrm{C}^{\prime}$ \\
\hline 54 & 92.2 & 1 & $\mathbf{p}^{3}$ & $\mathrm{~L}$ & 9.2 & 11.9 & 17 & $\mathbf{M}^{1}$ \\
\hline 55 & 92.2 & 17 & $\mathrm{P}^{3}$ & $\mathrm{R}$ & 9.2 & 11.7 & 17 & $\mathbf{M}^{1}$ \\
\hline 56 & 86 & 4 & $\mathrm{C}^{1}$ & $\mathrm{R}$ & 9.1 & 10.25 & 17 & $\mathbf{M}^{1}$ \\
\hline 57 & 86 & & $\mathrm{I}^{2}$ & $\mathrm{R}$ & 8.35 & 8.7 & 17 & $\mathbf{M}^{1}$ \\
\hline 58 & 95 & & $\mathbf{M}^{3}$ & $\mathbf{R}$ & 10.8 & 13.2 & 19 & \\
\hline 59 & 91 & 1 & $\mathrm{C}_{1}$ & $\mathbf{R}$ & 8.0 & 9.0 & 27 & $\mathrm{O}_{1}$ \\
\hline 60 & 90 & 6 & $\mathrm{I}_{2}$ & $\mathbf{R}$ & 6.1 & 8.8 & 27 & $\mathrm{O}_{2}$ \\
\hline 61 & 90 & & & & & & & \\
\hline 62 & 84 & & $\mathrm{dM}_{2}$ & $\mathrm{~L}$ & 9.85 & 8.65 & 8 & $\mathrm{~B}_{1}$ \\
\hline 63 & 84 & & $\mathrm{dM}_{2}$ & $\mathrm{~L}$ & 11.5 & 10.05 & 9 & $Q_{1}$ \\
\hline 64 & 84 & & $\mathrm{dM}_{2}$ & L & 10.1 & 9.1 & 7 & $P_{1}$ \\
\hline 65 & 84 & & $\mathrm{dM}_{2}$ & $\mathrm{~L}$ & 10.9 & 9.4 & 4 & \\
\hline & 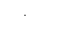 & & & & atinued) & & & \\
\hline
\end{tabular}


APPENDIX 1 (Continued)

Catalog of the isolated Krapina teeth and dental fragments by the new numbering. The information presented includes the original box (br) association and the number within the box when known. The author's tooth identification and side are followed by length and breadth measurements and the estimated age at death. Associations refer to the original maxillas and mandibles (APPENDIX 2) or the newly associated dental sets (table 2)

\begin{tabular}{|c|c|c|c|c|c|c|c|c|}
\hline \multirow{3}{*}{$\begin{array}{c}\begin{array}{c}\text { New } \\
\text { number }\end{array} \\
66\end{array}$} & \multicolumn{2}{|c|}{$\begin{array}{c}\text { Old } \\
\text { designation }\end{array}$} & \multirow{2}{*}{\multicolumn{2}{|c|}{$\begin{array}{l}\text { Tooth and } \\
\text { side }\end{array}$}} & \multirow[b]{2}{*}{ Length } & \multirow[b]{2}{*}{ Breadth } & \multirow{2}{*}{$\begin{array}{c}\text { Estimated } \\
\text { age }\end{array}$} & \multirow{2}{*}{$\begin{array}{l}\text { Associated } \\
\text { with }\end{array}$} \\
\hline & $\mathrm{Br}$ & No & & & & & & \\
\hline & 84 & & $\mathrm{dM}_{2}$ & $\mathrm{~L}$ & 10.65 & 10.0 & 11 & $\mathrm{C}_{1}$ \\
\hline 67 & 83 & & $\mathrm{dM}_{1}$ & $\mathrm{~L}$ & 9.8 & 7.9 & 7 & $P_{1}$ \\
\hline 68 & 84 & & $\mathrm{dM}_{2}$ & $R$ & 11.4 & 9.9 & 3 & \\
\hline 69 & 90 & 1 & $\mathrm{I}_{2}$ & $\mathrm{~L}$ & 7.5 & 8.2 & 16 & $\mathrm{~L}_{1}$ \\
\hline 70 & 90 & 3 & $I_{1}$ & $\bar{R}$ & 6.2 & 8.0 & 16 & $L_{1}$ \\
\hline 71 & 90 & 2 & $\mathrm{I}_{2}$ & $\mathrm{R}$ & 7.5 & 8.1 & 16 & $\mathrm{~L}_{1}$ \\
\hline 72 & 90 & & $I_{1}$ & $\mathrm{~L}$ & 6.25 & 8.0 & 16 & $\mathrm{~L}_{1}$ \\
\hline 73 & 90 & & $I_{1}$ & L & 6.3 & 8.15 & 11 & $\mathrm{C}_{1}$ \\
\hline 74 & 90 & 4 & $I_{1}$ & $\mathbf{R}$ & 5.95 & 6.75 & 8 & $\mathrm{~B}_{1}$ \\
\hline 75 & 91 & 2 & $\mathrm{C}_{1}$ & $\mathrm{R}$ & 8.5 & 9.3 & 12 & \\
\hline 76 & 91 & 16 & $\mathrm{C}^{1}$ & $\mathrm{R}$ & 9.4 & 9.5 & 15 & $\mathrm{I}^{1}$ \\
\hline 77 & 94 & 5 & $\mathbf{M}_{1}$ & $\mathbf{R}$ & 12.8 & 12.05 & 15 & $\mathbf{E}_{1}$ \\
\hline 78 & 94 & 10 & $\mathrm{M}_{3}$ & $\mathrm{~L}$ & 11.2 & 10.4 & 24 & Ramus 66 \\
\hline 79 & 94 & 4 & $M_{1}$ & $\mathrm{R}$ & 13.55 & 12.9 & 16 & $\mathrm{~L}_{\mathrm{I}}$ \\
\hline 80 & 94 & 7 & $\mathbf{M}_{1}$ & $\mathrm{R}$ & 12.7 & 11.5 & 10 & \\
\hline 81 & 94 & 1 & $\mathbf{M}_{1}$ & $\mathrm{~L}$ & 12.1 & 10.8 & 7 & $\mathbf{P}_{1}$ \\
\hline 82 & 94 & 2 & $\mathbf{M}_{1}$ & $\mathrm{~L}$ & 12.85 & 12.0 & 19 & $\mathbf{M}_{1}$ \\
\hline 83 & 94 & 6 & $\mathbf{M}_{2}$ & L & 11.5 & 9.8 & 15 & $\mathrm{D}_{1}$ \\
\hline 84 & 94 & 3 & $\mathbf{M}_{1}$ & $\vec{R}$ & 11.4 & 11.05 & 20 & $\mathrm{~N}_{1}$ \\
\hline 85 & 94 & 8 & $\mathbf{M}_{3}$ & $\mathrm{~L}$ & 12.9 & 9.8 & 16 & $\mathbf{L}_{1}$ \\
\hline 86 & 94 & 9 & $\mathbf{M}_{2}$ & $\mathrm{~L}$ & 13.1 & 11.1 & 16 & \\
\hline 87 & 94 & & Crow & frag & & & & \\
\hline 88 & 94 & & Crow & frag & & & & \\
\hline 89 & 86 & 6 & $\mathrm{C}^{1}$ & $\mathrm{R}$ & 9.0 & 9.5 & 8 & $A^{1}$ \\
\hline 90 & 85 & & $\mathbf{I}_{2}$ & L & 7.1 & 8.0 & 7 & \\
\hline 91 & 85 & 3 & $\mathrm{I}^{2}$ & $\mathbf{R}$ & 10.5 & 8.75 & 4 & $\mathbf{G}^{1}$ \\
\hline 92 & 85 & 1 & $\mathrm{I}^{1}$ & $\mathrm{R}$ & 10.9 & 9.4 & 14 & \\
\hline 93 & 85 & 4 & $\mathrm{I}^{1}$ & $\mathrm{~L}$ & 10.55 & 8.8 & 4 & $\mathrm{G}^{1}$ \\
\hline 94 & 85 & 2 & $\mathbf{I}^{1}$ & $\mathbf{R}$ & 9.6 & 8.1 & 6 & \\
\hline 95 & 85 & 6 & $\mathrm{I}^{2}$ & $\mathbf{R}$ & 8.2 & 6.0 & 4 & $\mathrm{G}^{1}$ \\
\hline 96 & 88 & & $\mathbf{M}^{2}$ & $\mathbf{R}$ & 11.1 & 13.0 & 7 & $\mathrm{~B}^{\mathrm{I}}$ \\
\hline 97 & 88 & & $\mathbf{M}^{2}$ & $\mathrm{~L}$ & 9.3 & 12.1 & 6 & \\
\hline 98 & 88 & & $\mathrm{M}^{2}$ & $\mathbf{R}$ & 10.1 & 11.65 & 8 & $\mathbf{A}^{1}$ \\
\hline 99 & 88 & 5 & $\mathrm{M}^{3}$ & $\mathrm{R}$ & 11.35 & 12.5 & 11 & \\
\hline 100 & 88 & 1 & $\mathbf{M}^{1}$ & $\mathbf{L}$ & 11.9 & 12.0 & 4 & \\
\hline 101 & 88 & 3 & $\mathbf{M}^{2}$ & L & 10.3 & 11.8 & 8 & $\mathrm{~A}^{1}$ \\
\hline 102 & 91 & & $\mathrm{C}^{\prime}$ & $\bar{L}$ & 9.8 & 11.0 & 20 & $\mathbf{N}^{1}$ \\
\hline 103 & 91 & 4 & $\mathrm{C}^{\mathrm{I}}$ & L & 8.8 & 9.8 & 11 & \\
\hline 104 & 89 & 2 & $\mathbf{M}_{1}$ & $\mathbf{R}$ & 10.8 & 10.4 & 3 & \\
\hline 105 & 89 & 1 & $\mathbf{M}_{1}$ & $\mathbf{R}$ & 13.6 & 12.5 & 3 & \\
\hline 106 & 89 & 4 & $\mathbf{M}_{3}$ & $\mathrm{~L}$ & 12.3 & 11.1 & 15 & $E_{1}$ \\
\hline 107 & 89 & 5 & $\mathbf{M}_{2}$ & $\overline{\mathrm{L}}$ & 14.0 & 12.2 & 12 & \\
\hline 108 & 89 & 3 & $\mathrm{M}_{3}$ & $\mathbf{R}$ & 12.85 & 10.9 & 15 & $\mathbf{E}_{1}$ \\
\hline 109 & 89 & 6 & $\mathbf{M}^{3}$ & $\mathbf{R}$ & 11.0 & 13.5 & 15 & \\
\hline 110 & 87 & & $\mathrm{P}^{3}$ & $\mathbf{R}$ & 8.7 & 11.5 & 6 & \\
\hline 111 & 87 & 1 & $\mathrm{P}_{3}$ & $\mathrm{~L}$ & 8.9 & 10.3 & 11 & $\mathrm{C}_{1}$ \\
\hline 112 & 87 & & $\mathrm{P}^{3}$ & $\mathrm{~L}$ & 8.0 & 10.55 & 8 & $\mathbf{A}^{1}$ \\
\hline 113 & 87 & 9 & $P_{4}$ & L & 8.75 & 9.2 & 6 & \\
\hline 114 & 87 & 7 & $\mathrm{P}_{3}$ & $\mathbf{L}$ & 8.2 & 9.4 & 8 & \\
\hline 115 & 87 & & $P^{4}$ & $\mathbf{R}$ & 7.9 & 10.7 & 8 & $\mathbf{A}^{1}$ \\
\hline 116 & 87 & & $\mathrm{P}^{3}$ & $\mathrm{R}$ & 8.1 & 10.65 & 8 & $\mathbf{A}^{1}$ \\
\hline 117 & 87 & 2 & $\mathrm{P}^{4}$ & $\mathrm{~L}$ & 7.7 & 10.75 & 8 & $\mathbf{A}^{1}$ \\
\hline 118 & 87 & 8 & $\mathrm{P}_{4}$ & $\mathrm{~L}$ & 8.5 & 9.5 & 8 & \\
\hline 119 & 86 & 3 & $\mathrm{C}_{1}$ & L & 8.75 & 10.3 & 11 & $C_{1}$ \\
\hline 120 & 86 & 2 & $\mathrm{C}_{1}$ & $\overline{\mathrm{L}}$ & 7.6 & 8.6 & 8 & $\mathrm{~B}_{1}$ \\
\hline 121 & 86 & 1 & $C_{1}$ & $\mathrm{~L}$ & 8.2 & 9.85 & 7 & \\
\hline 122 & 90 & 6 & $\mathrm{I}^{2}$ & $\bar{L}$ & 8.2 & 9.1 & 13 & $\mathrm{H}^{\prime}$ \\
\hline 123 & 90 & 8 & $I^{1}$ & I & 10.7 & 9.5 & 13 & $\mathrm{H}^{1}$ \\
\hline 124 & 90 & 10 & $\mathbf{I}^{2}$ & $\bar{R}$ & 8.9 & 8.2 & 16 & $\mathbf{E}^{1}$ \\
\hline 125 & 90 & 14 & $\mathrm{I}^{2}$ & $\mathrm{~L}$ & 8.8 & 9.5 & 23 & $F^{I}$ \\
\hline 126 & 90 & 12 & $\mathrm{I}^{2}$ & $\mathrm{R}$ & 9.25 & 8.1 & 10 & \\
\hline 127 & 90 & 16 & $I^{2}$ & $\mathbf{R}$ & 8.7 & 8.9 & 20 & $\mathrm{~N}^{1}$ \\
\hline 128 & 90 & 13 & $\mathrm{I}^{2}$ & $\mathrm{R}$ & 8.9 & 9.15 & 15 & $I^{i}$ \\
\hline 129 & 90 & 17 & $\mathrm{I}^{\mathrm{I}}$ & $\mathrm{R}$ & 10.9 & 9.7 & 20 & $\mathbf{N}^{1}$ \\
\hline & & & & & Continued) & & & \\
\hline
\end{tabular}


APPENDIX 1 (Continued)

Catalog of the isolated Krapina teeth and dental fragments by the new numbering. The information presented includes the original box (br) association and the number within the box when known. The author's tooth identification and side are followed by length and breadth measurements and the estimated age at death. Associa. tions refer to the original maxillas and mandibles (APPENDIX 2) or the newly associated dental sets (table 2)

\begin{tabular}{|c|c|c|c|c|c|c|c|c|}
\hline \multirow{3}{*}{$\begin{array}{c}\begin{array}{c}\text { New } \\
\text { number }\end{array} \\
130\end{array}$} & \multicolumn{2}{|c|}{$\begin{array}{c}\text { Old } \\
\text { designation }\end{array}$} & & & \multirow[b]{2}{*}{ Length } & \multirow[b]{2}{*}{ Breadth } & \multirow{2}{*}{$\begin{array}{l}\text { Estimated } \\
\text { age }\end{array}$} & \multirow{2}{*}{$\begin{array}{c}\text { Associated } \\
\text { with }\end{array}$} \\
\hline & $\mathrm{Br}$ & No & \multicolumn{2}{|c|}{$\begin{array}{l}\text { Tooth and } \\
\text { side }\end{array}$} & & & & \\
\hline & 90 & 20 & $\mathrm{I}^{2}$ & $\mathrm{R}$ & 7.4 & 7.75 & 10 & \\
\hline 131 & 90 & 11 & $\mathrm{I}^{2}$ & $\mathrm{R}$ & 8.2 & 9.7 & 10 & \\
\hline 132 & 90 & 19 & $\mathrm{I}^{i}$ & $\mathbf{R}$ & 10.0 & 8.8 & 19 & $Q^{\prime}$ \\
\hline 133 & 90 & 15 & $\mathrm{I}^{\mathrm{i}}$ & L & 9.6 & 9.0 & 23 & $\mathbf{F}^{1}$ \\
\hline 134 & 95 & 1 & $\mathbf{M}^{1}$ & $\mathbf{R}$ & 13.35 & 13.45 & 11 & $\mathrm{C}^{1}$ \\
\hline 135 & 95 & 4 & $\mathbf{M}^{2}$ & $\mathbf{L}$ & 12.2 & 14.2 & 16 & $\mathbf{J}^{\mathrm{I}}$ \\
\hline 136 & 95 & 2 & $\mathbf{M}^{1}$ & $\mathrm{~L}$ & 13.3 & 13.6 & 16 & $J^{1}$ \\
\hline 137 & 95 & 6 & $\mathbf{M}^{3}$ & $\mathrm{R}$ & 10.6 & & 19 & $\mathrm{P}^{\mathrm{I}}$ \\
\hline 138 & 91 & 5 & $\mathrm{C}_{1}$ & L & 8.6 & 10.1 & 16 & $\mathrm{~L}_{1}$ \\
\hline 139 & 91 & 12 & $\mathrm{C}^{\mathrm{l}}$ & L & 9.3 & 10.25 & 17 & $\mathbf{M}^{1}$ \\
\hline 140 & 91 & & $\mathrm{C}^{t}$ & $\mathbf{R}$ & 8.75 & 9.9 & 23 & $\mathbf{N}^{\prime}$ \\
\hline 141 & 91 & 10 & $\mathrm{C}^{\mathrm{T}}$ & $\mathrm{R}$ & 9.2 & 10.0 & 15 & $D^{t}$ \\
\hline 142 & 91 & 11 & $\mathrm{C}^{\mathrm{I}}$ & L & 9.3 & 10.0 & 23 & $\mathrm{~F}^{1}$ \\
\hline 143 & 91 & 8 & $\mathrm{C}_{1}$ & $\mathbf{R}$ & 8.7 & 9.75 & 16 & $\mathrm{~L}_{2}$ \\
\hline 144 & 91 & & $\mathrm{C}^{1}$ & $\mathrm{~L}$ & 10.0 & 11.4 & 22 & \\
\hline 145 & 91 & 13 & $\mathrm{C}_{1}$ & $\mathbf{R}$ & 7.8 & 9.8 & 20 & $\mathbf{N}_{1}$ \\
\hline 146 & 91 & 9 & $\mathrm{C}^{1}$ & $\mathbf{L}$ & 8.2 & 9.9 & 25 & \\
\hline 147 & 91 & 14 & $\mathrm{C}^{1}$ & $\overline{\mathbf{L}}$ & 9.6 & 10.7 & 18 & $\mathrm{~K}^{1}$ \\
\hline 148 & 90 & & $\mathrm{I}^{2}$ & $\mathbf{R}$ & 7.8 & 9.9 & 19 & $Q^{I}$ \\
\hline 149 & 97 & & Germ & & & & & \\
\hline 150 & 97 & & Germ & & & & & \\
\hline 151 & 97 & & Germ & & & & & \\
\hline 152 & 97 & & Germ & & & & & \\
\hline 153 & 90 & 3 & $\mathrm{I}^{2}$ & $\mathrm{R}$ & 8.1 & 8.5 & 15 & $\mathrm{D}^{1}$ \\
\hline 154 & 90 & 1 & $I^{I}$ & $R$ & 10.0 & 8.75 & 15 & $D^{1}$ \\
\hline 155 & 90 & 2 & $1^{1}$ & $\mathrm{~L}$ & 10.0 & 8.6 & 15 & $\mathrm{D}^{\mathrm{I}}$ \\
\hline 156 & 90 & 9 & $\mathrm{I}^{2}$ & L & 8.7 & 9.2 & 18 & $\mathbf{K}^{1}$ \\
\hline 157 & 90 & 18 & $\mathrm{I}^{\mathrm{t}}$ & $\vec{R}$ & 10.5 & 9.3 & 18 & $\mathbf{K}^{1}$ \\
\hline 158 & 90 & 6 & $\mathrm{I}^{\mathrm{t}}$ & L & 11.1 & 9.5 & 18 & $\mathrm{~K}^{1}$ \\
\hline 159 & 90 & 7 & $1^{2}$ & $\mathbf{R}$ & 8.3 & 8.8 & 18 & $\mathbf{K}^{1}$ \\
\hline 160 & 90 & 4 & $\mathrm{I}^{2}$ & $\mathrm{~L}$ & 8.4 & 8.75 & 15 & $\mathrm{D}^{1}$ \\
\hline 161 & 93 & $\mathrm{~g}$ & $\mathbf{M}^{1}$ & $\mathrm{~L}$ & 11.3 & 11.3 & 8 & $\mathrm{~A}^{1}$ \\
\hline 162 & 93 & 18 & $\mathbf{M}^{3}$ & $\mathbf{R}$ & 9.9 & 12.1 & 25 & $0^{I}$ \\
\hline 163 & 93 & 4 & $\mathbf{M}^{3}$ & $\mathbf{R}$ & 10.05 & 12.55 & 15 & $D^{1}$ \\
\hline 164 & 93 & 20 & $\mathbf{M}^{1}$ & L & 11.85 & 12.1 & 23 & $F^{1}$ \\
\hline 165 & 93 & 12 & $\mathbf{M}^{2}$ & $\mathrm{R}$ & 11.1 & 12.1 & 15 & $\mathrm{D}^{1}$ \\
\hline 166 & 93 & 1 & $\mathbf{M}^{\mathrm{I}}$ & $\mathrm{R}$ & 13.05 & 14.2 & 17 & $\mathrm{~L}^{\prime}$ \\
\hline 167 & 93 & 10 & $\mathbf{M}^{\mathrm{I}}$ & $\mathbf{R}$ & 12.0 & 12.1 & 17 & $\mathbf{M}^{\mathbf{3}}$ \\
\hline 168 & 93 & 8 & $\mathbf{M}_{\mathbf{1}}$ & $\mathrm{L}$ & 13.4 & 11.3 & 9 & $Q_{1}$ \\
\hline 169 & 93 & 11 & $\mathbf{M}^{2}$ & $\mathrm{R}$ & 11.2 & 12.9 & 17 & $\mathbf{M}^{1}$ \\
\hline 170 & 93 & 5 & $\mathbf{M}^{3}$ & $\mathrm{R}$ & 9.9 & 12.0 & 17 & $\mathbf{M}^{\mathbf{I}}$ \\
\hline 171 & 93 & 3 & $\mathbf{M}^{1}$ & $\mathbf{R}$ & 12.0 & 12.1 & 15 & $\mathrm{D}^{\mathrm{r}}$ \\
\hline 172 & 93 & 13 & $\mathbf{M}^{2}$ & $\mathrm{R}$ & 10.0 & 12.0 & 25 & $0^{\prime}$ \\
\hline 173 & 93 & 6 & $\mathbf{M}^{3}$ & $\mathrm{~L}$ & 9.8 & 11.65 & 23 & $F^{\prime}$ \\
\hline 174 & 93 & 15 & $\mathbf{M}^{!}$ & $\mathrm{R}$ & 11.5 & 11.5 & 8 & $\mathrm{~A}^{1}$ \\
\hline 175 & 93 & 16 & $\mathbf{M}^{2}$ & L & 10.35 & 12.6 & 23 & $F^{\mathrm{I}}$ \\
\hline 176 & 93 & 14 & $\mathbf{M}^{2}$ & $\mathrm{~L}$ & 10.4 & 13.3 & 19 & $P^{1}$ \\
\hline 177 & 93 & 2 & $\mathbf{M}^{2}$ & $\mathrm{R}$ & 13.1 & 13.1 & 17 & $\mathrm{~L}^{\mathrm{s}}$ \\
\hline 178 & 93 & 19 & $M^{s}$ & $\mathbf{R}$ & 9.95 & 12.8 & 17 & $\mathrm{~L}^{\mathrm{t}}$ \\
\hline 179 & 93 & 17 & $\mathbf{M}^{3}$ & L & 11.0 & & 19 & $\mathrm{P}^{\mathrm{I}}$ \\
\hline 180 & 93 & 7 & $\mathbf{M}^{3}$ & $\tilde{L}$ & 11.0 & 12.1 & 16 & \\
\hline 181 & 81 & 3 & $\mathrm{~d} \mathbf{M}^{2}$ & $\mathbf{R}$ & 7.4 & 9.4 & 3 & $\mathrm{R}^{1}$ \\
\hline 182 & 81 & 2 & $\mathrm{dM}^{\mathrm{t}}$ & $\mathbf{R}$ & & 9.0 & 8 & \\
\hline 183 & 81 & 1 & $\mathrm{~d} \mathbf{M}^{1}$ & L & 8.9 & 9.9 & 4 & $G^{1}$ \\
\hline 184 & 82 & & $\mathbf{M}^{\mathrm{T}}$ & $\mathrm{L}$ & & & 15 & \\
\hline 185 & 82 & 2 & $\mathrm{~d}^{\mathbf{M}^{2}}$ & L & 10.8 & 11.5 & 4 & $\mathrm{G}^{1}$ \\
\hline 186 & 82 & 1 & $\mathrm{dM}^{2}$ & $\mathrm{~L}$ & 10.1 & 10.4 & 3 & $\mathbf{R}^{1}$ \\
\hline 187 & 82 & 1 & $\mathrm{dM}^{2}$ & $\mathrm{R}$ & 9.1 & 9.9 & 8 & $\mathbf{A}^{1}$ \\
\hline 188 & 82 & 3 & $\mathrm{~d}^{2}{ }^{2}$ & $\mathbf{R}$ & 10.4 & 11.4 & 3 & \\
\hline 189 & 82 & 2 & $\mathrm{dM}^{2}$ & $\mathrm{R}$ & 11.1 & 11.35 & 11 & $\mathrm{C}^{1}$ \\
\hline 190 & 82 & 4 & $\mathbf{d M}^{2}$ & $\mathrm{R}$ & 10.05 & 10.3 & 3 & $\mathbf{R}^{1}$ \\
\hline 191 & $\begin{array}{l}\text { Incorre } \\
\mathrm{C} \text { maxi }\end{array}$ & $y$ in & $\mathrm{C}^{\mathrm{I}}$ & $\mathrm{L}$ & 8.9 & 10.6 & 6 & \\
\hline
\end{tabular}


APPENDIX 2

Catalog of in situ teeth, presented by the original letter designations and catalog number. Tooth identification, side, and length and breadth measurements were determined by the author as was the age at death estimate. The appendix also provides numbers of the additional teeth (if any) that have been associated with each jaw (APPENDIX 1)

\begin{tabular}{|c|c|c|c|c|c|c|c|}
\hline \multirow{3}{*}{$\begin{array}{c}\begin{array}{c}\text { Letter } \\
\text { designation } \\
\text { maxillas }\end{array} \\
\text { A }\end{array}$} & \multirow{3}{*}{$\begin{array}{c}\begin{array}{c}\text { Catalog } \\
\text { no. }\end{array} \\
45\end{array}$} & \multicolumn{2}{|c|}{$\begin{array}{l}\text { Tooth } \\
\text { and } \\
\text { side }\end{array}$} & \multirow{2}{*}{$\begin{array}{c}\text { Length } \\
7.95\end{array}$} & \multirow{2}{*}{$\frac{\text { Breadth }}{8.6}$} & \multirow{2}{*}{$\begin{array}{c}\begin{array}{c}\text { Estimated } \\
\text { age }\end{array} \\
8\end{array}$} & \multirow{3}{*}{$\begin{array}{l}\text { Additional associated teeth } \\
\begin{array}{l}161,187,12,89,98 \\
112,116,115,117,174,101\end{array}\end{array}$} \\
\hline & & $\mathrm{dM}^{1}$ & $\mathrm{~L}$ & & & & \\
\hline & & $\mathrm{dM}^{2}$ & $\mathrm{~L}$ & 9.6 & 10.1 & & \\
\hline \multirow[t]{12}{*}{$\mathbf{B}$} & 46 & $\mathbf{M}^{\prime}$ & $\mathrm{L}$ & 12.9 & 12.3 & 7 & 96 \\
\hline & & $\mathrm{M}^{1}$ & $\mathrm{R}$ & 12.45 & 12.1 & & \\
\hline & & $\mathbf{M}^{2}$ & & 10.8 & 12.8 & & \\
\hline & & $\mathrm{dI}^{\mathrm{I}}$ & $\mathrm{R}$ & 7.9 & 6.65 & & \\
\hline & & $\mathrm{dI}^{2}$ & $\mathrm{~L}$ & 7.1 & & & \\
\hline & & $\mathrm{dI}^{2}$ & $\mathbf{R}$ & 7.0 & 5.75 & & \\
\hline & & $\mathrm{dC}$ & $\mathbf{L}$ & 8.4 & 6.6 & & \\
\hline & & $\mathrm{dC}$ & $\mathrm{R}$ & 8.0 & 6.9 & & \\
\hline & & $\mathrm{dM}^{1}$ & $\mathbf{L}$ & 8.4 & 9.3 & & \\
\hline & & $\mathrm{dM}^{2}$ & $\mathrm{R}$ & 8.6 & & & \\
\hline & & $\mathrm{dM}^{2}$ & $\mathrm{~L}$ & 10.5 & 10.7 & & \\
\hline & & $\mathrm{dM}^{2}$ & $\mathbf{R}$ & 10.9 & 10.4 & & \\
\hline \multirow[t]{6}{*}{$\mathrm{C}$} & 47 & $\mathrm{I}^{1}$ & $\mathrm{~L}$ & 9.9 & 9.35 & 10 & $53,102,134,189$ \\
\hline & & $I^{i}$ & $\mathrm{R}$ & 10.1 & 9.35 & & \\
\hline & & $\mathrm{I}^{2}$ & $\mathbf{R}$ & 8.05 & 9.2 & & \\
\hline & & $\mathbf{M}^{\mathrm{I}}$ & $\mathbf{L}$ & 13.6 & 13.15 & & \\
\hline & & $\mathbf{M}^{2}$ & $\overline{\mathbf{L}}$ & 13.05 & 13.4 & & \\
\hline & & $\mathrm{dM}^{2}$ & $\mathbf{L}$ & 10.7 & 11.2 & & \\
\hline \multirow[t]{4}{*}{ D } & 48 & $\mathbf{p}^{3}$ & $\mathbf{L}$ & 8.6 & 11.3 & 15 & $141,153,154,155$ \\
\hline & & $\mathbf{P}^{4}$ & $\mathbf{L}$ & 8.35 & 11.2 & & $160,163,165,171$ \\
\hline & & $M^{1}$ & $\mathbf{L}$ & 11.9 & 12.3 & & \\
\hline & & $\mathbf{M}^{2}$ & $\mathrm{~L}$ & 11.5 & 12.3 & & \\
\hline \multirow[t]{6}{*}{$\mathrm{E}$} & 49 & $\mathbf{I}^{\mathrm{I}}$ & $\mathrm{L}$ & 9.5 & 8.1 & 16 & 124 \\
\hline & & $\mathbf{I}^{\mathrm{I}}$ & $\mathbf{R}$ & 10.0 & 8.3 & & \\
\hline & & $\mathbf{I}^{2}$ & $\mathrm{~L}$ & 8.5 & 8.4 & & \\
\hline & & $\mathrm{C}^{ \pm}$ & $\mathrm{L}$ & 9.3 & 9.55 & & \\
\hline & & $\mathbf{P}^{3}$ & $\mathrm{~L}$ & 8.2 & 10.25 & & \\
\hline & & $\mathrm{P}^{4}$ & L & 8.7 & 10.55 & & \\
\hline $\mathbf{F}$ & 50 & $\mathbf{I}^{1}$ & $\mathbf{R}$ & 9.4 & 8.9 & 23 & $45,48,49,125,133$ \\
\hline & & $\mathrm{I}^{2}$ & $\mathbf{R}$ & 8.7 & 9.25 & & $140,142,164,173,175$ \\
\hline \multicolumn{8}{|l|}{ Mandibles } \\
\hline \multirow[t]{2}{*}{$\mathbf{A}$} & 51 & $I_{1}$ & $\mathbf{R}$ & & 7.8 & 6 & 22 \\
\hline & & $\mathrm{dM}_{1}$ & $\mathrm{~L}$ & 9.5 & 8.2 & & \\
\hline \multirow[t]{5}{*}{$\mathbf{B}$} & 52 & $\mathrm{I}_{2}$ & $\mathbf{R}$ & 6.4 & 7.3 & 8 & $62,74,120$ \\
\hline & & $\mathrm{C}_{1}$ & $\mathrm{R}$ & & 8.5 & & \\
\hline & & $\mathbf{P}_{3}$ & $L$ & 8.0 & & & \\
\hline & & $\mathbf{M}_{1}$ & $\mathrm{~L}$ & 11.4 & 10.2 & & \\
\hline & & $\mathrm{dC}$ & $\mathrm{R}$ & 6.4 & 5.9 & & \\
\hline \multirow[t]{4}{*}{$\mathrm{C}$} & 53 & $\mathrm{I}_{2}$ & $\mathbf{L}$ & 7.5 & 8.75 & 11 & $66,73,111,119$ \\
\hline & & $\mathbf{M}_{1}$ & $\mathbf{R}$ & 12.5 & 12.15 & & \\
\hline & & $\mathbf{M}_{2}$ & $\mathbf{R}$ & 13.1 & 12.25 & & \\
\hline & & $\mathrm{dM}_{2}$ & $\mathbf{R}$ & 10.9 & 10.05 & & \\
\hline D & 54 & $I_{2}$ & $\mathrm{~L}$ & 6.65 & 7.3 & 15 & 83 \\
\hline & & $\mathrm{C}_{1}$ & $\mathbf{L}$ & 7.9 & 8.75 & & \\
\hline & & $P_{3}$ & $\mathbf{L}$ & 7.8 & 8.7 & & \\
\hline & & $\mathrm{P}_{4}$ & $\mathbf{L}$ & 6.9 & 9.45 & & \\
\hline & & $\mathbf{M}_{1}$ & & 11.55 & 10.7 & & \\
\hline $\mathbf{E}$ & 55 & $I_{I}$ & L. & 6.2 & 8.0 & 15 & $10,77,106,108$ \\
\hline & & $I_{1}$ & $\mathrm{R}$ & 6.1 & 8.0 & & \\
\hline & & $\mathrm{I}_{2}$ & L & 7.0 & 8.25 & & \\
\hline & & $\mathrm{C}_{1}$ & $\mathrm{~L}$ & 8.25 & 9.5 & & \\
\hline & & $\mathbf{P}_{3}$ & $\mathrm{~L}$ & 8.4 & 9.35 & & \\
\hline & & $\mathrm{P}_{4}$ & L & 8.0 & 9.6 & & \\
\hline & & $\mathbf{M}_{1}$ & $\mathbf{L}$ & 13.0 & 12.1 & & \\
\hline & & $\mathbf{M}_{2}$ & $\mathbf{L}$ & 12.9 & 11.7 & & \\
\hline $\mathbf{F}$ & 56 & $\mathbf{P}_{4}$ & $\bar{L}$ & 8.25 & 10.5 & 17 & \\
\hline & & & & & ontinued, & & \\
\hline
\end{tabular}


APPENDIX 2 (Continued)

Catalog of in situ teeth, presented by the original letter designations and catalog number. Tooth identification, side, and length and breadth measurements were determined by the author as was the age at death estimate. The appendix also provides numbers of the additional teeth (if any) that have been associated with each jaw (APPENDIX 1 )

\begin{tabular}{|c|c|c|c|c|c|c|c|}
\hline \multirow{4}{*}{$\begin{array}{c}\begin{array}{c}\text { Letter } \\
\text { designation } \\
\text { maxillas }\end{array} \\
\text { G }\end{array}$} & \multirow{2}{*}{$\begin{array}{c}\begin{array}{c}\text { Catalog } \\
\text { no. }\end{array} \\
57\end{array}$} & \multicolumn{2}{|c|}{$\begin{array}{l}\text { Tooth } \\
\text { and } \\
\text { side }\end{array}$} & \multirow{2}{*}{$\frac{\text { Length }}{12.5}$} & \multirow{2}{*}{$\begin{array}{c}\text { Breadth } \\
11.45\end{array}$} & \multirow{2}{*}{$\begin{array}{c}\begin{array}{c}\text { Estimated } \\
\text { age }\end{array} \\
18\end{array}$} & \multirow[t]{2}{*}{ Additional associated teeth } \\
\hline & & $\mathbf{M}_{1}$ & $\mathbf{R}$ & & & & \\
\hline & & $\mathbf{M}_{2}$ & $\mathrm{R}$ & 12.4 & 11.55 & & \\
\hline & & $\mathbf{M}_{3}$ & $\mathrm{R}$ & 11.6 & 11.15 & & \\
\hline \multirow[t]{16}{*}{$\mathrm{H}$} & 58 & $\mathbf{I}_{1}$ & $\mathrm{~L}$ & 5.0 & 7.3 & 23 & \\
\hline & & $\mathbf{I}_{1}$ & $\mathbf{R}$ & 5.3 & 7.3 & & \\
\hline & & $\mathbf{I}_{2}$ & $\mathrm{~L}$ & 6.6 & 7.85 & & \\
\hline & & $\mathbf{I}_{2}$ & $\overrightarrow{\mathbf{R}}$ & 6.7 & 7.75 & & \\
\hline & & $\mathrm{C}_{1}$ & $\mathrm{~L}$ & 8.4 & 8.85 & & \\
\hline & & $\mathrm{C}_{1}$ & $\mathbf{R}$ & 8.1 & 8.85 & & \\
\hline & & $P_{3}$ & L & 8.35 & & & \\
\hline & & $\mathbf{P}_{3}$ & $\mathbf{R}$ & 8.1 & 9.2 & & \\
\hline & & $\mathrm{P}_{4}^{3}$ & $\mathrm{~L}$ & 7.75 & 9.5 & & \\
\hline & & $\mathrm{P}_{4}$ & $\overline{\mathbf{R}}$ & 7.9 & 9.4 & & \\
\hline & & $\mathbf{M}_{1}$ & $\mathrm{~L}$ & 11.7 & 10.9 & & \\
\hline & & $\mathrm{M}_{2}$ & $\mathbf{R}$ & 12.0 & 10.8 & & \\
\hline & & $\mathbf{M}_{2}$ & $\mathrm{~L}$ & 11.85 & 11,4 & & \\
\hline & & $\mathbf{M}_{2}$ & $\mathbf{R}$ & 11.95 & 11.4 & & \\
\hline & & $\mathrm{M}_{3}$ & $\mathrm{~L}$ & 12.0 & 10.7 & & \\
\hline & & $\mathbf{M}_{3}$ & $\mathrm{R}$ & 12.2 & 10.85 & & \\
\hline \multirow[t]{13}{*}{$\mathrm{J}$} & 59 & $\mathrm{I}_{1}$ & $\mathrm{~L}$ & 5.35 & 7.4 & 20 & \\
\hline & & $\mathrm{I}_{1}$ & $\mathbf{R}$ & 5.5 & & & \\
\hline & & $\mathrm{I}_{2}$ & $\mathrm{~L}$ & 6.55 & 7.8 & & \\
\hline & & $\mathrm{I}_{2}$ & $\vec{R}$ & 6.4 & & & \\
\hline & & $\mathbf{C}_{1}$ & $\mathrm{~L}$ & 7.9 & 9.7 & & \\
\hline & & $\mathrm{C}_{1}$ & $\mathrm{R}$ & 7.9 & & & \\
\hline & & $\mathrm{P}_{4}$ & $\mathrm{~L}$ & 7.65 & 10.1 & & \\
\hline & & $\mathrm{P}_{4}$ & $\overrightarrow{\mathrm{R}}$ & 7.85 & & & \\
\hline & & $\mathbf{M}_{1}$ & L & 11.8 & 11.1 & & \\
\hline & & $\mathbf{M}_{1}$ & $\mathbf{R}$ & 11.5 & & & \\
\hline & & $\mathbf{M}_{2}$ & L & 12.2 & 11.5 & & \\
\hline & & $\mathbf{M}_{2}$ & $\mathrm{R}$ & 11.9 & & & \\
\hline & & $\mathbf{M}_{3}$ & $\mathrm{R}$ & 11.8 & 11.3 & & \\
\hline \multirow[t]{2}{*}{$\mathbf{K}$} & 60 & & & & & 4 & \\
\hline & 63 & $\mathbf{M}_{3}$ & $\mathbf{R}$ & 11.7 & & 22 & \\
\hline
\end{tabular}

